University of Louisville

ThinkIR: The University of Louisville's Institutional Repository

Electronic Theses and Dissertations

$8-2020$

\title{
Therapeutic rupture repair in treatment of military adolescents.
}

Brent Anthony Luebcke

University of Louisville

Follow this and additional works at: https://ir.library.louisville.edu/etd

Part of the Counseling Commons, and the Counseling Psychology Commons

\section{Recommended Citation}

Luebcke, Brent Anthony, "Therapeutic rupture repair in treatment of military adolescents." (2020).

Electronic Theses and Dissertations. Paper 3486.

https://doi.org/10.18297/etd/3486

This Doctoral Dissertation is brought to you for free and open access by ThinkIR: The University of Louisville's Institutional Repository. It has been accepted for inclusion in Electronic Theses and Dissertations by an authorized administrator of ThinkIR: The University of Louisville's Institutional Repository. This title appears here courtesy of the author, who has retained all other copyrights. For more information, please contact thinkir@louisville.edu. 


\title{
THERAPEUTIC RUPTURE REPAIR IN TREATMENT OF MILITARY ADOLESCENTS
}

\author{
By \\ Brent Anthony Luebcke \\ B.A., Purdue University, 2010 \\ M.S.Ed., Indiana University, 2012

\begin{abstract}
A Dissertation
Submitted to the Faculty of the College of Education and Human Development of the University of Louisville in Partial Fulfillment of the Requirements for the Degree of
\end{abstract} \\ Doctor of Philosophy in Counseling and Personnel Services \\ Department of Educational and Counseling Psychology, \\ Counseling, and College Student Personnel \\ University of Louisville \\ Louisville, Kentucky
}

August 2020 



\title{
THERAPEUTIC RUPTURE REPAIR IN TREATMENT OF MILITARY
} ADOLESCENTS

\author{
By \\ Brent Anthony Luebcke \\ B.A., Purdue University, 2010 \\ M.S.Ed., Indiana University, 2012
}

A Dissertation Approved on

July 7,2020

by the following Dissertation Committee:

Dissertation Chair

Mark Leach, Ph.D.

Jesse Owen, Ph.D.

Tyler Halford, Ph.D.

Amanda Mitchell, Ph.D. 


\section{DEDICATION}

This dissertation is dedicated to my mother Becky, my father Ray, and my wife Caitlin.

Thank you all for always believing in my abilities, for encouraging me to pursue my passions, and for celebrating in my successes. 


\section{ACKNOWLEDGEMENTS}

The acknowledgements that are provided below include persons for whom I am unyieldingly grateful to have in my life, and persons without whom this project would never have been completed.

I am thankful Caitlin, who has provided unwavering support in every way possible for the past several years. She supported my pursuits for my doctorate first as a friend, later as a partner, and now as a wife.

I am thankful for my parents, who throughout my entire life encouraged me to pursue my interests, for challenging me to do things well, and for believing that I could accomplish anything that I set out to do.

I would like to thank each member of my committee, without whom this dissertation would not be complete.

Dr. Tyler Halford and Dr. Amanda Mitchell each deserve credit for being good friends, and good models for transitioning from student to psychologist.

Dr. Jesse Owen provided the opportunity to grow as a clinician and researcher, and I credit many of my skills in these areas to him. He exceeded his role as a mentor, and I am extraordinarily grateful for him to have stuck with me long after he could have said goodbye.

And finally, I am thankful for Dr. Mark Leach who in addition to giving me every opportunity to complete this project, provided the exact support needed in the most challenging time of my life. I cannot thank him enough for reaching out and being there. 


\title{
ABSTRACT \\ THERAPEUTIC RUPTURE REPAIR IN TREATMENT OF MILITARY ADOLESCENTS
}

\author{
Brent A. Luebcke
}

July 7, 2020

Ruptures in the therapeutic alliance have shown to be a significant predictor of therapy outcomes, with non-repaired ruptures resulting in increased dropout rates of therapy, and repaired ruptures resulting in positive therapy outcomes. This study investigated the impact of alliance ruptures on outcomes of therapy among youth and adolescents, with a specific focus on military youth and adolescents. A sample of 5,640 military adolescents who were treated by 101 therapists were selected for analysis based on inclusion criteria of: a) being aged 13 to 19 years old; and b) attending more than one session of therapy. Each session, clients completed the Outcome Rating Scale to measure well-being, and the Session Rating Scale as a measure of the therapeutic alliance. Clients were coded as either a) No Rupture; b) Rupture Repair; or c) Rupture Non-Repair, based on presence or absence of therapy ruptures, and the final result of ruptures at the end of the therapy process. This study examined comparisons of alliance-outcome relationships by rupture condition, the effect of rupture conditions on premature termination from therapy, and moderation effects of stage-of-therapy ruptures, age, problem type, and therapist effects. Findings showed that there was significantly greater positive change in well-being 
amongst clients coded as Rupture Repair compared to No Rupture and Rupture NonRepair. Clients coded as Rupture Non-Repair were more likely to prematurely terminate from therapy and attend a fewer number of sessions compared to Rupture Repair clients. Among Rupture Repair clients, repairs more likely to occur in early sessions of therapy compared to later sessions. Neither age nor problem type was found to act as a moderator on the effect of rupture condition on therapy outcomes. Finally, although there is evidence of between-therapist effects on therapy outcomes, aggregate therapist alliance scores across client caseloads failed to predict an effect on either the intercept and/or slope of the alliance effect on therapy outcomes. In conclusion, monitoring betweensession therapy alliance and the presence of ruptures may influence therapy outcomes. Treatment implications and future directions were discussed. 
TABLE OF CONTENTS

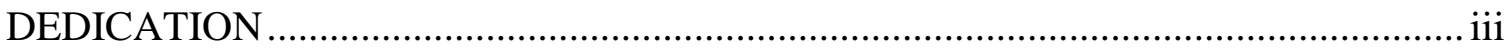

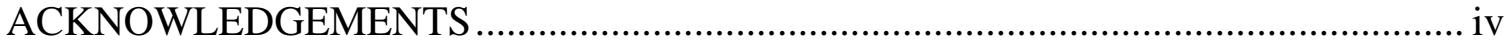

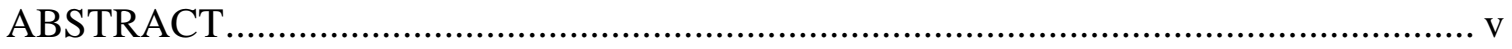

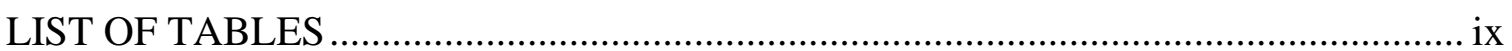

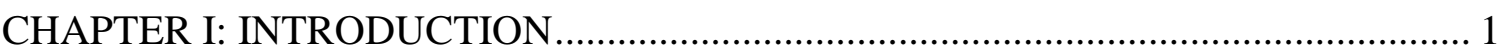

The Therapeutic Alliance ...................................................................................... 3

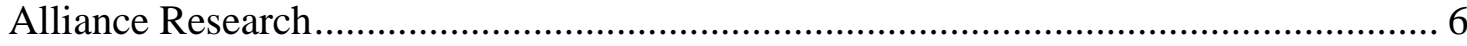

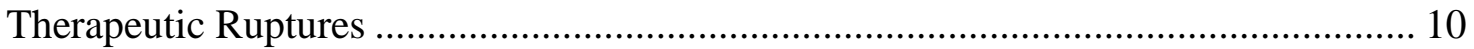

Breakdowns of the Goals, Tasks, and Bond ............................................................ 12

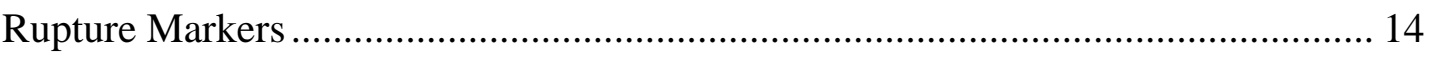

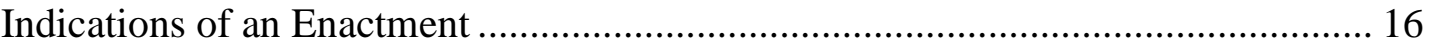

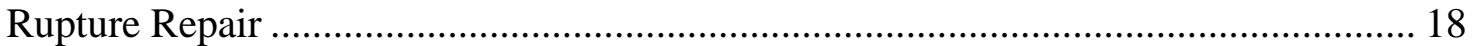

Client Factors: Adolescent Psychotherapy Process .................................................... 23

Client Factors: Adolescent Substance Use ............................................................... 26

Client Factors: Treatment of Adolescent Substance Use ................................................. 33

Client Factors: Military Culture ………………………….................................... 35

Research Question and Hypotheses ..................................................................... 38

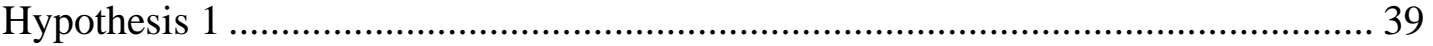

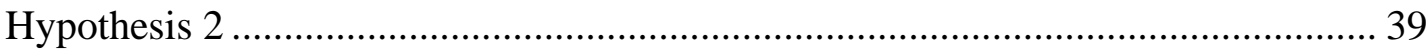

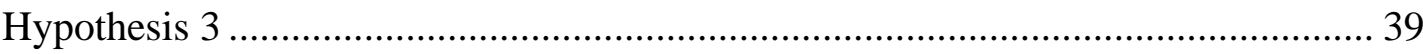

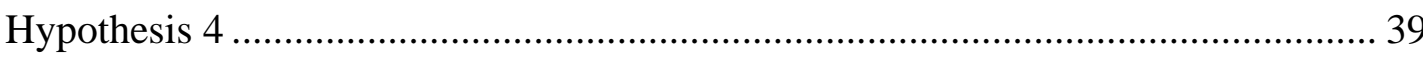

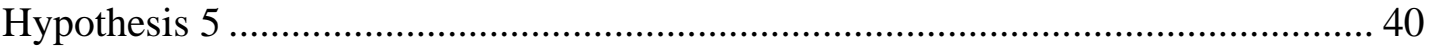

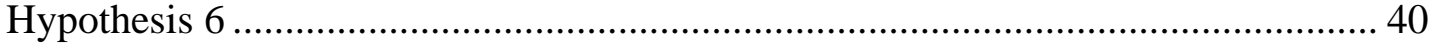

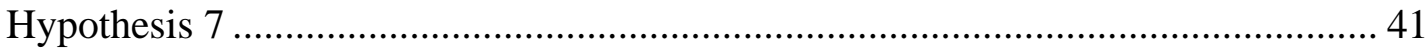

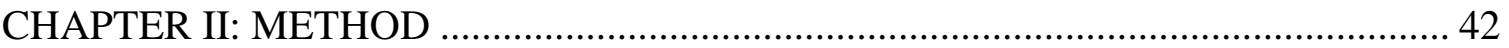

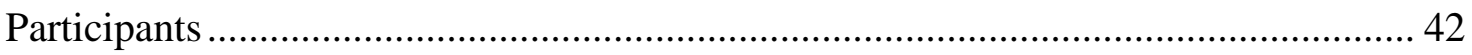

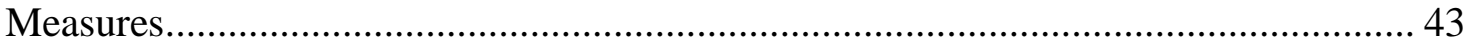

Outcome Rating Scale ..................................................................................... 43

Session Rating Scale ........................................................................................... 45 


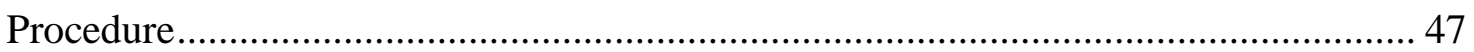

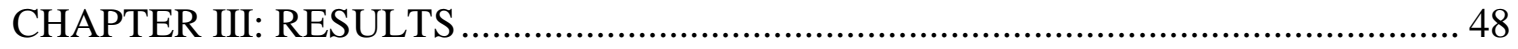

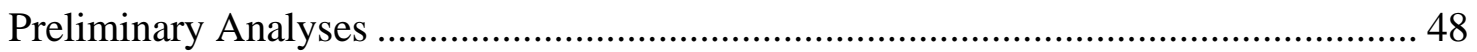

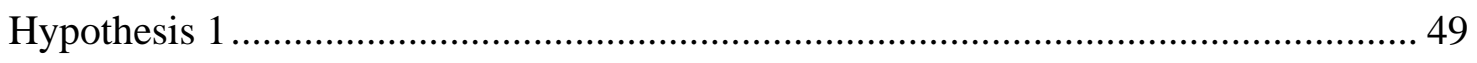

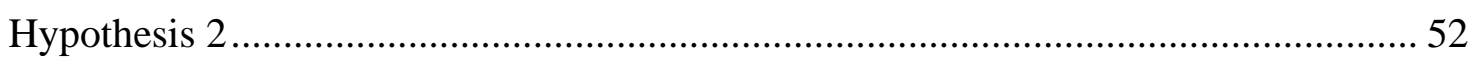

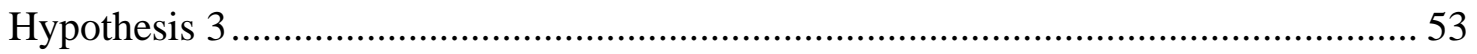

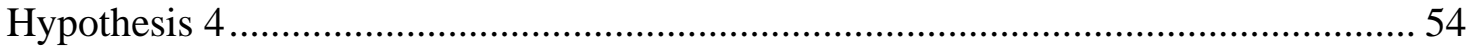

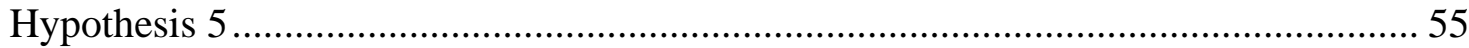

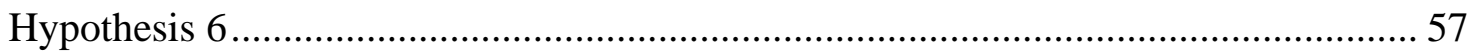

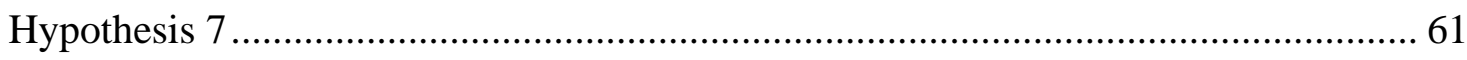

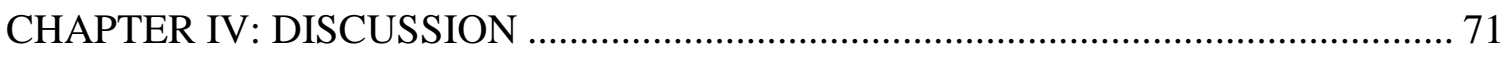

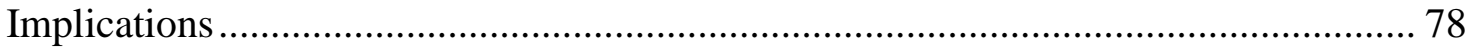

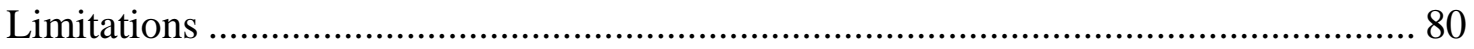

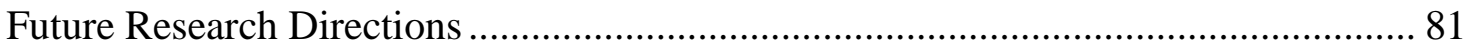

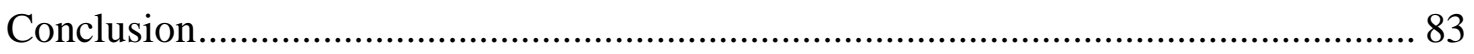

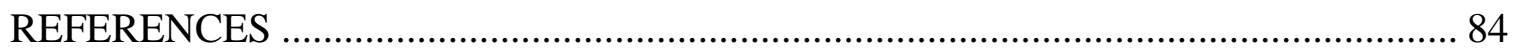

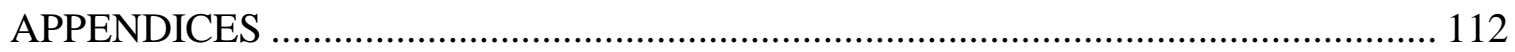

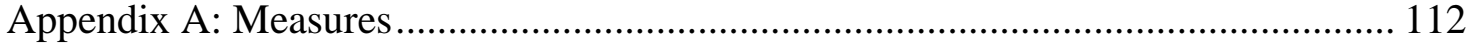

Outcome Rating Scale (ORS) ................................................................. 113

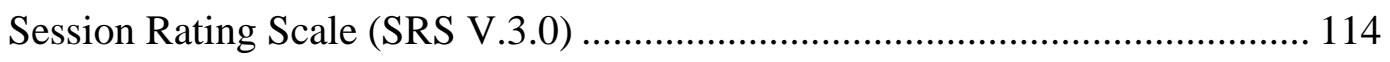

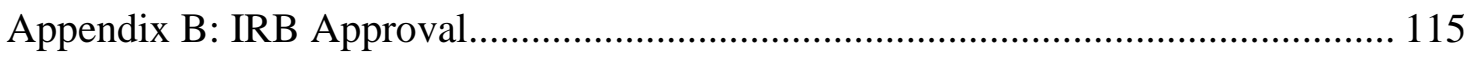

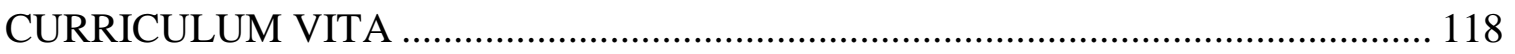




\section{LIST OF TABLES}

TABLE

PAGE

1. Means and Standard Deviations of ORS Outcome Scores by Rupture Category.......50

2. One-Way Analysis of Variance of Therapy Outcome Score by Rupture Category....50

3. Means and Standard Deviations of ORS Outcome Change by Rupture Category......52

4. One-Way Analysis of Variance of Therapy Outcome Change by Rupture Category...52

5. Premature Termination versus Staying in Therapy by Rupture Condition.............53

6. Presence of Rupture Repair in Therapy by Session Timing ......................55

7. Summary of Hierarchical Regression Analysis for Variables (Age) Predicting Therapy Outcome.............................................................. 56

8. Summary of Hierarchical Regression Analysis for Variables (Age) Predicting Change in Therapy Outcome.......................................................

9. Summary of Hierarchical Regression Analysis for Variables (SAD) Predicting Therapy Outcome...

10. Summary of Hierarchical Regression Analysis for Variables (SAD) Predicting Change in Therapy Outcome....................................................61

11. Summary of Hierarchical Linear Modeling (HLM) Specification Steps for Rupture Repair Final Outcomes................................................66

12. Summary of Hierarchical Linear Modeling (HLM) Specification Steps for Rupture Repair Change in Well-Being.......................................... 70 


\section{CHAPTER I: INTRODUCTION}

Extensive research in the area of psychotherapy process and outcome has consistently shown that the therapeutic alliance is a strong predictor of therapy outcome. The alliance has been shown to account for approximately $5-10 \%$ of the variance in treatment outcomes (Horvath et al., 2011), and is consistent across different therapy modalities (Castonguay et al., 2006; Constantino et al., 2002) and across age (Shirk et al., 2011). However, there are moments in which the client and/or therapist may perceive strains, tensions, or breakdowns in the therapeutic alliance (Safran \& Kraus, 2014). These moments of breakdown in the therapeutic alliance are known as ruptures (Safran \& Muran, 2000). Ruptures may present critical and potentially necessary opportunities to address persistent interpersonal difficulties in the client. Research has shown that therapeutic alliances with successful resolution of ruptures leads to greater therapeutic gains compared to alliances without rupture-repair episodes (Stiles et al., 2004). These critical moments, however, depend on the ability of therapists to successfully identify that a rupture has occurred, and also depend on the ability to resolve the rupture in order to avoid a premature termination in the therapy process (Saran et al., 2011; Safran et al., 2002).

Previous research has demonstrated that the alliance is an important predictor of therapy outcomes for child and adolescent therapy (Shirk et al., 2011), which is similar to the effect observed in studies of adult alliance-outcome relationships (Martin et al., 
2000). The alliance-outcome effect sizes among studies for children and adolescentthough have yielded inconsistent results. For example, a meta-analysis of 38 children and adolescent alliance-outcome studies found that the therapeutic alliance accounted for approximately $2 \%$ of the variance therapy outcomes (McLeod, 2011), compared to the $5-10 \%$ variance in adults mentioned above. However, the variance in outcomes in this study may be better explained by varying models of assessment. For example, when using a change-based-assessment model of assessment in which the alliance was continually monitored over time, the alliance accounted for $9.8 \%$ of the variance in select adolescent therapy outcomes (Owen et al., 2016).

The contrasting results of child and adolescent alliance-outcome studies exemplifies the continued need to examine factors which affect the outcome of therapy as related to the alliance and potential therapeutic ruptures (Safran \& Kraus, 2014). Much of the existing literature on alliance, including those exploring therapy ruptures, do not specifically focus on examining outcomes and alliance trajectories among youth and adolescents (Binder et al., 2008; Hurley et al., 2015). However, in examining therapy processes among adolescents, researchers should consider contextual variables which affect the complexity of adolescent development. One such population of adolescents which would benefit from specialized process research are military youth; that is, children and adolescents with parents who are personnel in the armed forces (EspositoSmythers, et al., 2011). Research for therapeutic outcomes among military adolescents are supported by systems theorists who state: "adolescent development must be understood in the context of the family, neighborhood, school and community. For adolescents in U.S. military families this context also includes the unique challenges 
indicative of military life, including multiple moves and parental deployment" (Milburn \& Lightfoot, 2013, p. 268). Although recent research addresses considerations for the importance of monitoring the therapeutic alliance when working with military adolescents (Owen et al., 2016), there are no studies examining therapeutic ruptures in the alliance with this population. Given unique features of military life and their effects on adolescents of military families it is important to examine these ruptures and their relationship to therapeutic outcomes.

The purpose of this project is to examine the impact of alliance ruptures on outcomes of therapy among youth and adolescents, with a specific focus on military youth and adolescents. The study will examine outcome trajectories of alliance outcomes comparing non-rupture, rupture-repair, and rupture-non-repair sessions. The study will also include observing potential moderating variables such as effects of age, effects of problem type, and therapist effects. Exploration of rupture-repair processes with military adolescents can provide increased understanding of effective therapeutic engagement among this specialized population of individuals.

\section{The Therapeutic Alliance}

Conceptual definitions for the therapeutic alliance were formulated during the earliest years of psychotherapy (Krause et al., 2011). Freud (1912/1958) described the relationship between the analyst and patient as consisting not only of transference experiences, but also "unobjectionable positive transference," which provides a continued and necessary perception of positive attribution towards the therapist. This unobjectionable positive transference was purposely left un-analyzed by the therapist, as it facilitated the patient's sense of safety to free associate and communicate distressing 
and disavowed parts of their personal history (Krause et al., 2011). While Freud extrapolated on positive transference toward the therapist as a driving force for change in therapy, later theorists considered the dynamics of both transference and countertransference experiences contributing to the process of therapy. Ferenczi $(1932 / 1988)$ suggested that it was essential for patients to relive and re-engage in past problematic relationship experiences during the therapy process with the psychotherapist. The therapist, in turn, provided transference-related subject material in the form of their personality, their behaviors, and their spoken verbalizations during session. Thus, the process of therapy was based largely on contributions of both the client and therapist.

During the 1930s there was a shift towards integration of multiple theories of psychotherapy, including theories on the relationship between clients and therapists. Among these theories was a differentiation between two key areas. First, the unconscious interpersonal aspects of the client-therapist dyad, which was based primarily on past experiences and considered "inaccessible" and "unalterable" (transference/countertransference interactions); and second, the co-created, "conscious" interpersonal aspects of the therapeutic relationship which could be identified, examined, and altered. The latter, which was coined as the therapeutic alliance (Greenson, 1965, 1967; Zetzel, 1956) was further extrapolated and extended to include relational elements of the interaction(s) between client and therapist, and how these elements influence the therapeutic process.

Theoretical developments of the therapeutic alliance have also considered the contributions of the real relationship between the client and therapist (Greenson, 1965, 1967). The necessary components of the real relationship, which emphasized rationality 
and objectivity between therapist and client, included not only undistorted perceptions of one another, but also authentic liking, trust, respect, and genuineness between one another (Gelso, 2009; Safran \& Muran, 2000). Gelso (2009) defined the real relationship, in sum, to be "the personal relationship existing between two or more people as reflected in the degree to which each is genuine with the other and perceives and experiences the other in ways that befit the other" (pp. 254-255). This definition assumes elements of realism and genuineness on part of the client and therapist, as well as the relational matrix between the two. This relationship is considered to be based less on transference and countertransference representations, and more on factual traits and personality dispositions that exist within each participant outside of the therapy setting. While there is some debate about the role of the real relationship being enacted during the therapy setting, it is important to consider how the genuine and real parts of the therapist and client affect the work being done in the room.

Bordin (1979) conceptualized a pantheoretical model of the alliance (which he termed as the working alliance ${ }^{l}$ ) as consisting of three related processes: 1) the tasks of therapy (i.e. the specific action of intervention(s) in which the client engages in therapy), (2) the goals of therapy (i.e. the outcome of therapy desired by the client), and (3) the relational bond between the client and therapist (Bordin, 1979). Bordin's conceptual model involves intentional efforts to explore and establish agreement about the goals and tasks of the therapeutic process in the context of a positive relational bond. In this sense,

\footnotetext{
${ }^{1}$ The terms alliance, therapeutic alliance, and working alliance all refer to the therapeutic relationship established between the therapist and client. It should be known that there are conceptual differences among these terms. For the purpose of this paper, the general term "alliance" will be used to reflect Bordin's (1979) conceptual model of the working alliance, focusing on the goals, tasks, and bonds established between clients and therapists.
} 
the alliance is not reducible to only the clients' experiences in therapy (Hatcher \& Barends, 2006). This can be compared to other alliance theorists that focus only on one part of the alliance, such as Greenson's (1967) focus on the clients' rational collaboration of therapy with the therapist. Negotiating the parts of the alliance allows for the client to feel a sense of autonomy, control, and connectedness with the therapist, which can also bolster trust and hope for the therapeutic process (Safran \& Muran, 2000).

\section{Alliance Research}

Substantial efforts have been made in recent years to explore the effects of the therapeutic alliance in a systematic, quantifiable fashion. A meta-analysis of more than 200 studies that included both outcome measures as well as measures of the therapeutic alliance revealed a mean effect of alliance on outcome corresponding to a correlation of $r$ $=0.275(95 \%$ CI [.249-.301]) (Horvath et al., 2011). This correlation indicates that a modest proportion of the variance in treatment outcomes is related to the working relationship between the client and therapist. Horvath et al. (2011) also explored variables that could potentially moderate the relation between alliance and outcome (i.e. alliance measure; alliance rater; time of alliance assessment; outcome measure; type of treatment; and publication source). Results revealed that all of the aggregate-alliance correlations in each category were statistically significant, indicating that "the impact of the alliance on therapy outcome is ubiquitous irrespective of how the alliance is measured, from whose perspective it is evaluated, when it is assessed, the way the outcome is evaluated, and the type of therapy involved" (Horvath et al., 2011, p. 13). The importance of the therapeutic alliance has been repeatedly verified and is now considered one of the common factors of the therapeutic process (Imel \& Wampold, 2008). 
While the relationship between alliance and outcome has been well-documented in recent years, there is still a question as to the causal inferences made about whether strong therapeutic alliance leads to positive therapy outcomes, or whether the perception of positive outcomes lead to a strong working therapeutic alliance (Crits-Christoph et al., 2006). Several studies have sought to determine predictive causality of the alliance on therapy outcomes. Many of these studies report that there is a significant association between alliance and subsequent symptom change over the course of therapy, indicating improvement in client well-being (Crits-Christoph et al., 2011; De Bolle et al., 2010; Falkenstöm et al., 2013; Klein et al., 2003). For example, Crits-Christoph et al. (2011) examined session-to-session temporal relationships between symptoms and alliance change, and found that increases in alliance scores from previous sessions were related to symptomatic improvement to the next session. These findings indicate not only that alliance does predict outcome, but also that the alliance may be more impactful on symptoms change at different points in the therapy process.

However, there have been multiple studies demonstrating mixed evidence of alliance-outcome relationships (Falkenstöm et al., 2013). There is contrasting evidence that suggests that therapist contribution to the alliance and therapist perceptions of the alliance do not adequately predict therapeutic outcomes, perhaps suggesting outcomes are moderated by contextual factors (such as client and therapist effects) related to the therapy process (Huppert et al., 2014). In one study, multilevel modeling was used to explore the client and therapist variability in the alliance-outcome relationship (Baldwin et al., 2007). Results indicated that therapist and client variability do not equally predict client outcomes in therapy. Specifically, the findings indicated that between-therapist 
variability in the alliance was a significant predictor of outcome. That is to say, on average, therapists who formed strong alliances with their patients showed better outcomes compared to therapists who did not form strong alliances. Conversely, client variability in the alliance (within-therapist) was found to be unrelated to therapy outcome. The clinical implications of this study support the need for therapists to monitor their alliances, and to develop training protocols to teach therapists how to appropriately develop and track the alliance throughout the therapy process. Subsequent research examined Baldwin et al.’s (2007) findings using meta-analytic methodology, and revealed similar findings; therapist variability in the alliance appears to be a stronger predictor than client variability in terms of client therapy outcomes (Del Re et al., 2012). These ratings of alliance are not one-sided however, as there is evidence which supports a dyadic reciprocity between clients and therapists, in which therapists who reported a strong alliance are also rated by their clients to have strong alliances (Marcus et al., 2009).

There is some evidence to suggest that the development of the alliance may occur differently among distinct modalities of therapies and therapists (Ulvenes et al., 2012). For example, differences were observed between therapists utilizing short-term dynamic psychotherapy (STDP) and cognitive therapy (CT) in regards to the focus on affect in therapy and the effect on the relational bond. In STDP, avoidance of affect suppressed the relationship between the therapeutic bond and symptom reduction, whereas avoidance of affect was positively related to the relationship of the therapeutic bond and symptom reduction (Ulvenes et al., 2012). 
Changes in therapy alliance exemplify the importance of examining how researchers measure alliance-outcome data. Three common approaches to examine the alliance in therapy are a mono-assessment model, an aggregate-assessment model, and a change-based model (Owen et al. 2016). A mono-assessment model utilizes a single score as indicative of overall alliance functioning. For example, McLeod's (2011) metaanalysis on alliance outcomes in youth psychotherapy used single session ratings of the alliance at early, middle, late, averaged, and post-treatment. An aggregate-assessment model utilizes an averaged, generalizable alliance score from multiple sessions. CritsChristoph et al. (2011) used aggregate alliance scores of seven early therapy sessions (Sessions 3-9) to examine predictive models of alliance-outcome analyses. The authors argued that a maximum of seven sessions were used because alliance measurement reached an asymptote after seven sessions. In this study, when the alliance scores of a single session (Session 3) were used, the percent variance explained was $4.7 \%(r=-.22$; a negative relationship between alliance and levels of depressive symptoms). However, when using aggregate alliance scores averaging Sessions 3-9, the percent variance explained in outcome was $14.7 \%$. Crits-Christoph et al. (2011) posited that the use of measures which typify the alliance across multiple sessions were substantially better predictors of outcome than single-session measures of alliance. A change-based model assumes that observed changes in the therapeutic alliance present meaningful information about how fluctuations in the alliance affect outcomes (Stiles et al., 2004).

It might seem that the ideal goal for the development of the therapeutic alliance would be to establish a strong working relationship and either build or maintain the alliance throughout the course of therapy. However, there are also moments when there 
are changes in alliance ratings during the therapy process. It is possible that alliance ratings remain stable throughout the course of therapy, changing little-to-none throughout the entire therapy process. Changes in the alliance may resemble a linear growth pattern, which demonstrate an increase in strength across sessions, in alliance ratings over the course of therapy. Additionally, researchers have observed "curvilinear" patterns, which often resemble a fluctuation of alliance ratings. For example, a client may experience a "U-shaped" pattern of the therapeutic relationship in which clients initially rate an alliance high, then experience a period of decrease, followed by a rebound toward high alliance ratings (Gelso \& Carter, 1994; Kivlighan \& Shaughnessy, 2000). More recent research found that the gains observed in fluctuating alliance ratings were greater when alliances demonstrated a sudden, sharp drop in rating followed by a sudden increase in alliance (Stiles et al., 2004); this particular pattern is consistent with rupture-repair sequences in the alliance. Compared to Kivlighan and Shaughnessy's (2000) U-shaped alliance graph, Stiles et al. (2004) observed a V-shaped rupture-repair cycle which led to even greater outcomes compared to stable or linear growth in alliance. These patterns suggest the possibility that rupture-repair sequences demonstrate evidence for interpersonal learning (Stiles et al., 2004). The process of repairing ruptures should be observed, acknowledged, and attended to by therapist and clients in order for interpersonal growth to occur (Safran et al., 2011).

\section{Therapeutic Ruptures}

Over the past few decades, researchers have investigated what has been termed a "second generation" of alliance research which aims to clarify what factors not only affect the development of the alliance, but also which processes are involved in the 
maintenance of the alliance and, when necessary, potential resolution of ruptures in the alliance (Safran et al., 2002). Despite the relative normalcy of ruptures occurring during the course of therapy, inattention to the quality of the alliance may lead to unrepaired ruptures, which then result in premature termination of therapy.

While most therapists seek to maintain a positive working alliance throughout the course of therapy, there are moments in which there are strains, tensions, or breakdowns between the client and therapist in terms of the working alliance (Safran \& Muran, 2000). Since the beginning of psychotherapy as a disciplined field of practice and research, there have been several terms used to describe these therapeutic breakdowns, such as empathic failures, transference/countertransference enactments, misunderstanding events, ruptures, and enactments (Safran \& Kraus, 2014). While each of these terms contain nuanced differences in how the alliance is affected, each addresses disagreements of the working alliance between the therapist and client.

Navigating the goals, tasks, and bonds of the therapeutic alliance does not often occur without difficulty, as there is often ongoing push and pull between a client's and therapist's affective states, underlying needs, and interpersonal behaviors (Safran \& Muran, 2006). Because of these push-and-pull dynamics in the relationship, there is a need for mutual recognition of personal wishes and needs (to be met by others), which can include interpersonal patterns of power plays, hostilities, accommodations, and refusals to accommodate (Safran et al., 2010). Struggles negotiating these dynamics between therapists and clients are conceptualized to be a basic component to every rupture in the therapeutic alliance.

Alliance ruptures have been more accurately defined as: 
(1) breakdowns in the negotiation of the goals, tasks, and affective bond between patient and therapist; (2) markers of tension between the respective needs or desires of the patient and therapist as they continuously press against each other; (3) indications of an enactment- a relational matrix of patient and therapist beliefs and action patterns, a vicious cycle involving the unwitting participation of both patient and therapist" (Safran et al., 2010, p. 322).

In the following subsections, this definition will be examined more closely in an effort to describe the ways in which the therapeutic alliance is affected by-and-through ruptures.

\section{Breakdowns of the Goals, Tasks, and Bond}

In recent decades, leading theorists and researchers have defined the occurrence of therapeutic ruptures as a breakdown in the therapeutic alliance (Safran \& Muran, 2000; Safran \& Kraus, 2014; Watson \& Greenberg, 2000). Furthermore, ruptures can be considered a breakdown of Bordin's (1979) conceptualization of the alliance insomuch as it is a collaborative and/or negotiated agreement about the goals and tasks of therapy, and a weakening of the affective bond between therapist and client (Safran \& Muran, 2006). Indeed, it has been well documented that divergent views on the goals and tasks of therapy may reflect an impasse, strain, or rupture in the alliance and, if left unresolved, potentially lead to premature termination or poor therapy outcome (Bachelor, 2013; Eubanks et al., 2019; Hill et al., 1996; O’Keeffe et al., 2020; Safran et al., 2010; Safran et al., 1990).

Consistent with Bordin's (1979) model of the therapeutic/working alliance, interdependence among alliance factors (i.e. goals, tasks, and bonds) suggests that 
difficulties maintaining any one of these could negatively influence the other factors, as well as perceptions of the alliance overall. That is, differentiating a cause-and-effect among the three parts of the alliance can prove difficult, as each likely impacts the others. For this reason, Safran \& Muran (2006) broadly defined alliance ruptures as “"problems in quality of relatedness' or 'deteriorations in the communicative process' (or at least...both 'breakdowns in collaboration' and 'poor quality of relatedness"') (p. 289).

Furthermore, there is evidence to suggest that, although the parts of the alliance may influence each other, it is possible to perceive and evaluate different aspects of the alliance. For example, empirical evidence used in the validation of measures of the alliance found strong correlations among subscales, often with goals and tasks being loaded into one large factor (Andrusyna et al., 2001; Horvath \& Greenberg, 1989; Tracey \& Kokotovic, 1989). For example, a client who undergoes a process of negotiation and agreement on the goals and tasks of therapy, would also likely experience a strong bond with their therapist (especially if there are positive outcomes from therapy) (Webb et al., 2011). Conversely, a strong bond may be a necessary component which precedes agreement between therapists and clients on goals and tasks (Wampold \& Budge, 2012).

Consequently, differential development of the alliance (including alliance outcomes) suggest that ruptures would likely occur either between the collaboration on the goals and tasks or in the affective bond, and that the result of a breakdown in one of these areas would affect the other (Safran \& Muran, 2000). In one study that investigated the qualitative experiences of both therapists and clients (Coutinho et al., 2011), consistent themes emerged indicating breakdowns in the goals, tasks, and bonds during rupture episodes. For example, one common therapist action that preceded ruptures was 
the use of new interventions not previously used during that therapy process. The therapists' reflections of their actions indicated that implementing new interventions may have transgressed the previously agreed-upon tasks of therapy. Client reflections of precipitants to rupture events were related to discussing a painful topic, feeling upset or unmotivated to coming to the session, or that the therapist had done something that the client did not like or agree with.

\section{Rupture Markers}

Ruptures can be conceptualized by two types: withdrawal ruptures and confrontation ruptures (Safran \& Muran, 1996; 2000). These markers are behaviorally enacted in session. Withdrawal markers involve client disengagement from the therapist, their own emotions, or some aspect of the therapeutic process (Harper, 1989a; Safran \& Muran, 2000). The behavioral markers evidenced during a withdrawal rupture are: denial of feelings or affective states which may be observationally evident; providing minimal responses to therapist inquiries, such as short or one-word answers to open-ended and/or exploratory questions; shifting topics from substantive issues to tangential or distantlyrelated points of conversation; intellectualizing a distressing experience in a detached manner; engaging in long storytelling and providing extensive and non-necessary information devoid of feelings or insights; and focusing on other people and their actions.

Withdrawal behaviors are thought to be either movement away from the therapist or therapeutic process, or movement toward the therapist and away from the self. In some cases, withdrawal ruptures manifest through clients having difficulty expressing their individual needs or expressing concerns in the therapeutic relationship. Other cases might involve withdrawal from the self and toward the therapist in the form of compliance or 
appeasement of some part of therapy at the cost of experiencing anxiety (Muran, Safran, \& Eubanks-Carter, 2010). The client may present in a way they act or otherwise present themselves how they think they "should" be during therapy.

In addition to withdrawal markers, there are also confrontation markers, which demarcate that a therapeutic rupture has occurred in session. Confrontation markers involve clients' expressions of affective anger, resentment, or dissatisfaction with the therapist or therapy process (Safran \& Muran, 2000; Harper, 1989b). These markers often take the form of a verbal complaint and are aimed toward: the therapist as a person, in which the client attacks personal traits of the therapist; the therapist's competency; the specific tasks, activities, or interventions of therapy; being in therapy, including doubts about beginning or continuing therapy; the parameters or boundaries in therapy; and the progress in therapy.

Confrontation ruptures are considered to be primarily movements away from the therapist or parts of the therapy process, and often involves aggression and control on the part of the client (Muran et al., 2010). Confrontation ruptures are generally evidenced through direct expression of anger through behavioral or verbal aggression about their dissatisfaction with the therapist or some part of the therapy process.

In terms of psychological conflict, withdrawal rupture events position the client favoring their need for relatedness over their need for agency. In confrontation ruptures, clients shift their balance toward their need for agency or self-definition over their need for relatedness (Safran \& Muran, 2000). In one previous qualitative study examining the experiences of ruptures, therapists consistently reported that they felt more effective in resolving or working through withdrawal ruptures compared to confrontation ruptures 
(Coutinho, et al., 2011). It is important to remember, however, that the rupture markers can be largely contextual and need to be considered in terms of what is happening in the moment versus preconceived conceptualizations of clients' internal conflicts.

\section{Indications of an Enactment}

The increase of focus of relational themes in psychotherapy since the 1980s has meant that many of the interpersonal elements of interventions relegated to psychoanalytic, psychodynamic, experiential, interpersonal, and humanistic traditions have bled into many other therapies, which traditionally did not have a strong relational focus (Wachtel, 2008). This relational focus means that as therapists assume a two-person psychology in which they co-contribute to the happenings in the therapy room, they open the door for possibility of engaging in co-constructed, relational matrices of interpersonal patterns (Wachtel, 2008, 2014). This two-party interaction stemming largely from unconscious sources have also been called enactments (Jacobs, 1986; Safran \& Muran, 2000), and borrows theoretically from various relationally-focused therapies (Westwood et al., 2003).

These patterns can be found across multiple theoretical orientations and appear to affect the therapeutic alliance in similar ways. Examples include interpersonal or relational schemas (Baldwin, 1992; Beck, 1976; Beck, 2011), the Core Conflictual Relationship Theme (CCRT; Luborsky, 1984), the Cyclical Maladaptive Pattern (CMP; Strupp \& Binder, 1984); and Early Maladaptive Schemas (EMS; Young et al., 2003). These maladaptive interpersonal patterns are thought to originate early in life, relate to early childhood relationships, and serve an adaptive purpose to somehow maintain relatedness to caregivers or other persons considered important in the child's life. Early 
maladaptive patterns are then repeated throughout the life course, laying the foundation for expectation interpersonal tensions, strains, and push-pull dynamics with persons in their lives (Binder, 2004). The unwitting therapists will find themselves in a reenactment of those maladaptive interpersonal patterns, fulfilling the expected roles of persons innumerable over the course of the client's life (Wachtel, 2014). It is when these maladaptive interpersonal patterns are reenacted or triggered during the therapeutic process that ruptures occur, exhibited through the behavioral markers described above.

Among clients who tend to demonstrate recurring patterns of maladaptive interpersonal cycles are those diagnosed with personality disorders (Castillo, 2003). For example, it is well documented that clients diagnosed with borderline personality disorder demonstrate chronic relational problems and have difficulty practicing affective management and regulating emotional distress. Among rupture researchers, borderline personality disorder stands out as a robust influence, as it has been found that between $42 \%$ and $67 \%$ of clients with borderline personality disorder prematurely drop out of treatment (Bennett, Parry, \& Ryle, 2006), and many of these clients report negative views of their therapy process (Castillo, 2003). Between premature termination and negative experiences in therapy, it stands to reason that these clients experienced ruptures in therapy sessions at a greater rate than clients without pervasive maladaptive interpersonal patterns (Kellett et al., 2013; Muran et al., 2005). Similar findings were also evident for clients diagnosed with avoidant personality disorder and obsessive-compulsive personality disorder (Strauss et al., 2006).

It is important to note that it is not just the clients who may elicit an enactment in session; therapists' own interpersonal patterns may also bring about a rupture. 
Differentiation between the rupture markers during the therapy process are thought to elicit different responses from therapists. For example, the presence of withdrawal makers may fly under the radar and go unnoticed by therapists who are either not aware of the client's tension which results from their efforts to maintain relatedness, or they have co-created an interpersonal pattern of client deference and therapist "expertise" (Safran \& Muran, 2000). Alternatively, confrontation markers are more likely to be noticed by therapists (Coutinho et al., 2011) and are more likely to elicit negative, maladaptive, or even hostile responses from therapists. In one study, therapists who observed confrontation markers (labeled as impasses in this study) and were subsequently pulled into the confrontation dynamics reported feelings of frustration, hurt, disappointment, anger, and confusion (Hill et al., 1996).

\section{Rupture Repair}

Despite therapists' best attempts to minimize the frequency and intensity of ruptures during the therapy process (Safran \& Muran, 2000), there is reason to suggest that this is not only unreasonable, but also potentially counterproductive to necessary processes leading to positive therapy outcomes (Daly et al., 2010; Eubanks-Carter et al., 2010). In fact, it is estimated that clients perceive ruptures occurring in $19 \%$ of sessions, and therapists perceive ruptures occurring in $43 \%$ of sessions (Eames \& Roth, 2000). Early sessions in the therapeutic relationship may be more prone to alliance ruptures. Stiles et al. (2004) found that the majority of clients who met criteria for rupture repair sequences demonstrated these processes in early sessions (Sessions 2-4 in 8 session treatments and Sessions 2-7 in 16-session treatments). Muran et al. (2009) found that in the first six sessions of treatment, $56 \%$ of therapists and $37 \%$ of clients perceived rupture 
occurrences. There is a similarity in therapists perceiving ruptures at a higher rate than clients, which may reflect therapists' training to be more attuned to the presence of rupture markers or clients' hesitance to indicate the presence of a rupture marker or decreased working alliance rating.

Of course, the presence of a rupture in the therapeutic alliance does not automatically mean that the course of therapy is irreparable, nor does it necessarily mean that the relationship is tarnished or otherwise damaged beyond repair. Bordin (1979) described what he considered an inevitable tear-and-repair process, fueled largely by clients' pathologies, to be a necessary catalyst for meaningful therapeutic gains to be made. That is, it was hypothesized that clients and therapists experiencing ruptured alliances would lead to the best outcomes in therapy. This was empirically validated, in part, through the work of Kivlighan and Shaughnessy (2000) when they observed that alliances which resembled a quadratic development (U-shaped patterns) were associated with greater improvement on measure of counseling compared with linear alliance development (increasing consistently throughout the course of therapy) and stable positive alliances. This U-shaped growth pattern suggests a period of therapy in which the quality of the alliance decreases and is then restored.

Subsequent research by Stiles et al. (2004) sought to replicate the alliance growth patterns observed by Kivlighan and Shaughnessy (2000). Despite observing similarities in terms of linear growth and stable ratings of the alliance, Stiles et al. (2004) failed to accurately replicate the curvilinear, U-shaped alliance trend. Instead, what was found was a more sudden decrease in ratings of the alliance. That is, a V-shaped rupture-repair pattern was observed, suggesting a strong alliance in the early sessions of therapy, 
followed by a brief interruption (such as by "doubt or antagonism" (Stiles et al., 2004, p. 89), followed then by a repair and restoration to positive alliance ratings. Despite the differences in visualization of charting of alliance ruptures ( $\mathrm{V}$-shaped versus $\mathrm{U}$-shaped) and, therefore, the differences in timing/suddenness of decline in alliance ratings, clients experiencing ruptured working alliances tended to have better outcomes compared to clients in non-rupture therapy processes. As such, Stiles et al. (2004) provided a quantitative characterization of what defines a rupture-repair sequence. These criteria include:

1. A core alliance score being lower than the predicted value of the client's intercept, slope, and curve parameters by at least two standard deviations below the fitted curve.

2. Low scores (rupture makers) not occurring in the first or final session.

3. The overall slope is nonnegative (which eliminate inclusion on ruptures, which were not fully repaired).

4. The low (rupture) score is numerically lower than the preceding score. Stiles et al. (2004) used the Agnew Relationship Measure (ARM; Agnew-Davies, Stiles, Hardy, Barkham, \& Shapiro, 1998) to measure alliance. As such, the authors stated that the lower-preceding-score criteria was cited to be lower than 6.0 on the 7-point ARM scale. Clinical cutoff for alliance will be discussed in relation to the present study in the Method section.

These criteria have been used previously to detect the presence of ruptures in calculating alliance fluctuations (e.g. Gülüm et al., 2018; and Strauss et al., 2006). Additional quantitative changes observed in alliance scores may indicate the presence of ruptures as 
well. For example, analysis of the Session Rating Scale (SRS; Miller et al., 2002; Miller \& Duncan, 2004) has shown that single-point declines from session to session have been found to be associated with decreased outcomes at termination, even for clients that consistently rate alliance above alliance cutoffs for "cause for concern" (Miller et al., 2007).

It is important to consider that the overall process of repairing ruptures differs depending on the rupture marker exhibited in therapy. For example, the resolution process for withdrawal ruptures may involve exploration of intrapersonal or interpersonal fears, which inhibit the expression and communication of "negative" emotions (Safran \& Kraus, 2014; Safran \& Muran, 2000). Conversely, the rupture repair process for confrontation makers often involves the therapist's empathic engagement with the client in order to facilitate unconscious or disavowed emotions, which drive the maladaptive interpersonal patterns (Safran \& Kraus 2014; Safran \& Muran, 2000).

In recent years, researchers have created models, which focus on the process and interventions focused on rupture repair (Bennett et al., 2006; Safran \& Muran, 2000). These interventions generally include: repeating the therapeutic rationale; changing the tasks or goals; clarifying misunderstandings at a surface level; exploring relational themes associated with the rupture; linking the alliance rupture to common patterns in a client's life; and providing a new relational experience (that is, acting in a way which will provide a new relational experience for the client without necessarily making this insight explicitly known) (Safran et al., 2011). Before these interventions can be implemented into a relational, give-and-take process between client and therapist, the therapist must acknowledge the presence of a rupture marker and be able to detachfrom the 
interpersonal process in order to explore the disconnect in alliance (Muran et al., 2010;

Rhodes et al.,1994). In order for the detection of rupture markers to occur, therapists must cultivate a stance of ongoing self-awareness and remain affectively and interpersonally attuned to shifts in the alliance throughout the course of therapy (Safran \& Kraus, 2014). For example, therapists often experience interpersonal push/pull dynamics during sessions, which mirror clients' maladaptive interpersonal patterns. It is necessary for the therapist to identify their own implicit or explicit responses to these patterns, and to be able to "step outside" of the dynamic and offer encouragement to explore the occurrence with the client.

The importance of rupture identification and repair brings about the question of whether these skills can be taught, and whether training proves beneficial for rupture repair (Aspland et al., 2008). Training models for rupture repair involves the accurate identification of rupture makers occurring during therapy sessions. Evidence from qualitative client interviews as well as observer ratings of ruptures show that therapist often miss rupture markers, and that failure to address ruptures is related to client dropout (Muran et al., 2010). Furthermore, identifying the presence of ruptures is predicated upon therapists (who are observing the potential ruptures) as possessing three basic, necessary skills: self-awareness; affect regulation; and interpersonal sensitivity (Muran et al., 2010).

One meta-analysis examined the impact of rupture resolution training or supervision on therapy outcomes (Safran et al., 2011). The training analysis search process identified studies specifically indicating the involvement of therapists who had undergone some form of rupture-resolution training or supervision, most of which also contained a comparison control group. Results of the meta-analysis provided evidence 
that rupture resolution training led to significant client improvement, yielding an effect size of $.52, z=6.94,95 \% \mathrm{CI}[.40-.63], p<.001$. Additionally, the results indicated that rupture resolution training/supervision led to a small but statistically significant client improvement compared to therapists without rupture resolution training, yielding an effect size of .11, $z=2.24,95 \%$ CI [.01-.21], $p=.03$.

\section{Client Factors: Adolescent Psychotherapy Process}

There has been a question as to whether the three-factor (goals, tasks, bond) alliance model described above appropriately predicts treatment outcomes in youth and adolescents similar to that of adults (Shirk \& Karver, 2003). There is evidence to suggest that attention to these components of the alliance prove to be beneficial to therapy outcomes. One such example is that goal maintenance, one component of maintaining or rebuilding a strong alliance, has been found to improve retention in psychotherapy among youth and adolescence and improve therapy outcomes (Cairns et al., 2019). Less is known about rupture repair patterns among child and adolescent clients. For example, when considering therapy with adolescents, mood irregularities and other personal and social developmental factors may increase the likelihood of therapeutic ruptures (Chu et al., 2010). However, there are no existing quantitative studies exploring the effects of rupture-repair processes on therapeutic outcomes specifically among adolescents. Suggestions for continued research come from studies on alliance-outcome research among adolescents. Still, this can be helpful in providing direction for what can be expected in adolescent rupture-repair research.

Previous research demonstrated that the association between the alliance and outcomes in adolescent psychotherapy did not account for as much variance compared to 
adult populations (McLeod, 2011; Shirk \& Karver, 2003). A follow-up meta-analysis using updated studies resulted in similar findings (Shirk et al., 2011). Subsequent exploratory analyses were conducted to determine potential moderator variables for the association between alliance and outcome. Shirk et al. (2011) found that presenting problem type (substance abuse and mixed problems vs. eating disorders) significantly moderated alliance-outcome associations. Shirk et al. (2011) also found trends indicating that age (child vs. adolescent) and therapy type (behavioral vs. nonbehavioral therapies) affected alliance-outcome associations. However, age and therapy type were found to be statistically non-significant moderators of alliance outcome associations.

The research literature on premature therapeutic termination among adolescents (e.g. adolescents who prematurely dropped out of therapy) provides evidence that therapeutic ruptures may further affect the alliance-outcome relationship. For example, Robbins et al. (2006) examined therapeutic alliances as predictors of premature therapy dropout in therapy for adolescents who abuse drugs. The results showed that Session 1 to Session 2 change in youth-rated alliance was statistically significant for adolescents who dropped out of therapy. The changes in alliance from Session 1 to Session 2 were not statistically significant for adolescents who completed therapy. Additionally, it was found that adolescents who prematurely dropped out of therapy were, on average, older than those who completed. Adolescents who dropped out also reported fewer internalizing symptoms, and fewer externalizing symptoms on the YSR than those who completed treatment (Robbins et al., 2006). These findings suggest that there was significant reduction in alliance from Session 1 to Session 2 among adolescents who dropped out of therapy, and that this decline in alliance did not occur among adolescents who completed 
therapy (Robbins et al., 2006). There is evidence that exemplifies the use of monitoring the presence of an alliance rupture and the relationship to therapy dropout (Eubanks et al., 2019; O'Keeffe et al., 2020). Previous use of monitoring systems, however, often involves incomplete selection of sessions to identify the presence of alliance ruptures, and does not consistently address the session-to-sessions changes that occur in alliance ratings. As mentioned previously, the variance in outcomes of therapy with youth and adolescents may be better explained by using different models of assessment (Marker et al., 2013; Shirk et al., 2008). For example, when using a change-based-assessment model of assessment in which the alliance was continually monitored over time, the alliance accounted for $9.8 \%$ of the variance in select adolescent therapy outcomes (Owen et al., 2016). Additionally, alliance-outcome findings have observed discrepancies in timing (e.g. early versus late alliance ratings) (Hukkelberg \& Ogden, 2013; Kazdin \& Whitley, 2006).

As important as therapeutic outcomes and symptom change are during the therapy process, information about the importance of the therapeutic alliance can also be observed by studying clients who do not continue after an alliance rupture has occurred. A study by Garcia and Weisz (2002) used factor analyses to determine that problems in the therapeutic relationship accounted for the most variance (16\%) in differentiating youth clients who dropped out of therapy versus those who completed. The therapeutic relationship, as well as financial concerns, were the only two predictors of youth client dropouts (non-factors included time and effort concerns as well as whether treatment was even seen as needed). Indeed, this finding relating to adolescent client attrition and dropout is seen in substance abuse treatment. A study examining perceived barriers to 
treatment in adolescent substance abuse treatment revealed that practical obstacles, treatment readiness, treatment relevance, and treatment compatibility (as rated by therapists) were significant predictors of variability in client attendance (Mensigner et al., 2006). The researchers conclude that mental health providers, administrators, and researchers should give appropriate attention to these areas as a means to reduce chances of premature termination and to increase chances of client buy-in.

\section{Client Factors: Adolescent Substance Use}

Adolescence is defined as the period of transition between childhood and adulthood, and generally marked as of the most significant phases of development that one experiences in their lifetime (Crone \& Dahl, 2012). Tasks of this developmental phase include, but are not limited to: the physiological and changes of puberty and sexual maturation; physical, structural, and neurocognitive changes in the brain; psychological and emotional maturation; individuation and formation of self-identity; establishment and cultivation of social and interpersonal relationships beyond the family of origin or primary guardianship (Blakemore \& Mills, 2014; Kilford et al., 2016; Suleiman \& Harden, 2016; Veed et al., 2019). Amongst many of these biological, neurological, psychological, and social milestones, adolescence also represents for many a period of vacillating pleasure and distress involving self-and-other uncertainty, challenges with perspective-taking, and alternative forms of reward- and sensation-seeking. For some or many of the above-listed reasons, adolescence is also a time in which biopsychosocial factors facilitate experimentation with drugs and alcohol (Gray \& Squeglia, 2018).

The United States National Survey on Drug Use and Health state that the majority of adolescent substance use/abuse within a previous year was in the forms of alcohol, 
nicotine products, and marijuana/THC products (NSDUH, 2018). It was estimated that 9.0 percent of adolescents aged 12 to 17 were alcohol users, corresponding to 2.2 million adolescents who drank alcohol in the past month. This included an estimated 1.2 million adolescents in this age group that had engaged in binge drinking within the past month (4.7 percent of adolescents) and an estimated 131,000 adolescents that were considered "heavy drinkers." An estimated 672,000 adolescents smoke cigarettes within the past month (about 2.7 percent). This actually represents a decline in use, which may be reflected by the increased use of electronic cigarettes (e-cigs) and other vaporizing products ("vaping"). Although the NSDUH does not specifically inquire about use of electronic nicotine products, there is substantial evidence that e-cigarette use is on the rise in the United States (Park et al., 2020), with an estimated 35.1 percent of 12th graders reporting use in the past twelve months, an increase of 5.4\% from 2018 to 2019 alone (Miech et al., 2019). In 2018, an estimated 3.1 million adolescents used marijuana within the past year ( 1 in 8 , or 12.5 percent). While these numbers are consistent with recent years, there is evidence of increased use of vaping products for THC, which themselves present new and deleterious health effects (National Institute on Drug Abuse [NIDA], 2019).

As mentioned, it is imperative to consider adolescent substance use through the lens of the biopsychosocial model (Gray \& Squeglia, 2018). Biologically, adolescents are experiencing rapid physical and neurological changes (Steinberg \& Sheffield Morris, 2001). Regarding the neural components of the brain, a large percentage of human behaviors are moderated by the reward mechanisms which involve subcortical structures that interface between limbic and motor circuitry, thereby translating emotional 
experiences in to motor/behavioral activity (Sharma \& Morrow, 2016). This involves the nucleus accumbens, a part of the ventral striatum, which itself is a part of the basal ganglia. Pleasurable/rewarding activities such as sex and food acquisition result in a release of dopamine in the nucleus accumbens, and create a feedback loop for repeating behaviors motivated by attaining similar dopaminergic responses in the brain (Hyman et al., 2006). The repetitive reward network influences creation of neurological growth that results in learning and memory for the purpose of achieving similar subcortical responses. As the human brain matures and develops, it does not do so equally across all areas, and tends to begin in the subcortical regions of the brain. This means that an adolescent brain has more temporal precedent for biological resources driving pleasureseeking behaviors compared to adaptive cognitive control mechanisms, which develop later in the prefrontal cortex (McCutcheon et al., 2012). This neurodevelopmental trajectory often results in adolescents engaging in more impulsive, risk-taking behaviors, including substance use (Humphrey \& Dumontheil, 2016; Somerville et al., 2010). Additionally, there is evidence that the subcoritcal processes are more powerful in terms of dopaminergic activity in the nucleus accumbens in adolescents than in adults (Doremus-Fitzwater et al., 2010). While adolescents are considered to be capable of engaging in logical risk analyses equivalent to adults by the age of 15 , there may be more incentive to engage in risky behaviors, including substance use, due to the salience of rewards and how these are processed in the brain (Sharma \& Morrow, 2016). Because the brain's maturation is not complete until approximately age 25 (or later for some), the deleterious effects of substance use can have lasting or even permanent consequences on brain development (Giedd \& Rapoport, 2010; Guerri \& Pascual, 2019; Hill, 2004). 
In addition to the biophysical effects of adolescence and potential predisposition to substance use, there are also several psychosocial variables to take into consideration (Jordan \& Andersen, 2017; Mayberry et al., 2009; Schindler \& Bröning, 2015). Individually, adolescents are experiencing many transitions that increase a sense of independence, individualization, identity formation, goal-direction and feelings of autonomy (Davidow et al., 2018; Meeus, 2016). While often-cited reasons of using drugs and alcohol include adolescent rebellion and demonstrations of anti-authoriatism, research suggests this may play less of an explicit role in the cited reasons why teenagers seek substance use. In one study by Boys et al. (2001), the most common functions of substance use among adolescents were a) to relax (96.7\% of respondents), to become intoxicated (96.4\%), to keep awake at night while socializing (95.9\%), to enhance an activity $(88.5 \%)$, and to alleviate depressed mood $(86.8 \%)$. This is consistent with previous literature that posits four types of motivation(s) for adolescent substance use: social, enhancement, coping, and conformity (Cooper, 1994). Regarding individual characteristics that may influence substance use, there is evidence that personality and temperament facilitate an adolescent's personal approach or avoidance of drug and alcohol use (Malmberg et al., 2012). For example, although it is suggested that some adolescents may choose to use substances to socialize or to mitigate emotional distress, Colder et al. (2017) found that increased levels of fear or shyness were associated with increases in negative experiences and appraisals of use, which may be in part due to sensitivity to aversive stimuli or outcomes of substance use, such as becoming sick or getting into trouble. Additionally, there is an increasing amount of research that shows evidence that psychological distress has a significant mediating effect on adolescent 
substance use. For example, adolescents who experience abuse, physical and/or psychological maltreatment, and exposure to physical violence are more likely to engage in binge drinking and other use of illicit substances compared to their peers (Bailey \& McCloskey, 2005; Greger et al., 2017; Hayre et al., 2019).

Social and interpersonal factors may also have a strong influence on adolescents initiating substance use and developing substance use disorders (Hemovich et al., 2011; Siennick et al., 2015). Throughout childhood and into adolescence, individuals' exposure to familial behaviors such as substance use has long been understood to influence perceptions of substances and drug use behaviors, and is a significant predictor of early onset of drug use, and later substance use disorders (Brook et al, 2010; Miller, et al., 2013; Kerr et al., 2013). Adolescents from a family with a history of substance abuse are particularly vulnerable for developing substance-related problems themselves, which have shown both social and biological predisposition for future use (Cservenka, 2016). Prenatal exposure has been linked to early onset of substance use (Baer et al., 1998; Baer et al., 2003; Day et al., 2006; Richardson et al., 2013). Parental factors may also be a deterrent for substance use in adolescence. For example, multiple studies (Piko and Kovács, 2010; Wen, 2017) have found that parental monitoring was a universal protective factor for adolescents. Acceptance and respect for parents' values may also serve as a protective factor against substance use. The quality of the parent-child relationships has also been found to influence alcohol use, binge drinking, and marijuana use onset (Rusby, 2018). With regards to the current study, one such specific cultural consideration is how being in a military community affects the potential for military adolescents to use substances. In one study, it was found that higher parentification 
factors, such as having more responsibilities at home, being more independent, and being able to solve problems better relative to peers, serves as a protective factor against polysubstance use compared to lower parentification adolescents (Sullivan et al., 2018).

The role of peers and peer influence becomes particularly influential during adolescence (Connell et al., 2010; D’Amico \& McCarthy, 2006). As such, rates of drug and alcohol use are shown to increase with age (Johnston et al., 2016). This may be due in part because as adolescents age, they become acquainted with more peers who have access to social sources of drugs and alcohol, such as older siblings of friends or peers in higher grades levels (Harrison et al, 2000), and general exposure to drug and alcohol use (Siennick et al., 2015). The pressure to initiate substance use is mediated by peer influence, as well as the frequency of becoming intoxicated (Wesche et al., 2018). After controlling for individual substance use, perceived peer alcohol use predicted both increased alcohol and marijuana use, and initiation of alcohol use. Perceived peer alcohol and marijuana use predicted onset of marijuana use (D'Amico \& McCarthy, 2006). There is some evidence to suggest a bi-directional relationship between peer relationships and adolescent substance use. McDonough et al. (2016) found that negative peer influence predicted increased use of substances, and that individuals who use alcohol, cigarettes, and marijuana show increased negative peer influence on others. Aside from peer and social influence as a pressure to use, there is also evidence that overt peer pressure, such as directly offering substances and encouraging drug use predicts substance use (Hendricks et al., 2015). Although there is question of the presence or effect of an individual's deviance of family rules on substance use (mentioned previously), there is evidence that an adolescent's perceptions of the degree to which their peers explicitly 
encourage disobeying their parents and engaging in dangerous behaviors predict substance use (Whitesell et al., 2014). That is, an adolescent is more likely to use substances if they believe that their peers are actively encouraging them to do so.

Of course, it is also important to consider how broader ecological systems influence adolescent behaviors such as substance use (Bronfenbrenner, 1979; Cook et al., 2002). In addition to direct peer influence to use substances, there is evidence that adolescents are at increased risk of alcohol use onset because of their position within social networks in relation to their friends, and friends of friends (Mundt, 2011). Mundt (2011) found that in comparison with adolescents who abstained from alcohol use, those that initiated alcohol use had more popular friends as measured by peer nominations, and having more friends who drank alcohol. Neighborhood factors also affect drug and alcohol use among adolescents. For example, perceptions of increased neighborhood disorganization, decreased social cohesion, and increased amounts of neighborhood problems with alcohol and drug use were associated with higher odds of the use of alcohol, tobacco, and other drugs among adolescents (Shih et al., 2017). School-level substance use is positively associated with an adolescent's individual substance use (Eisenberg et al., 2014). This means that students who attend schools in which there is more prevalent substance use among the student body, are more likely themselves to use drugs and alcohol compared to students who attend schools with less substance use among peers. Conversely, school-level effects have also been shown to have moderating factors against student substance use. For example, increased school-level disapproval (i.e. a higher proportion of students expressing negative attitudes about substance use in a school) was negatively associated with adolescent substance use, meaning that when 
more students in a given school endorse disapproval of using drugs and alcohol, a student is less likely to report using drugs and alcohol themselves (Su \& Supple, 2016).

Similarly, there is evidence that ratings of a positive school climate and positive sense of community were associated with less adolescent substance use (Mayberry et al., 2009). Furthermore, a positive sense of community moderated the relationship between peer and parental influences on substance use, and serves as a protective factor (Mayberry et al., 2009). Additional evidence exists that for males, perceived increase in school support, and increased teacher support and expectations is associated with reduced odds of engaging in substance use (Shekhtmeyster et al., 2011; Suldo et al., 2008). For females, family and peer factors largely accounted for influence of substance use, whereas school caring relationships did not significantly affect substance use (Shekhtmeyster et al., 2011).

\section{Client Factors: Treatment of Adolescent Substance Use}

Because of the multiple factors affecting the vulnerability of adolescents to use drugs and alcohol, understanding the biopsychosocial influences of adolescent substance use has important implications for prevention and intervention. Gottfredson and Wilson (2003) found that substance use prevention programs were most effective when they occurred with those in early adolescence (i.e. middle school), suggesting that there is a sensitive period with which to intervene and prevent and/or treat substance use problems. As mentioned above, parents monitoring adolescent behaviors and the quality of their relationships with adolescents, and openly communicating expectations of drug and alcohol can increase the age of onset of use and decrease drug use frequency (Rusby et al., 2018). Prevention programs that are most effective include targeting salient risk and 
protective factors at the individual, family, and community levels (Griffin \& Botvin, 2010). School-based interventions can include social resistance skills, normative education, competence-enhancement, and program models such as Life Skills Training (LST). Interventions that target community factors may be helpful, such as school district leadership practices, collective efficacy, residential instability, and economic risks (Chilenski \& Greenberg, 2009). Incorporating discussions to foster a sense of social cohesion and connection with their immediate community may also have protective factors against substance use, and may moderate the effects of other predictors of substance use (Fagan et al., 2014). Finally, there is evidence that larger societal efforts such as changing minimum purchase ages may help reduce adolescent substance use by reducing the social networks that have access to certain drugs (e.g. nicotine) and alcohol products (Friedman et al., 2019; Norberg et al., 2009).

In addition to efforts for prevention, therapeutic treatment intervention has also been found to be effective in reducing onset, frequency, and amount of adolescent substance use (Das et al., 2016). In the past two decades, there has been a considerable increase in recognizing the need for developmentally appropriate and individualized treatment approaches that investigate specific techniques and therapeutic factors that facilitate treatment with youth (Fagan, 2006; Margret \& Ries, 2016). One example of this was evidenced by a study in which adolescents that received intentional interventions designed to help identify and overcome impediments to treatment attendance led more frequent attendance and reduced substance use compared to adolescents that received standard care, without the brief interventions (Tait et al., 2004). 
Several psychosocial therapies including individual therapy, group therapy, family therapy, and motivational enhancement therapy (MET) have shown to be efficacious in reducing substance use and reducing the effects of substance use on other areas of adolescent's lives (Waldron \& Turner, 2008). Hogue et al. (2014) conducted metaanalytic review of adolescent substance use studies and found that ecological familybased treatment, group cognitive-behavioral therapy, and individual cognitive-behavioral therapy were considered "well-established" treatment approaches for substance use treatment, as well as integrated approaches that combined more than one approach. Hogue et al. (2014) also determined that behavioral family-based treatment and motivational interviewing were deemed "probably efficacious." One study exemplifying the effects of family therapy on adolescent substance abuse was conducted by Horigian et al. (2015), and found that that manualized Brief Strategic Family Therapy (BSFT) is effective in reducing alcohol use in parents, and in reducing adolescents' substance use in families in which parents were using substances. Additionally, BSFT also showed improvement in ratings of family functioning (Horigian et al., 2015).

\section{Client Factors: Military Culture}

Psychotherapy researchers would be wise not to assume that process and outcome findings among non-military/civilian clients directly translate to the mental health needs of military clients. One of the primary factors to examine is the level of engagement in mental health services among military personnel and their families. One of the most common findings across the literature is that although there have been increased efforts to increase awareness of services offered for active duty and veterans returning from deployment (Pickett et al., 2015), though there continues to be lower-than-desired 
engagement in mental health services among the military population. For example, a study by Schell and Marshall (2008) found that $47 \%$ of surveyed military participants who had met criteria for symptoms PTSD or major depression had not sought any form of mental health care in the previous year. Additionally, $30 \%$ of those who did seek care reported receiving only a minimally adequate amount of care, with many premature therapy dropouts. As many as $60-70 \%$ of veterans with a mental health diagnosis do not receive adequate mental health treatment within a year of receiving a diagnosis, with stigma cited as one of the most common and prevalent barriers to seeking treatment (Corrigan, Druss, \& Perlick, 2014; Green-Shortridge, Britt, \& Castro, 2007; Hoge et al., 2004; Sharp et al., 2015). The most endorsed stigma concerns were that leadership might treat military personnel differently and that they would be seen as weak (Sharp et al., 2015).

In addition to monitoring the well-being and provision of care for military personnel, the Department of Defense also acknowledges the need to review systems of care for military families (Department of Defense [DoD], 2018). As such, children of military personnel may experience unique personal and familial stressors, which are not experienced by civilian youth. Some of these stressors may include the impact of deployment, the need for flexibility and adjustment during relocation, separation and reunion from family members, as well as residual mental health effects to parents returning from combat (Drummet et al., 2003; Huebner et al. 2007; Steenkamp \& Litz, 2013; White et al., 2011). One might assume that these effects of military youth do not differ from civilian youth. After all, families are often split through divorce, relocation occurs through changes in parental employment, and mental illness is not unique only to 
military families. However, military families experience these stressors more frequently and assume these stressors as a part of a shared military culture. As Weiss et al. (2010) state, "Unlike civilian families, military families represent a unique culture that emphasizes the adherence to specific guidelines of conduct. Service men and women conform to a core set of values and traditions inherent to military life. Additionally, military families have the pressure to make a similar commitment to the military's norms, beliefs, and traditions" (p. 396). This can be explained, in part, by considering the interdependencies within military families (Wadsworth et al., 2013), which may include intergenerational transmission of shared cultural values. While this may be beneficial in many ways, the shared values may also present opportunities for shared values with reduce help-seeking behaviors for mental health. For example, the military has a culture of stoicism in which one is expected to navigate problems without complaint (Hall, 2011). This belief could affect the level of communication between military parents and adolescents (Milburn \& Lightfoot, 2013). Additionally, the military culture of personal agency can serve as rationale for adolescents to cope with their problems and concerns independently, and forgo seeking help from others (Huebner \& Mancini, 2005; Milburn \& Lightfoot, 2013). However, there is evidence that peer support groups can be established based on a shared identity among military adolescents in distress, such as those organized by school psychologists (Bradshaw et al., 2010).

Despite the theorized factors which could affect therapy outcomes among military adolescents, little-to-no research has been conducted among this population in regard to therapy process and outcomes. This paucity of research includes an absence of studies examining dropout rates, outcome comparison studies, and studies looking at evidence- 
based interventions. Only one study was found which examines the effects of alliance in therapy outcomes of military youth (Owen et al., 2016). These authors posit that it would be beneficial to explore the reasons why "successful treatments are associated with increases in the alliance" (p. 208), specifically postulating that changes or fluctuations in the alliance may be a stronger mechanism of change compared to high, steady alliances. Much has been written about the effects of military life on the mental well-being of adolescents and the need for empirically validated treatment considerations (EspositoSmythers et al., 2011). However, there remains to be systematic evaluation of psychotherapeutic process and outcome factors directed specifically to military youth.

\section{Research Question and Hypotheses}

Previous research with the existing data shows that alliance accounts for as much as $9.8 \%$ of the variance in youth outcomes (Owen et al., 2016). The purpose of this study is to examine therapeutic outcomes comparing psychotherapy processes in which there were therapeutic ruptures present and not-present (rupture versus non-rupture) among military youth who attended therapy for concerns related to substance use. Specifically, this study will address whether there are significant differences in alliance-outcome associations comparing processes with and without alliance ruptures, as well as comparing ruptures which were repaired and not repaired. The study will also investigate if rupture-repair processes serve as a predictor for adolescents who stay in therapy versus adolescents who prematurely dropout of therapy. Finally, the current study will investigate whether rupture-alliance-outcomes are moderated or covary by: A) Early versus late therapy ruptures; B) Age; C) Problem-type; and D) Therapist effects. 


\section{Hypothesis 1}

There will be evidence of treatment effects comparing psychotherapy processes with no alliance ruptures, psychotherapy processes with evidence of rupture repair, and psychotherapy processes with no evidence of rupture repair. Specifically, it is predicted that psychotherapy processes in which there is rupture repair will have significantly higher outcome scores than those processes without rupture repair and processes with no rupture (Kivlighan \& Shaughnessy, 2000; Stiles et al., 2004).

\section{Hypothesis 2}

There will be evidence of treatment effects in the prediction of therapy dropout. Specifically, it is predicted that adolescents will be significantly more likely to stay in therapy (versus prematurely leaving therapy) when ruptures are repaired compared to processes in which ruptures are not repaired.

\section{Hypothesis 3}

Psychotherapy processes in which there is evidence of rupture will show differences in outcomes in terms of whether the rupture was repaired or not. Specifically, it is predicted that adolescents that experience rupture-repair will be associated with a higher number of sessions attended compared to adolescents that experience unrepaired ruptures.

\section{Hypothesis 4}

Rupture repair sequences among military adolescents will occur mainly in earlysession treatments. More specifically, among processes in which rupture-repair sequence 
criteria is met (Stiles et al., 2004), most of these processes will occur in the first half of the therapy process. This will replicate Stiles et al.'s (2004) findings which included adult study participants (age $M=41$, range 23-60). Stiles et al. (2004) found that 15 of 18 ruptures-repairs $(83.3 \%)$ occurred in early sessions, with all but one in 8-session (4 of 5) and all but two in 16-session (10 of 12).

\section{Hypothesis 5}

Age will act as a moderator on the effect of rupture-repair on outcome. As it is predicted that there will be an effect of repaired versus unrepaired ruptures on outcomes, it is further predicted that the relationship between rupture condition and outcome will be affected by the age of the client. This prediction is based on previous meta-analytic findings (McCleod, 2011) that weighted mean alliance-outcome effects were significantly higher for children (mean age below 13) compared to alliance-outcomes effects for adolescents (mean age 13 or older). Although the current study does not include children under the age of 13, McLeod's (2011) meta-analysis separated studies by mean age, which may have excluded age effects by year as opposed to age grouping. This prediction is also based on previous findings that adolescents who prematurely dropped out of therapy were on average older than those that completed treatment (15.38 vs. 14.59), $F(1$, 27) $=4.19, p=.05, \eta^{2}=.13$ (Robbins et al., 2006).

\section{Hypothesis 6}

There will be significant differences between groups (differentiated by definition of problem-type) on the effect of rupture repair on outcome. Specifically, it is predicted that meeting criteria for a substance use disorder (versus having subthreshold symptoms 
of a substance use disorder) will act as a moderator on the effect of rupture condition (repaired versus non-repaired) on adolescent therapy outcome. It is predicted that meeting criteria for a substance use disorder will show increased therapy outcomes compared to those not meeting criteria, but are shown to be at risk for other reasons. Previous research has demonstrated differing effects on alliance-outcome relationships between those presenting for substance abuse and those presenting with other target problems. In a meta-analysis of alliance-outcome effects in adolescent therapy, the weighted mean effect size for externalizing symptoms was significantly higher than the effect size for substance abuse $(g=.15, p<.05 ;$ McLeod, 2011).

\section{Hypothesis 7}

There will be evidence of a therapist effect on the effect of treatment on the outcomes of therapy. Specifically, it is predicted that therapists who, on average, report higher aggregate alliance scores among their clients will lead to higher therapeutic outcomes in post-rupture-repair sequences than those reporting lower aggregate alliance scores. It has been shown that between-therapist variability in alliance is a significant predictor of therapeutic outcomes, whereas client effects (within therapist) were not significant predictors of outcomes (Baldwin, et al., 2007; Del Re, Flückiger, et al., 2012). Similar to these previous studies, construction of a multilevel model will provide additional information to account for variability in hypothesized treatments effects on outcomes. 


\section{CHAPTER II: METHOD}

\section{Participants}

Clients. For the current study, a full sample of 6,668 military adolescent/youths were selected based on participation in psychotherapy for factors related to substance abuse, including personal substance abuse, parent substance abuse, and risk factors associated with substance abuse (Owen et al., 2016). The mean number of sessions for the full sample was $8.46(S D=6.57$, Median $=7$, range: $1-74)$. Presenting concerns were adolescents that: a) Met criteria for a substance use disorder; b) Presented with subthreshold substance use disorders; c) Have parents who had a substance use disorder; and d) Were diagnosed with psychological distress which presented with externalizing behaviors, but did not reach threshold for diagnosis (predictive risk factors or substance abuse). Planned analyses will be compared for gender (male vs. female), age, and presenting problem type.

Of this full sample, a subsample of clients were utilized based on inclusion criteria which included age and number of sessions attended. Inclusion criteria for clients included those: a) Attended more than one session (excluded $n=342$ ).; and b) 13-19 years old (excluded $n=686$ ) After criteria were met, the final subsample included 5640 subjects.

Therapists. In total, 101 therapists treated the 5,640 clients (caseload $M=55.84$, range: 1-207). 


\section{Measures}

\section{Outcome Rating Scale}

Clients were administered the Outcome Rating Scale (ORS; Miller \& Duncan, 2000; Miller \& Duncan, 2004) during each therapy session. The ORS is a four-item selfreport measure intended to assess psychological well-being and distress on a session-tosession basis (Miller, Duncan, Brown, Sparks, \& Claud, 2003). Clients rate their current state of well-being/distress by marking on four visual analogue scales, each measuring 10 $\mathrm{cm}$ in length. The four scales represent separate domains of the client's functioning, and include how they are doing: Individually (personal well-being); interpersonally (family, close relationships); socially (work, school, friendships); and overall (general sense of well-being). The ORS was designed and normed for adults and adolescents (ages 13+), which additional versions made for children ages 6-12 (Children's Outcome Rating Scale; CORS) and a clinical engagement tool for children under 6 (Young Children's Outcome Rating Scale; YCORS). Client marks are measures and scored on a total range of scores from 0-40 (higher scores indicate greater well-being). Adults typically have a clinical cutoff of 25, however, younger clients tend to score higher on the ORS resulting in a clinical cutoff of 28 (Bertolino \& Miller, 2012). To measure treatment over time, a statistical index known as the reliable change index (RCI; Jacobson \& Truax, 1991) allows for scores to be attributed to non-random, substantial changes, crosses the clinical cutoff (from clinical to nonclinical), and not a result of change fluctuations between scores. For the ORS, the RCI is five, meaning that ORS scores that move five "points" and end above a total score of 28 are considered to represent clinically significant change (Bertolino \& Miller, 2012). 
Several studies have provided empirical evidence for the validity and reliability of the ORS (Bringhurst et al., 2006; Campbell \& Hemsley, 2009; Duncan et al., 2006; Miller et al., 2003). A preliminary investigation (Miller, et al., 2003) of the psychometrics of the ORS revealed an internal consistency among a non-clinical sample $(N=86)$ and across 336 administrations revealed a Cronbach's alpha of .93 . This result was also found to have significant correlations with the Outcome Questionnaire 45.2 (OQ-45.2). Test-retest reliability yielded a correlation which ranged from $r=.49$ to $r=.66$, with correlations becoming weaker with subsequent administrations. Concurrent validity was computed using Pearson product-moment correlations between the ORS and OQ45.2. A moderate indication of concurrent validity was revealed, with an overall correlation between ORStotal scores and OQ45.2 total scores being .59.

A follow-up study by Bringhurst et al. (2006) used a non-clinical sample of 98 participants to attempt to replicate the findings of Miller et al. (2003). Estimates of internal consistency using Cronbach's alpha revealed similar findings $(\alpha=.97)$. Testretest reliability in the replication study was shown to be markedly higher in the second administration (.80 compared to .66) and third administration (.81 compared to .58$)$. Bringhurst et al. (2006) also demonstrated stronger evidence of concurrent validity compared to the initial study, with Pearson product-moment correlations yielding a correlation of .69 (compared to .59 in Miller et al. (2003).

In a study that investigated the psychometrics of the ORS among children and adolescents. Duncan et al. (2006) found the ORS and the CORS displayed strong evidence of reliability, with coefficient alpha estimates of .93 and .84 respectively. Testretest reliability yielded correlations of .78 for the ORs and .60 for the CORS. As with 
adult samples, subsequent administrations yielded weaker correlations. Concurrent validity was computed with Pearson product moment correlations. These correlations yielded a significant correlation of .53 for adolescents who completed the ORS and Youth Outcome Questionnaire 30 (YOQ).

In a previous study using the ORS to assess the role of the working alliance in adolescent treatment (Owen et al., 2016), client ORS ratings were compared against therapists' categorical evaluation of their client's improvement. Therapists rated their client's overall, end-of-treatment outcomes with an informal 3-point scale; outcomes were rated as either: Poor, Fair, or Good. In this study, client's rated by their therapists as having "Good" outcomes $(M=34.59, S D=6.84)$ was significantly higher than those rated as having "Fair" outcomes $(M=32.32, S D=8.00, p<.001, d=0.31)$ and "Poor" outcomes $(M=29.82, S D=8.80, p<.001, d=.66)$. Differences between "Fair" and “Poor” outcomes were also statistically significantly different $(p<0.001, d=0.34)$.

\section{Session Rating Scale}

Clients were administered the Session Rating Scale (SRS; Miller et al., 2002; Miller \& Duncan, 2004) at the end of each therapy session. Like the ORS, the SRS is a four-item visual analogue self-report scale. The SRS is intended to measure the client's perception of the quality of the working alliance (Duncan et al., 2003, Miller \& Duncan, 2004). Clients rate their perception of the therapeutic alliance by marking on four visual analogue scales, each measuring $10 \mathrm{~cm}$ in length. The four scales reflect interacting elements of Bordin's (1979) model of the therapeutic alliance, including the relational bond, and the degree of agreed-upon goals, methods, and overall approach to therapy (Miller \& Duncan, 2004). The SRS was designed and normed for adults and adolescents 
(ages 13+). Additional versions are included for children ages 6-12 in the Children's Outcome Rating Scale (CORS) and for children under 6 (Young Children's Session Rating Scale; YCSRS). Client marks are measured and scored on a total range of scores from 0-40 (higher scores indicate stronger therapeutic alliance). There is an alliance "cutoff point" which represents scores in which therapists are advised to be alert to the potential for a failure in the working relationship and/or the potential for a rupture in the therapeutic alliance (Bertonlino \& Miller, 2012). On the SRS, a score of 36 or lower is considered alarming and cause for concern as, per Miller and Duncan (2004), fewer than $24 \%$ of cases scored lower than 36 . As such, this alliance cutoff can be used in conjunction with identifying ruptures as defined by Stiles et al.'s (2004) criteria for rupture repair, as mentioned in a previous section.

Several studies have provided empirical evidence for the validity and reliability of the SRS (Campbell \& Hemsley, 2009; Duncan et al., 2003). In their preliminary findings, Duncan et al. (2003) found that among 70 participants and 420 total administrations, Cronbach's coefficient alpha was .88. The researchers' determined that the high rating of internal consistency was related to the four items of the SRS correlating well with one another (Duncan et al., 2003). Pearson product moment correlations were used to measure test-retest reliability, which measured correlations between the test scores at each administration (each of the 70 participants had six administrations). From the Pearson product moment correlations, a Pearson's $r$ was found to be .70 between first and second administrations, and .64 for overall test-retest reliability. For comparison, the Helping Alliance Questionnaire II (HAQ-II; Luborsky et al., 1996) was shown to have an overall test-retest reliability of .63. Pearson product moment correlations, for all 
administrations among all subjects (420 total paired administrations), were used against the HAQ-II to determine concurrent validity. The correlation between the measures was found to be .48 , and individual items were found to have correlations between .39 and .44. These correlations demonstrate evidence that items on the SRS are measuring the same constructs as the previously validated HAQ-II, and that the SRS is a valid brief measure of the therapeutic alliance (Duncan et al., 2003). A follow-up study investigating the psychometrics of the SRS found similar results to Duncan et al., 2003 (Campbell \& Hemsley, 2009). Internal consistency resulted in a Cronbach's alpha of .93. Concurrent validity was again explored using Pearson product moment correlations and demonstrated moderate and consistent correlations with measures of the Working Alliance Inventory12 (WAI; Horvath \& Greenberg, 1989). Correlations between the SRS and WAI-12 ranged from .37 to .63 (Campbell \& Hemsley, 2009).

\section{Procedure}

Outcome and alliance measures were collected during counseling services, which were offered to adolescents living on military bases with their families. Counseling services were voluntary, and offered through the Adolescent Support and Counseling Services (ASACS). There were multiple sources of referral, including: school (51.3\%), self $(17.3 \%)$, family $(13.6 \%)$, command/military police $(7.6 \%)$, medical $(4.0 \%)$, peer $(3.7 \%)$, and other sources $(2.5 \%)$. Clients who attended counseling sessions were given the ORS at the beginning of each session and the SRS at the end of each session. 


\section{CHAPTER III: RESULTS}

\section{Preliminary Analyses}

The mean ORS-pre score was $25.85(S D=8.18)$ and the mean ORS-post score was $33.83(S D=6.40)$, with a Cohen's $d=0.98$. Of the 5640 clients, $62.06 \%(n=3,500)$ reported reliable change (i.e. an increase of five points or more on the ORS). There were $3305(58.60 \%)$ clients out of 5640 who started below the clinical cut-off on the ORS (i.e. 28 points), and of these 3305 clients, 2732 (82.66\%) showed reliable change. Of the 3305 clients that started below the clinical cut-off, 2420 (73.22\%) reported clinically significant change in which they started with below 28 on the ORS, observed at least a 5 point increase on the ORS, and ended treatment over 28 on the ORS.

There was a total of 49,931 sessions attended by the 5640 clients included in analyses for the current study $(M=8.85, M d n=7.00, S D=6.56)$. Of these 49,931 sessions, there were ruptures in 5510 sessions (11.04\% of session total). There were a total of 2211 rupture repair sequences and 3299 non-repaired rupture sequences evidenced among the entire sample population. Clients in the current study were given codes of either a) No Rupture; b) Rupture Repair; or c) Rupture Non-Repair. Clients coded No Rupture did not meet criteria for a therapeutic alliance rupture at any point during their therapy process. Clients coded Rupture Repair were identified as having one or more rupture sequences (defined as an at-minimum one-point decrease in SRS scores from the previous session), followed by an increase in SRS score equal to or greater than 
the amount of rupture decrease in the following session. These rupture-repair sequences also stipulated that there were no unrepaired ruptures at termination from therapy. Clients coded Rupture Non-Repair were identified as having one of more rupture sequences that were left unrepaired during the therapy process. This also included clients that may have demonstrated rupture-repair episodes at some point(s) during their therapy process, but experienced an unrepaired rupture at the time of termination. Of the 5640 clients whom met criteria for inclusion for this study, $51.2 \%(n=2885)$ did not meet criteria for a therapeutic alliance rupture at any point of their therapy process, whereas $48.8 \%$ ( $n=$ $2755)$ met criteria for at least one alliance rupture episode. A total of 1416 clients $(25.1 \%$ of sample population) met criteria to be coded as Rupture Repair, whereas 1339 clients (23.7\% of sample population) met criteria to be coded as Rupture Non-Repair.

\section{Hypothesis 1}

For Hypothesis 1, it was predicted that there would be evidence of treatment effects comparing psychotherapy processes with no alliance ruptures, psychotherapy processes with evidence of rupture repair, and psychotherapy processes with no evidence of rupture repair. Specifically, it was predicted that psychotherapy processes in which there is rupture repair would have significantly higher outcome scores than those processes without rupture repair and processes with no rupture (Kivlighan \& Shaughnessy, 2000; Stiles et al., 2004). Hypothesis 1 was tested using a one-way independent ANOVA to assess for statistically significant differences between rupture groups on ORS scores taken at the final session. Results showed that there was a significant effect of rupture condition on therapy outcomes, $F(2,5637)=58.97, p<.001$. Post hoc comparisons using the Tukey HSD test indicated that there were significant 
differences between the Non-Rupture group and both the Rupture-Repair group $(p=.027$, $d=.083)$, and Rupture Non-Repair group $(p<.001, d=0.35)$. The tests also revealed a significant difference between the Rupture-Repair group and the Rupture Non-Repair group $(p<.001, d=0.27)$. Thus, Hypothesis 1 was partially confirmed with evidence of treatment effects between rupture conditions. However, final outcome scores were found to be highest in the Non-Rupture category compared to the predicted result that final outcome scores would be significantly higher in the Rupture Repair condition. Results of means and standard deviations and results of one-way ANOVA on ORS outcome scores are presented in Tables 1 and 2 below.

Table 1

Means and Standard Deviations of ORS Outcome Scores by Rupture Category

\begin{tabular}{llll}
\hline & & \multicolumn{2}{c}{ Self-reported ORS outcome scores } \\
\cline { 3 - 4 } Rupture Group & $n$ & $M$ & $S D$ \\
\hline Non-Rupture & 2885 & 34.50 & 6.24 \\
Rupture Repair & 1416 & 33.97 & 6.03 \\
Rupture Non-Repair & 1339 & 32.23 & 6.83 \\
Total & 5640 & 33.83 & 6.40 \\
\hline
\end{tabular}

Table 2

One-Way Analysis of Variance of Therapy Outcome Score by Rupture Category

\begin{tabular}{lllll}
\hline Source & $d f$ & $S S$ & $M S$ & $F$ \\
\hline Between groups & 2 & 4728.67 & 2364.34 & $58.97^{*}$ \\
Within groups & 5637 & 226015.10 & 40.10 & \\
Total & 5639 & 239743.771 & & \\
\hline Note. ${ }^{*}=p<.001$ & & &
\end{tabular}


Hypothesis 1 was additionally tested by assessing overall change in ORS outcome scores by subtracting ORS scores at the initial session from ORS scores at the final session. This change in ORS score could yield positive or negative integers, reflecting progression or regression of well-being, respectively. Additionally, the ORS-change integer could have yielded an integer of zero, reflecting that there was no change/difference in well-being in the final session compared to the initial session. Hypothesis 1 change in well-being was tested using a one-way independent ANOVA to assess for statistically significant differences between rupture groups on change in ORS scores between first and final sessions. Results showed that there was a significant effect of rupture condition on change in outcome scores, $F(2,5637)=52.58, p<.001$. Post hoc comparisons using the Tukey HSD test indicated significant differences between the Rupture Repair group and both the Non-Rupture group $(p<.001, d=.31)$ and the Rupture Non-Repair group $(p<.001, d=.31)$. There was no significant difference between change in outcome scores between the Non-Rupture group and the Rupture NonRepair group ( $p=.995, d=.002)$. Hypothesis 1 was additionally confirmed in that change in ORS was predicted between conditions, with Rupture Repair clients showing significantly greater change in well-being throughout therapy compared to Non-Rupture and Rupture Non-Repair conditions. Results of means and standard deviations and results of one-way ANOVA on change in outcome scores are presented in Tables 3 and 4 below. 
Table 3

Means and Standard Deviations of ORS Outcome Change by Rupture Category

\begin{tabular}{llll}
\hline & & \multicolumn{2}{c}{ Self-reported ORS change scores } \\
\cline { 3 - 4 } Rupture Group & $n$ & $M$ & $S D$ \\
\hline Non-Rupture & 2885 & 7.34 & 8.07 \\
Rupture Repair & 1416 & 9.92 & 8.38 \\
Rupture Non-Repair & 1339 & 7.32 & 8.33 \\
Total & 5640 & 7.98 & 8.29 \\
\hline
\end{tabular}

Table 4

One-Way Analysis of Variance of Therapy Outcome Change by Rupture Category

\begin{tabular}{lllll}
\hline Source & $d f$ & $S S$ & $M S$ & $F$ \\
\hline Between groups & 2 & 7093.15 & 3546.57 & $52.58^{*}$ \\
Within groups & 5637 & 380254.18 & 67.46 & \\
Total & 5639 & 387347.32 & & \\
\hline
\end{tabular}

Note. ${ }^{*}=p<.001$

\section{Hypothesis 2}

For Hypothesis 2, it was predicted that adolescents that experience at least one non-repaired rupture will be more likely to prematurely terminate from therapy compared to adolescents that experience a repaired alliance rupture. Premature termination was defined by clients meeting all three of the following conditions: a) Attended fewer than the mean number of sessions (less than eight); b) Ended treatment with a ORS outcome score of below the clinical cutoff (ORS < 28); and c) Demonstrated a less-than five point increase in ORS score from initial session to their final session. Thus, these adolescents engaged in fewer than the average number of sessions attended in the sample population, exhibited no clinically significant change, and ended therapy prior to advancing wellbeing above clinical distress. 
A chi-square test of independence was performed to examine the relation between rupture-repair condition and premature termination (versus continuing in therapy).

Results showed that there was a significant association between whether or not ruptures were repaired and whether or not clients prematurely terminated from therapy, $\chi^{2}(1)=$ $16.70, p<.001$. An odds ratio analysis shows that adolescents that experienced nonrepaired ruptures are 1.93 times more likely to prematurely terminate from therapy compared to adolescents that experienced repaired therapeutic ruptures. Thus, results confirmed Hypothesis 2. Results from Hypothesis 2 chi-square test of independence is presented below in Table 5.

Table 5

Premature Termination versus Staying in Therapy by Rupture Condition

\begin{tabular}{lllll} 
& \multicolumn{3}{c}{ Rupture Condition } & \\
Termination & Non-Repaired & Repaired & $\chi^{2}$ & $\Phi_{c}$ \\
\cline { 2 - 3 } Yes & 118 & 58 & $16.70^{*}$ & .078 \\
& $(2.7)$ & $(-2.90)$ & & \\
No & 1319 & 1260 & & \\
\hline Note. ${ }^{*}=p<.001$. Standardized residuals appear in parentheses below group frequencies.
\end{tabular}

\section{Hypothesis 3}

For Hypothesis 3, it was predicted that adolescents coded as Rupture Repair will be associated with a higher number of sessions attended compared to adolescents coded as Rupture Non-Repair. This hypothesis was tested using an independent t-test. Results showed that on average, a greater number of sessions were attended by adolescents that experienced rupture repair $(M=12.32, S E=.21)$ compared to adolescents that experienced ruptures that were not repaired $(M=8.60, S E=.16)$. This difference was 
statistically significant, $t(2753)=14.19, p<.001, d=.54$. Thus, Hypothesis 3 was confirmed.

\section{Hypothesis 4}

For Hypothesis 4, it was predicted that among processes in which rupture-repair sequence criteria is met (Stiles et al., 2004), most of these processes would occur in earlystage versus late-stage therapy processes. Measures of central tendency were used to categorize early- versus late-stage rupture repair processes. Early-stage rupture repairs were defined as a rupture repair process that occurred prior to the average number of attended sessions $(M=8.85)$, and late-stage rupture repairs occurred after the average number of attended sessions. As it is not feasible to code for partial sessions, early-stage rupture repairs were defined as a session in which a rupture repair was present in sessions $3-8$, and late-stage rupture repairs were defined as a session in which a rupture repair was present in sessions 9-74. Each session attended was coded as either "Rupture Repair" or "Other." It should be noted that Sessions 1 and 2 were not included in analyses, as they could not be coded as "Rupture Repair" due to the operational definition of a rupture repair process in this study.

A chi-square test of independence was performed to examine the relation between sessions with rupture repairs and session timing (early versus late). Results showed that there was a significant association between the presence of rupture repairs in early-stage therapy sessions compared to late-stage therapy sessions, $\chi^{2}(1)=66.27, p<.001$. An odds ratio analysis shows that an early-stage rupture repair was 1.46 times more likely to occur compared to a late-stage rupture repair. Thus, Hypothesis 4 was confirmed. Results from Hypothesis 4 are presented in Table 6 below. 
Table 6

Presence of Rupture Repair in Therapy by Session Timing

\begin{tabular}{lllll} 
& \multicolumn{3}{c}{ Session Timing } & \\
\cline { 2 - 4 } Session Code & Early & Late & $\chi^{2}$ & $\Phi_{\mathrm{c}}$ \\
\hline Rupture Repair & 1516 & 695 & $66.27^{*}$ & .041 \\
& $(5.0)$ & $(-6.1)$ & & \\
Other & 21,803 & 14,630 & & \\
& $(-1.2)$ & $(1.5)$ & & \\
\hline
\end{tabular}

Note. $*=p<.001$. Standardized residuals appear in parentheses below group frequencies.

\section{Hypothesis 5}

For Hypothesis 5, it was predicted that age would act as a moderator on the effect of rupture-repair on adolescent therapy outcome. To first test this hypothesis, a hierarchical multiple regression analysis was conducted. In the first step, two predictive variables were included: rupture condition (Rupture Repair versus Rupture Non-Repair) and age. These variables accounted for a significant amount of variance in adolescents' end-of-treatment well-being as measured by ORS score collected at the final session, $R^{2}=$ $.023, F(2,2752)=32.63, p<.001$. Multicollinearity diagnostics were assessed and were found to be non-problematic, $V I F=1.00$, Tolerance $=1.00$. Next, the interaction term between rupture condition and age was added to the regression model, which did not account for a significant proportion of the variance in final session ORS scores, $\Delta R^{2}=$ $.001, \Delta F(3,2751)=1.22, p=.27, b=.030, t(2751)=1.103, p=.270$. Thus, Hypothesis 5 was not confirmed was using final session ORS scores. Results from Hypothesis 5 with ORS outcomes are presented in Table 7 below. 
Table 7

Summary of Hierarchical Regression Analysis for Variables (Age) Predicting Therapy Outcome

\begin{tabular}{|c|c|c|c|c|c|c|}
\hline \multirow[b]{2}{*}{ Variable } & \multicolumn{3}{|c|}{ Model 1} & \multicolumn{3}{|c|}{ Model 2} \\
\hline & $B$ & $S E B$ & $\beta$ & $B$ & $S E B$ & $\beta$ \\
\hline Constant & 32.23 & .18 & & 32.23 & .18 & \\
\hline \multicolumn{7}{|l|}{ Rupture } \\
\hline Condition* & 1.72 & .25 & .133 & 1.73. & .25 & .133 \\
\hline Age & -.48 & .13 & -.07 & -.62 & .18 & -.09 \\
\hline \multicolumn{7}{|l|}{ Rupture } \\
\hline \multicolumn{7}{|l|}{ Condition $\mathrm{x}$} \\
\hline Age & & & & .28 & .25 & .03 \\
\hline$R^{2}$ & & .023 & & & .024 & \\
\hline $\begin{array}{l}F \text { for } \\
\text { change in } \\
R^{2}\end{array}$ & & 32.63 & & & $1.22^{* * * *}$ & \\
\hline
\end{tabular}

Hypothesis 5 was also tested for therapy outcomes with overall change in wellbeing used as a therapy outcome. Similar to the use of final ORS score as the outcome variable, it was predicted that age would act as a moderator on the effect of rupture-repair on change in well-being in therapy with adolescents. To test this hypothesis, a hierarchical multiple regression analysis was conducted. In the first step, two predictive variables were included: rupture condition (Rupture Repair versus Rupture Non-Repair) and age. These variables accounted for a significant amount of variance in adolescents' overall change in well-being as measured by ORS scores, $R^{2}=.025, F(2,2752)=34.69$, $p<.001$. However, only rupture condition was determined to be a significant predictor of therapy change, $t(2752)=8.15, p<.001$, whereas age was found to be a non-significant predictor of change in therapy outcomes, $t(2752)=-1.59, p=.11$. Multicollinearity diagnostics were assessed and were found to be non-problematic, $V I F=1.00$, Tolerance $=1.00$. Next, the interaction term between rupture condition and age was added to the 
regression model, which did not account for a significant proportion of the variance of change in ORS scores, $\Delta R^{2}=.00, \Delta F(3,2751)=0.10, p=.75, b=-.10, t(2751)=-.32, p$ $=.75$. Thus, Hypothesis 5 was again not confirmed when using ORS change as the outcome variable. Results from Hypothesis 5 with ORS change are presented in Table 8 below.

Table 8

Summary of Hierarchical Regression Analysis for Variables (Age) Predicting Change in Therapy Outcome

\begin{tabular}{|c|c|c|c|c|c|c|}
\hline \multirow[b]{2}{*}{ Variable } & \multicolumn{3}{|c|}{ Model 1} & \multicolumn{3}{|c|}{ Model 2} \\
\hline & $B$ & $S E B$ & $\beta$ & $B$ & $S E B$ & $\beta$ \\
\hline (Constant) & 7.32 & .23 & & 7.32 & .23 & \\
\hline \multicolumn{7}{|l|}{ Rupture } \\
\hline Condition* & 2.60 & .32 & .15 & 2.60 & .32 & .15 \\
\hline Age & -.26 & .16 & -.03 & -.21 & .23 & -.02 \\
\hline \multicolumn{7}{|l|}{ Rupture } \\
\hline \multicolumn{7}{|l|}{ Condition $\mathrm{x}$} \\
\hline Age & & & & -.10 & .33 & -.01 \\
\hline$R^{2}$ & & .025 & & & .025 & \\
\hline $\begin{array}{l}F \text { for } \\
\text { change in }\end{array}$ & & & & & & \\
\hline$R^{2}$ & & $34.69^{*}$ & & 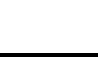 & $.10^{* * *}$ & \\
\hline
\end{tabular}

\section{Hypothesis 6}

For Hypothesis 6, it was predicted that meeting criteria for a substance use disorder (versus having subthreshold symptoms of a substance use disorder) would act as a moderator on the effect of rupture condition (repaired versus non-repaired) on adolescent therapy outcome. To first test this hypothesis, a hierarchical multiple regression analysis was conducted. In the first step, two predictive variables were 
included: rupture condition (Rupture Repair versus Rupture Non-Repair) and substance abuse. Substance abuse was coded as a "Yes/No" dichotomous categorical variable determined by whether adolescents met criteria for a substance use disorder. Adolescents who were deemed "at risk" or were referred to therapy due to a parent's use of substances were coded as "No" for substance use disorder, with respect that they meet subthreshold criteria for diagnostic consideration. Adolescents who met criteria for a substance use disorder were coded as "Yes" for the substance use disorder variable. These variables accounted for a significant amount of variance in adolescents' end-of-treatment wellbeing as measured by ORS score collected at the final session, $R^{2}=.018, F(2,2752)=$ $25.406, p<.001$. However, only rupture condition was determined to be a significant predictor of therapy change, $t(2752)=7.10, p<.001$, whereas substance abuse diagnosis was found to be a non-significant predictor of change in therapy outcomes, $t(2752)=-$ $.016, p=.41$. Multicollinearity diagnostics were assessed and were found to be nonproblematic, VIF $=1.00$, Tolerance $=1.00$. Next, the interaction term between rupture condition and substance abuse diagnosis was added to the regression model, which did not account for a significant proportion of the variance in final session ORS scores, $\Delta R^{2}=$ $.00, \Delta F(3,2751)=0.01, p=.91, \mathrm{~b}=-.18, t(2751)=-.50, p=.62$. Thus, Hypothesis 6 was not confirmed, as meeting criteria for a substance use disorder did not moderate the effect of rupture condition on final session therapy outcomes. Results of the moderation analysis are presented in Table 9 below. 
Table 9

Summary of Hierarchical Regression Analysis for Variables (SAD) Predicting Therapy Outcome

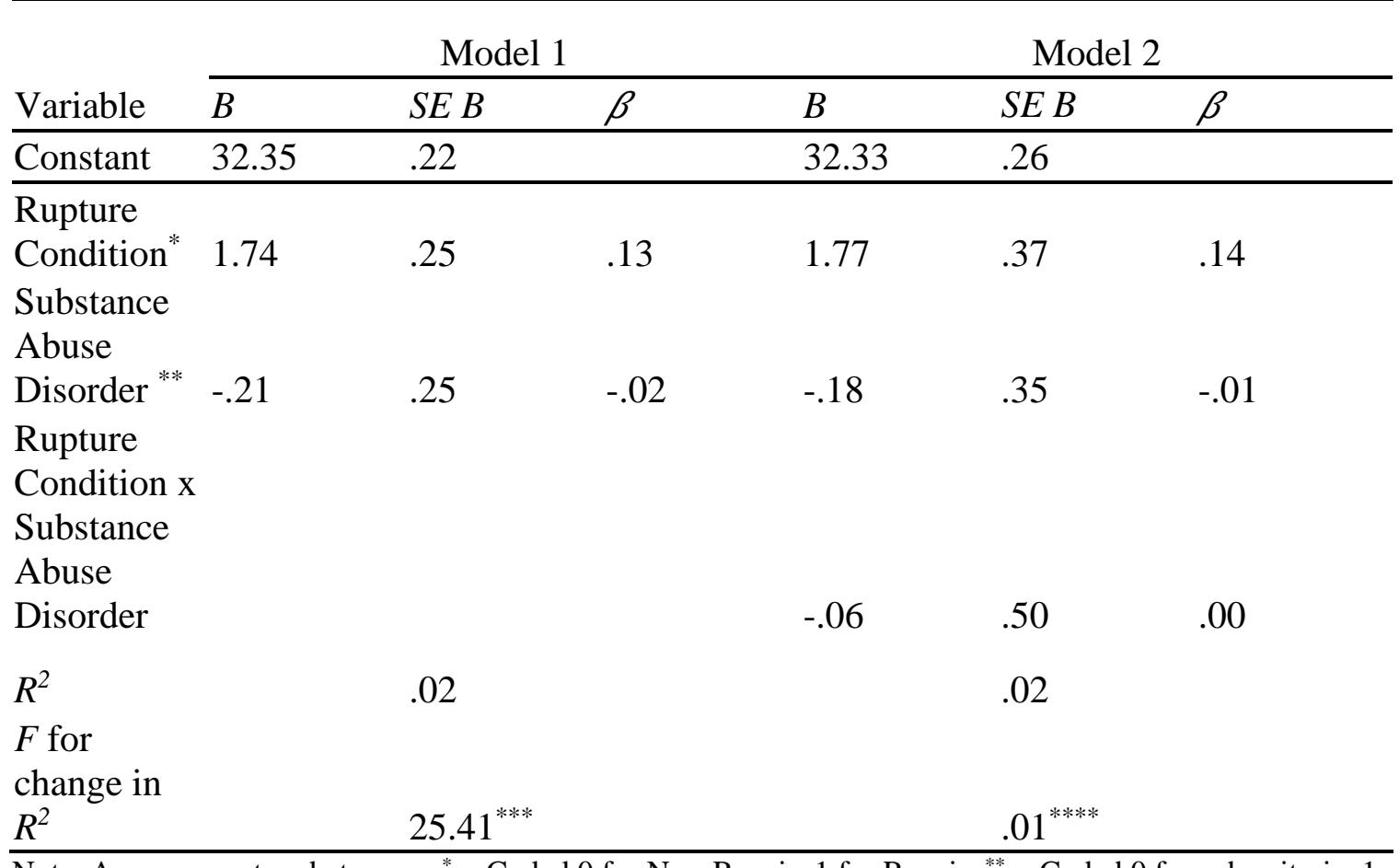

Note. Age was centered at mean. ${ }^{*}=$ Coded 0 for Non-Repair, 1 for Repair. ${ }^{* *}=$ Coded 0 for sub-criteria, 1 for meeting criteria. ${ }^{* * *}=p<.001 .{ }^{* * * *} p=.91$

Hypothesis 6 was also tested for therapy outcomes with overall change in wellbeing used as a therapy outcome. Similar to the use of final ORS score as the outcome variable, it was predicted that meeting criteria substance abuse diagnosis (versus having subthreshold symptoms of a substance use disorder) would act as a moderator on the effect of rupture-repair on change in well-being in therapy with adolescents. To test this hypothesis, a hierarchical multiple regression analysis was conducted. In the first step, two predictive variables were included: rupture condition (Rupture Repair versus Rupture Non-Repair) and substance abuse. Substance abuse was coded as a "Yes/No" dichotomous categorical variable determined by whether or not adolescents met criteria for a substance use disorder. Adolescents who were deemed "at risk" or were referred to 
therapy due to a parent's use of substances were coded as "No" for substance use disorder, with respect that they meet subthreshold criteria for diagnostic consideration. Adolescents who met criteria for a substance use disorder were coded as "Yes" for the substance use disorder variable. These variables accounted for a significant amount of variance in adolescents' overall change in well-being as measured by ORS scores, $R^{2}=$ $.02, F(2,2752)=33.58, p<.001$. However, only rupture condition was determined to be a significant predictor of therapy change, $t(2752)=8.19, p<.001$, whereas substance abuse diagnosis was found to be a non-significant predictor of change in therapy outcomes, $t(2752)=-.61, p=.54$. Multicollinearity diagnostics were assessed and were found to be non-problematic, $V I F=1.00$, Tolerance $=1.00$. Next, the interaction term between rupture condition and substance abuse diagnosis was added to the regression model, which did not account for a significant proportion of the variance in final session ORS scores, $\Delta R^{2}=.00, \Delta F(3,2751)=0.51, p=.48, b=-.46, t(2751)=-.71, p=.48$. Thus, Hypothesis 6 was again not confirmed, as meeting criteria for a substance use disorder did not moderate the effect of rupture condition on change therapy outcomes across therapy. Results of the moderation analysis are presented in Table 10 below. 
Table 10

Summary of Hierarchical Regression Analysis for Variables (SAD) Predicting Change in Therapy Outcome

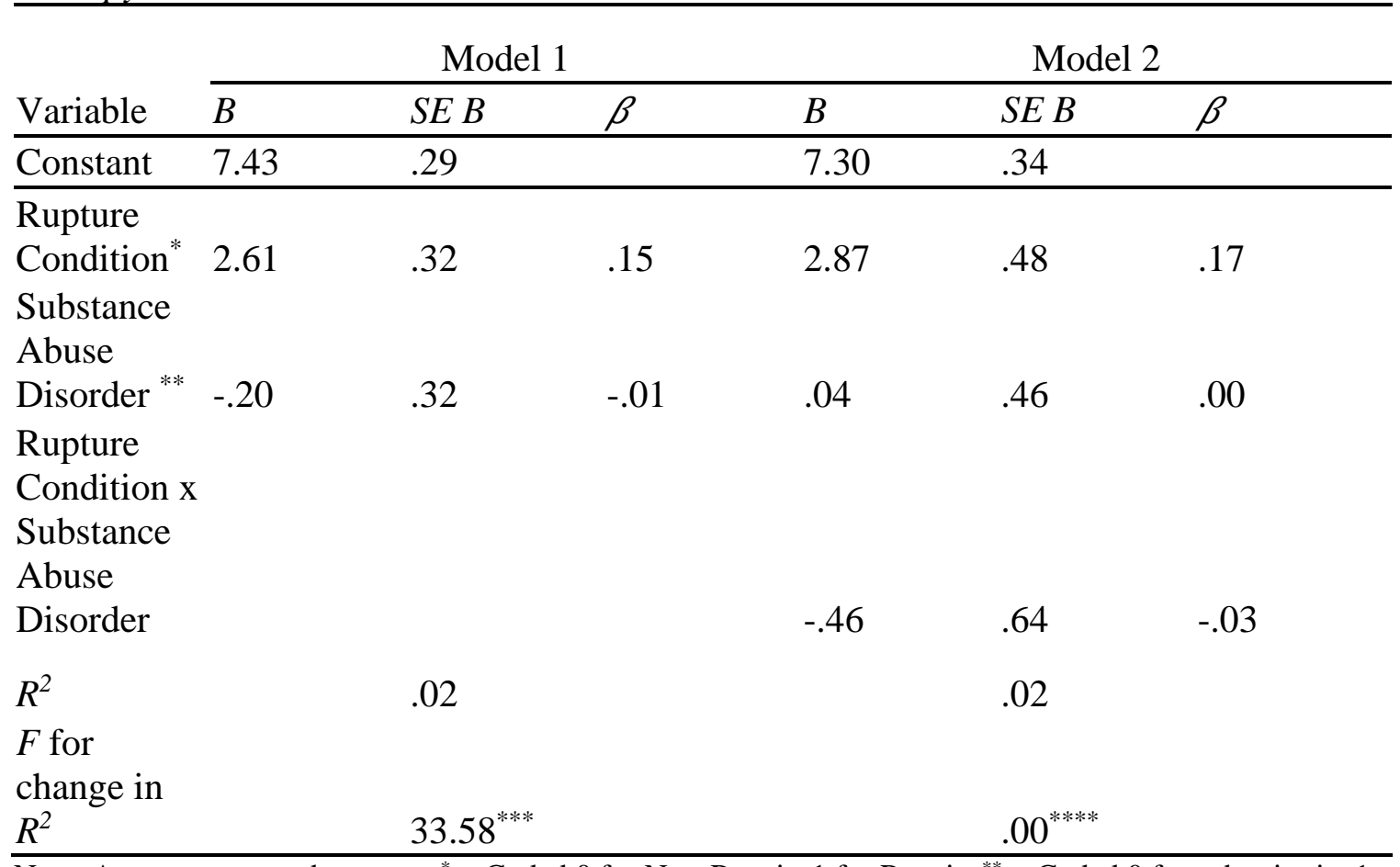

Note. Age was centered at mean. ${ }^{*}=$ Coded 0 for Non-Repair, 1 for Repair. ${ }^{* *}=$ Coded 0 for sub criteria, 1 for meeting criteria. ${ }^{* * *}=p<.001 .^{* * * *} p=.48$

\section{Hypothesis 7}

For Hypothesis 7 it was predicted that therapists who, on average, reported higher aggregate alliance scores among their patients would lead to higher therapeutic outcomes in post-rupture-repair sequences than those reporting lower aggregate alliance scores. To test this hypothesis, construction of a multilevel model was considered to provide additional information to account for variability in hypothesized group-level treatments effects on outcomes. The outcome variable for this hypothesis was therapeutic outcomes (measured by client ORS scores). The Level-1 predictor was the client's average measure of the therapeutic alliance (measured by client SRS scores). The Level-2 predictor variable was the therapists' aggregate alliance scores rated across all of their clients in this study. A Level-1 within-client model was intended to examine the hypothesized 
relationship for between-client therapeutic alliances and therapy outcomes. The construction of a Level-2 between-therapist model was to provide additional information to account for the variability in regression in client outcomes (Raudenbush \& Bryk, 2002).

A sequential approach to fitting the models was utilized. First, an unconditional intercept-only (null) model was created and in order to calculate the intraclass correlation coefficient (ICC) and to assess the deviance statistic (-2LL) for later comparisons of more complex models. Thus, the intercept-only model will address whether or not there is a (Level 2) therapist effect on the (Level 1) ORS outcome score. If there is a therapist effect, then this will help determine that linear mixed modeling is required. The unconditional model is presented below:

$$
\begin{array}{cr}
\underline{\text { Mixed Model }} & \underline{\text { Hierarchical Model }} \\
\text { ORSLast }=\gamma_{00}+u_{0 j}+r_{i j} & \text { ORSLast }=\beta_{0 \mathrm{j}}+r_{\mathrm{ij}} \\
\beta_{0 \mathrm{j}}=\gamma_{00}+u_{0 j}
\end{array}
$$

The Level 1 intercept term $\left(\beta_{0 \mathrm{j}}\right)$ is a function of a random intercept term $\left(\gamma_{00}\right)$ at Level 2 and a Level 1 error term $\left(r_{i j}\right)$. The Level 1 intercept is a function of the grand mean $\left(\gamma_{00}\right)$ across Level 2 therapists as well as a random error term $\left(u_{0 j}\right)$. The method of estimation utilized was maximum likelihood (ML) due to its preferred use for unbalanced data (Albright \& Marinova, 2010). The value of $\tau$ was significantly different from zero ( $\tau$ $=2.82, p<.001$ ), indicating the presence of therapist level effects on outcomes. The comparison of the therapist effect to the residual variance component $\left(\sigma^{2}=33.84\right)$ indicated that there was still considerable residual variation in ORS outcome scores yet to be explained, and additional predictors in the model may be needed (Garson, 2013). The 
intraclass correlation coefficient (ICC) for between-therapist variability was .08, indicating that $8 \%$ of variance in ORS outcomes could be accounted for by factors associated with (i.e. between) therapists.

The next step in the sequential modeling was to create a random coefficients (RC) regression model. In this model, the Level 1 predictor was a client's average SRS alliance score (SRSavg) computed across all sessions predicting client outcome (ORSLast) at Level 1 controlling for ORS-pretest (ORSpre; $\beta_{1 \mathrm{j}}$ ). The Level 2 grouping variable (Therapist) remained a random factor. This model was intended to identify whether the therapist effect discovered in the null model may be attributed in part to the client caseloads of some therapists' reporting more elevated alliance scores than others. While there were no Level 2 predictors, the Level 1 intercept was predicted by the Level 2 mean $\left(\gamma_{00}\right)$ of ORSLast plus a Level 2 error term $\left(u_{0 j}\right)$. The Level 1 regression coefficient (slope) of SRSavg $\left(\beta_{2 \mathrm{j}}\right)$ was predicted by the regression coefficients of the mean of the 1416 client SRS alliance scores across all therapy sessions plus a Level 2 error term $\left(u_{2 j}\right)$ representing the random therapist effect on the Level 1 regression score of SRSavg on ORSLast. The random coefficients regression model is presented below:

$\begin{array}{cc}\text { Mixed Model } & \text { Hierarchical Model } \\ \text { ORSLast }=\gamma_{00}+\gamma_{10}(\text { ORSpre })+ & \text { ORSLast }{ }_{\mathrm{ij}}=\beta_{0 \mathrm{j}}+\beta_{1 \mathrm{j}}(\mathrm{ORSpre})+ \\ \gamma_{20}(\text { SRSavg })+u_{0 \mathrm{j}}+ & \beta_{2 \mathrm{j}}(\text { SRSavg })+r_{\mathrm{ij}} \\ u_{1 \mathrm{j}}(\text { ORSpre })+u_{2 \mathrm{j}}(\text { SRSavg }) & \beta_{0 \mathrm{j}}=\gamma_{00}+u_{0 \mathrm{j}} \\ +r_{i j} & \beta_{1 \mathrm{j}}=\gamma_{10}+u_{1 j} \\ & \beta_{2 \mathrm{j}}=\gamma_{20}+u_{2 j}\end{array}$

The fixed effects outcomes for the RC regression model indicated that SRSavg was a statistically significant predictor $(t=5.17, p<.001)$ of final therapy outcomes (ORSLast) when controlling for ORS-pretest scores $(t=8.29, p<.001)$. The random effect of 
therapist on slopes of SRSavg was statistically significant $(p=.005)$, but accounted for only $0.4 \%$ of total effects. A deviance likelihood ratio test was used as an overall test of whether the RC regression model with predictors was a significantly better fit than the intercept-only unconditional (null) model without predictors. The deviance likelihood indicated that deviance decreased from 9073.73 in the null model to 8842.07 in the RC regression model $\left(\chi^{2}=231.66, p<.001\right)$, therefore improving the fit of the overall model. AIC and BIC values also indicated improved model fit with the Level 1 predictor(s). Based on the final estimation of variance components from the RC regression model $(\tau 22=.12, p<.001)$, there remained some variability left to be explained in client outcomes.

The construction of a Level 2 full random coefficients (RC) model (interceptsand-slopes-as-outcomes) was intended to provide additional information to account for the variability in regression in client outcomes (Raudenbush \& Bryk, 2002). The current model tested the hypothesis that the mean (intercept) for ORSLast is a function of a client's alliance ratings averaged across sessions (SRSavg), and that the strength of the alliance-outcome relationship is a function of a therapist's ability to maintain strong therapeutic alliances. In other words, a therapist's average ability to maintain strong alliances moderates the effect of a client's alliance scores on therapy outcomes. In this model, the Level 1 predictors from the RC regression model remained the same. The Level 2 predictor was calculated as the aggregate therapist alliance across all of their clients (THSRSagg) and entered (grand-mean centered) to both the intercept and slope equations of the model. The full random coefficients model is presented below: 


$$
\begin{gathered}
\underline{\text { Mixed Model }} \\
\text { ORSLast }=\gamma_{00}+\gamma_{01}(\text { THSRSagg })+ \\
\gamma_{10}(\text { ORSpre })+\gamma_{20}(\text { SRSavg })+ \\
\gamma_{21}(\text { THSRSagg })+u_{0 \mathrm{j}}+ \\
u_{1 \mathrm{j}}(\text { ORSpre })+u_{2 \mathrm{j}}(\text { SRSavg })+r_{i j}
\end{gathered}
$$

$$
\begin{aligned}
& \underline{\text { Hierarchical Model }} \\
& \text { ORSLast }_{\mathrm{ij}}=\beta_{0 \mathrm{j}}+\beta_{1 \mathrm{j}}(\text { ORSpre })+ \\
& \beta_{2 \mathrm{j}}(\mathrm{SRSavg})+r_{\mathrm{ij}} \\
& \beta_{0 \mathrm{j}}=\gamma_{00}+ \\
& \gamma_{01}\left(\text { THSRSagg }_{\mathrm{j}}\right)+u_{0 j} \\
& \beta_{1 \mathrm{j}}=\gamma_{10}+u_{1 j} \\
& \beta_{2 \mathrm{j}}=\gamma_{20}+\gamma_{21}\left(\text { THSRSagg }_{\mathrm{j}}\right)+ \\
& u_{2 j}
\end{aligned}
$$

In the full RC model, fixed effects outcomes indicated that aggregate therapist alliance scores (THSRSagg) was not a statistically significant predictor of either the effect of SRSavg in the intercept $(t=.60, p=.55)$ or the effect of SRSavg on the growth slope $(t=$ $-.64, p=.53)$ of ORSLast. Additionally, although the full RC model showed that deviance declined compared to the previous $\mathrm{RC}$ regression model, the difference between the current model and the $\mathrm{RC}$ regression model was not statistically significant $\left(\chi^{2}=.72\right.$, $p>$.500). Based on THSRSagg failing to predict either the effect of SRSavg on the intercept and slope, as well as the Level 2 covariate included in the current model reducing deviance by a non-significant amount, the previous $\mathrm{RC}$ regression model is preferred.

Results of the final model (see Table 11) indicate that the average unadjusted mean client outcome score on the ORS $\left(\gamma_{00}\right)$, among adolescents who experience rupture repair is $33.94(S D=2.47, p<.001)$. This would be the predicted therapy outcome value for an adolescent who experienced a rupture-repair. The within-group effect of the aggregate client alliance (SRSavg; $\left.\gamma_{20}\right)$ is $0.35(p<.001)$. This means that for every one unit above the group mean (within-therapist) for therapy alliance, the client therapy outcome would be predicted to increase 0.35 points on their final ORS. Although there is evidence of among-therapist effects on therapy outcomes, aggregate therapist alliance 
scores across client caseloads failed to predict an effect on either the intercept and/or slope of the alliance effect on outcomes. Further considerations are provided in the discussion section.

Table 11

Summary of Hierarchical Linear Modeling (HLM) Specification Steps for Rupture Repair Final Outcomes

\begin{tabular}{|c|c|c|c|c|c|c|c|c|c|}
\hline & \multicolumn{3}{|c|}{ Model 1} & \multicolumn{3}{|c|}{ Model 2} & \multicolumn{3}{|c|}{ Model 3} \\
\hline Fixed Effects & $b$ & $S E$ & $t$ & $b$ & $S E$ & $t$ & $b$ & $S E$ & $t$ \\
\hline Intercept $\left(\gamma_{00}\right)$ & 33.97 & .25 & $136.16^{* * *}$ & 33.94 & .25 & $134.22^{* * *}$ & 33.96 & .26 & $132.94^{* * *}$ \\
\hline THSRSagg $\left(\gamma_{01}\right)$ & & & & & & & .10 & .17 & .60 \\
\hline ORSpre $\left(\gamma_{10}\right)$ & & & & .22 & .03 & $8.29^{* * *}$ & .22 & .03 & $8.28^{* * * *}$ \\
\hline $\operatorname{SRSavg}\left(\gamma_{20}\right)$ & & & & .35 & .07 & $5.17^{* * *}$ & .33 & .07 & $4.97^{* * * *}$ \\
\hline THSRSagg $\left(\gamma_{21}\right)$ & & & & & & & -.03 & .05 & -.64 \\
\hline Variance Components & $\sigma^{2}$ & $S D$ & $\chi^{2}$ & $\sigma^{2}$ & $S D$ & $\chi^{2}$ & $\sigma^{2}$ & $S D$ & $\chi^{2}$ \\
\hline Residual $\left(r_{i j}\right)$ & 33.84 & 5.82 & & 27.36 & 5.23 & & 27.38 & 5.23 & \\
\hline Intercept $\left(u_{0 \mathrm{j}}\right)$ & 2.82 & 1.68 & $206.05^{* * *}$ & 3.25 & 1.80 & $172.31^{* * *}$ & 3.26 & 1.81 & $172.29^{* * *}$ \\
\hline ORSpre $\left(u_{1 \mathrm{j}}\right)$ & & & & .03 & .16 & $131.98^{* * * *}$ & .03 & .16 & $131.97^{* * *}$ \\
\hline $\operatorname{SRSavg}\left(u_{2 \mathrm{j}}\right)$ & & & & .12 & .35 & $117.36^{* *}$ & .12 & .34 & $114.62^{* *}$ \\
\hline Deviance & & 9073.7 & & & 8842 & & & 8841 & \\
\hline
\end{tabular}

Hypothesis 7 was also tested with overall change in ORS (ORSChange) used as the outcome variable. Similar to the above-predicted hypothesis, it was predicted that therapists who, on average, report higher aggregate alliance scores among their patients would lead to greater changes in client well-being in post-rupture-repair sequences than those reporting lower aggregate alliance scores. A similar sequential modeling approach was utilized to determine the need for multilevel models. The unconditional (null) model is presented below: 
Mixed Model

$$
\text { ORSChange }=\gamma_{00}+u_{0 j}+r_{i j}
$$

Hierarchical Model

ORSChange $=\beta_{0 \mathrm{j}}+r_{\mathrm{ij}}$

$$
\beta_{0 \mathrm{j}}=\gamma_{00}+u_{0 j}
$$

The value of $\tau$ was significantly different from zero $(\tau=3.99, p<.001)$, indicating the presence of therapist level effects on outcomes. The comparison of the therapist effect to the residual variance component $\left(\sigma^{2}=66.25\right)$ indicated that there was still considerable residual variation in ORS outcome scores yet to be explained, and additional predictors in the model may be needed (Garson, 2013). The intraclass correlation coefficient (ICC) for between-therapist variability was .06 , indicating that $6 \%$ of variance in ORSChange could be accounted for by factors associated with (i.e. between) therapists.

For the random coefficients (RC) regression model, the Level 1 regression coefficient (slope) of SRSavg $\left(\beta_{2 \mathrm{j}}\right)$ was predicted by the regression coefficients of the mean of the 1416 client SRS alliance scores across all therapy sessions plus a Level 2 error term $\left(u_{2 j}\right)$ representing the random therapist effect on the Level 1 regression score of SRSavg on ORSChange. The random coefficients regression model is presented below:

$\begin{array}{cc}\underline{\text { Mixed Model }} & \underline{\text { Hierarchical Model }} \\ \text { ORSChange }=\gamma_{00}+\gamma_{10}(\text { ORSpre })+ & \text { ORSChange }_{\mathrm{ij}}=\beta_{0 \mathrm{j}}+\beta_{1 \mathrm{j}}(\text { ORSpre })+ \\ \gamma_{20}(\text { SRSavg })+u_{0 \mathrm{j}}+ & \beta_{2 \mathrm{j}}(\mathrm{SRSavg})+r_{\mathrm{ij}} \\ u_{1 \mathrm{j}}(\text { ORSpre })+u_{2 \mathrm{j}}(\mathrm{SRSavg})+ & \beta_{0 \mathrm{j}}=\gamma_{00}+u_{0 j} \\ r_{i j} & \beta_{1 \mathrm{j}}=\gamma_{10}+u_{1 j} \\ \beta_{2 \mathrm{j}}=\gamma_{20}+u_{2 j}\end{array}$

The fixed effects outcomes for the RC regression model indicated that SRSavg was a statistically significant predictor $(t=5.17, p<.001)$ of client change in well-being (ORSChange) when controlling for ORS-pretest scores $(t=-29.60, p<.001)$. The random effect of therapist on slopes of SRSavg was statistically significant $(p=.005)$, 
but accounted for only $0.4 \%$ of total effects. A deviance likelihood ratio test was used as an overall test of whether the $\mathrm{RC}$ regression model with predictors was a significantly better fit than the intercept-only unconditional (null) model without predictors. The deviance likelihood indicated that deviance decreased from 10,011.29 in the null model to 8842.07 in the $\mathrm{RC}$ regression model $\left(\chi^{2}=1169.22, p<.001\right)$, therefore improving the fit of the overall model. AIC and BIC values also indicated improved model fit with the Level 1 predictor(s). Based on the final estimation of variance components from the RC regression model $\left(\tau_{22}=.12, p<.001\right)$, there remained some variability left to be explained in client outcomes.

The construction of a Level 2 full random coefficients (RC) model (interceptsand-slopes-as-outcomes) was intended to provide additional information to account for the variability in regression in client overall change in well-being (Raudenbush \& Bryk, 2002). The current model tested the hypothesis that the mean (intercept) for ORSChange is a function of a client's alliance ratings averaged across sessions (SRSavg), and that the strength of the alliance-outcome relationship is a function of a therapist's ability to maintain strong therapeutic alliances. In other words, a therapist's average ability to maintain strong alliances moderates the effect of a client's alliance scores on change in well-being during the course of therapy. In this model, the Level 1 predictors from the $\mathrm{RC}$ regression model remained the same. The Level 2 predictor was calculated as the aggregate therapist alliance across all of their clients (THSRSagg) and entered (grandmean centered) to both the intercept and slope equations of the model. The full random coefficients model is presented below: 
Mixed Model

ORSChange $=\gamma_{00}+\gamma_{01}($ THSRSagg $)+$

$\gamma_{10}($ ORSpre $)+\gamma_{20}($ SRSavg $)$

$+\gamma_{21}($ THSRSagg $)+u_{0 \mathrm{j}}+$

$u_{1 \mathrm{j}}($ ORSpre $)+u_{2 \mathrm{j}}(\mathrm{SRSavg})$

$+r_{i j}$
Hierarchical Model

ORSChange $_{\mathrm{ij}}=\beta_{0 \mathrm{j}}+\beta_{1 \mathrm{j}}(\mathrm{ORSpre})+$

$\beta_{2 \mathrm{j}}(\mathrm{SRSavg})+r_{\mathrm{ij}}$

$\beta_{0 \mathrm{j}}=\gamma_{00}+\gamma_{01}\left(\right.$ THSRSagg $\left._{\mathrm{j}}\right)$

$+u_{0 j}$

$\beta_{1 \mathrm{j}}=\gamma_{10}+u_{1 j}$

$\beta_{2 \mathrm{j}}=\gamma_{20}+\gamma_{21}\left(\right.$ THSRSagg $\left._{\mathrm{j}}\right)$

$+u_{2 j}$

Based on the results for the full RC regression model on ORSLast, it was expected that the Level 2 analysis of THSRSagg would yield similar results of a non-significant effect on SRSavg on ORSChange. In fact, the final estimation of fixed effects and final estimation of the variance components mirrored the results shown in the previous section of Hypothesis 7. In the full RC model, fixed effects outcomes indicated that aggregate therapist alliance scores (THSRSagg) was not a statistically significant predictor of either the effect of SRSavg in the intercept $(t=.60, p=.55)$ or the effect of SRSavg on the growth slope $(t=-.64, p=.53)$ of ORSChange. In the current model, deviance declined only .72 points compared to the previous $\mathrm{RC}$ regression model, a difference that was not statistically significant $\left(\chi^{2}=.72, p>.50\right)$. Based on THSRSagg failing to predict either the effect of SRSavg on the intercept and slope, as well as the Level 2 covariate included in the current model reducing deviance by a non-significant amount, the previous RC regression model is preferred.

Results of the final model (see Table 12) indicate that the average unadjusted mean client change in well-being, measured as overall change on the ORS $\left(\gamma_{00}\right)$, among adolescents who experience rupture repair is $9.88(S D=2.47, p<.001)$. This would be the predicted overall change in well-being as rated by ORS scores for an adolescent who experienced a rupture-repair. The within-group effect of the aggregate client alliance 
(SRSavg; $\left.\gamma_{20}\right)$ is $0.35(p<.001)$. This means that for every one unit above the group mean (within-therapist) for therapy alliance, the overall change client therapy outcome would be predicted to increase 0.35 points across the therapy process. Although there is evidence of between-therapist effects on therapy outcomes, aggregate therapist alliance scores across client caseloads failed to predict an effect on either the intercept and/or slope of the alliance effect on change in well-being. Further considerations are provided in the discussion section.

Table 12

Summary of Hierarchical Linear Modeling (HLM) Specification Steps for Rupture Repair Change in Well-Being

\begin{tabular}{|c|c|c|c|c|c|c|c|c|c|}
\hline \multirow[b]{2}{*}{ Fixed Effects } & \multicolumn{3}{|c|}{ Model 1} & \multicolumn{3}{|c|}{ Model 2} & \multicolumn{3}{|c|}{ Model 3} \\
\hline & $b$ & $S E$ & $t$ & $b$ & $S E$ & $t$ & $b$ & $S E$ & $t$ \\
\hline Intercept $\left(\gamma_{00}\right)$ & 9.81 & .32 & $30.59^{* * *}$ & 9.88 & .25 & $39.10^{* * * *}$ & 9.91 & .26 & $38.79^{* * *}$ \\
\hline THSRSagg $\left(\gamma_{01}\right)$ & & & & & & & .10 & .17 & .60 \\
\hline ORSpre $\left(\gamma_{10}\right)$ & & & & -.78 & .03 & $-29.60^{* * *}$ & -.78 & .03 & $-29.47^{* * *}$ \\
\hline SRSavg $\left(\gamma_{20}\right)$ & & & & .35 & .07 & $5.17^{* * *}$ & .33 & .07 & $4.97^{* * * *}$ \\
\hline THSRSagg $\left(\gamma_{21}\right)$ & & & & & & & -.03 & .05 & -.64 \\
\hline Variance Components & $\sigma^{2}$ & $S D$ & $\chi^{2}$ & $\sigma^{2}$ & $S D$ & $\chi^{2}$ & $\sigma^{2}$ & $S D$ & $\chi^{2}$ \\
\hline Residual $\left(r_{i j}\right)$ & 66.25 & 8.14 & & 27.36 & 5.23 & & 27.38 & 5.23 & \\
\hline Intercept $\left(u_{0 \mathrm{j}}\right)$ & 3.99 & 2.00 & $177.02^{* * * *}$ & 3.25 & 1.80 & $172.31^{* * * *}$ & 3.26 & 1.81 & $172.29^{* * * *}$ \\
\hline ORSpre $\left(u_{1 \mathrm{j}}\right)$ & & & & .03 & .16 & $131.98^{* * *}$ & .03 & .16 & $131.97^{* * *}$ \\
\hline SRSavg $\left(u_{2 \mathrm{j}}\right)$ & & & & .12 & .35 & $117.36^{* *}$ & .12 & .34 & $114.62^{* *}$ \\
\hline Deviance & & 0,011 & & & 8842 & & & 8841 & \\
\hline
\end{tabular}




\section{CHAPTER IV: DISCUSSION}

There is no known research to date that has explored the effects of rupture repair processes and outcomes among military adolescents. There is only one known study that addresses therapeutic alliance among this specific population (Owen et al., 2016), and the authors detailed the need for both increasing the understanding of alliance effects that occur during the therapy process, as well as an evidence-based recommendation to monitor fluctuations and provide feedback throughout the therapy process. While there is strong theoretical and empirical evidence for the effect of repairing ruptures increasing therapeutic outcomes (Eubanks et al., 2018), there are persisting limitations affecting understanding of the mechanisms of change. The most recent meta-analysis of rupture repair literature specified that one of the biggest limitations to rupture research is that many studies include a single rating of the alliance, and there is a necessity for "study designs that assess alliance ruptures and repairs throughout treatment” (Eubanks et al., 2018, p. 516). The authors called for increased use of measurement of the alliance and outcome at every session. There is recent evidence that assessing rupture episodes throughout the therapy processes yields better understanding of how ruptures affect treatment (Gersh et al., 2017), however, session selection involved looking at early, middle, and late session effects, potentially missing opportunities for observing ruptures occurring in between non-analyzed sessions.

The primary aim of this study was to examine the impact of alliance ruptures on outcomes of therapy among military youth and adolescents. More specifically, the study 
was intended to examine outcome trajectories of alliance outcomes comparing nonrupture, rupture-repair, and rupture-non-repair sessions throughout therapy processes. The study also included observing potential moderating variables of age, effects of problem type, and therapist effects. Ratings of well-being and alliance were taken at each session, and alliance measures were used to quantitatively define and identify the presence of ruptures, repairs, and non-repairs.

Findings for this study provided reinforcement for existing literature on the effects of rupture processes and expanded results to military adolescents. Hypothesis 1 showed significant mean differences between the No Rupture group and both the Rupture Repair group and Rupture Non-Repair group. There was also a significant difference between the Rupture-Repair group and the Rupture Non-Repair group. The initial outcome study did not yield hypothesized results in that clients coded as No Rupture had significantly higher end-of-treatment outcome scores compared to those coded Rupture Repair. Rupture Repair, however, did lead to expected results of significantly higher endof-treatment outcomes compared to Rupture Non-Repair. Although findings from final treatment outcome score did not meet hypothesized results, overall change in ORS outcome scores did meet expected results, in that adolescents coded as Rupture Repair showed significantly increased change in well-being over the course of therapy compared to both the No Rupture and Rupture Non-Repair groups. Differences between results of the current study Hypothesis 1 and previous literature on rupture effects on outcomes (Eubanks et al., 2018) may indicate the necessity for consideration about how outcomes are defined and measured throughout the therapy process. 
Findings from Hypothesis 2 confirmed predictions that adolescents coded as Rupture Non-Repair would be more likely to prematurely terminate from therapy compared to adolescents coded as Rupture Repair. Findings from Hypothesis 3 were also confirmed in that adolescents coded as Rupture Repair attended a significantly higher number of sessions compared to those coded Rupture Non-Repair. There is previous evidence that exemplifies the use of monitoring the presence of an alliance rupture and the relationship to therapy dropout (Eubanks et al., 2019; O'Keeffe et al., 2020; Safran et al., 2010). In the current study, special consideration was given for how to define premature dropout. As mentioned previously, premature termination in this study was defined as those adolescents engaged in fewer than the average number of sessions attended in the sample population, exhibited no clinically significant change, and ended therapy prior to advancing well-being above clinical distress. This operational definition of premature termination combined previously-used criteria for not only sub-average attended sessions based on the entire sample, but also includes a quantitative metric to establish clinically significant change (Hatchett \& Park, 2003), reducing subjective biases in coding client categorization of outcomes. The practical implications of understanding early- versus late-session dropouts could help therapists to make clinical intervention decisions sooner in therapy, before increasing the risk of a client dropping out of the therapy process. One such example is that therapist behaviors/interventions occur more frequently in sessions that experience temporary ruptures compared to pre-dropout sessions; those sessions that occur just prior to premature termination (Gülüm et al., 2018). 
Retention in therapy, versus dropping out prematurely, may directly or indirectly affect findings found in Hypothesis 3 regarding increased number of sessions attended overall in Rupture Repair groups versus Rupture Non-Repair. It may not be the case that attending a higher number of sessions necessarily leads to improved therapy outcomes (Barkham et al., 2006), however, certain therapists' effects combined with retention in therapy may lead to improved therapy outcomes (Saxon et al., 2017). It should be noted that the mean number of sessions for the full sample was 8.46 and may be a greater number of sessions attended compared to non-military adolescents. For comparison, one previous study that included adolescents $(n=5,325)$ who received almost-exclusively primary care psychotherapy services showed that the average number of sessions attended was 4.24 visits (Hapaz-Rotem et al., 2004). Length of therapy and number of attended sessions may be influenced by setting, modalities, and presenting problems, and should be considered in context for the current study with military adolescents (Castonguay et al., 2015). Considerations for session attendance will be discussed further in the section on future directions for research.

Findings from Hypothesis 4 were consistent with predictions that among processes in which rupture-repair sequence criteria is met, most of these processes would occur in early-stage versus late-stage therapy processes. This result is consistent with previous findings by Stiles et al., (2004), which found that the majority of clients who met criteria for rupture repair sequences demonstrated these processes in early sessions (Sessions 2-4 in 8 session treatments and Sessions 2-7 in 16-session treatments). Muran et al. (2009) found that in the first six sessions of treatment, 56\% of therapists and 37\% of clients perceived rupture occurrences. Monitoring early alliance fluctuations and 
willingness to process a rupture with a client can set the tone for working through the alliance throughout the remainder of therapy. Previous research has shown that earlyprocess ruptures that were repaired were found to show steady strengthening of the alliance later in treatment, while early-process unresolved ruptures predicted no subsequent increases or improvement in the therapeutic alliance (Zilcha-Mano \& Errázuriz, 2017). There may also be a need for paying close attention to early-process ruptures because the alliance is not firmly established and/or in a state of flux.

Findings from Hypotheses 5 did not confirm predicted hypotheses that age would act as a moderator variable on the effect of rupture-repair on therapy outcome or change in well-being across therapy. When using final ORS ratings as the outcome variable, both rupture condition (repair versus non-repair) and age were found to be statistically significant predictor variables, showing an observable effect on outcome. However, the interaction term was statistically non-significant, suggesting that the relationship between rupture condition and outcomes was not affected by age, and/or that the effect of age did not differ between rupture conditions. In the present study, calculating rupture conditions using alliance fluctuations (creating definitive groups), as opposed to generalized relationship between alliance and outcomes, was predicted to yield significant group differences. The null findings in this study are consistent with Shirk et al.'s (2011) finding that age did not statistically significantly moderate alliance-outcome associations, but different from McCleod's (2011) finding of differences on alliance-outcome between child and adolescent age groups. As these studies explored alliance-outcome relationships as opposed to grouping by alliance-calculated conditions, it was expected that age effects would be more observable. Differences in this hypothesis were expected due to Robbins 
et al.'s (2006) previous findings that adolescents who prematurely dropped out of therapy were on average older than those that completed treatment, although it was not specified that dropouts were due to alliance ruptures. When change in ORS was used as the outcome variable, age did not statistically predict outcomes, and did not influence the effect of rupture condition on outcomes.

Findings from Hypothesis 6 did not confirm predicted hypotheses that meeting criteria for a substance use disorder (versus having subthreshold symptoms of a substance use disorder) would act as a moderator on the effect of rupture-repair on adolescent therapy outcome. When using final ORS ratings as the outcome variable, only rupture condition (repair versus unrepaired) was determined to be a significant predictor of therapy change, whereas presence of a substance use disorder (coded as "Yes/No") was statistically non-significant. Additionally, meeting criteria for a substance use disorder did not moderate the effect of rupture condition on therapy outcomes. When change in ORS was used as the outcome variable, analyses yielded similar results as final ORS scores as outcome, with rupture condition predicting outcome scores, but substance use disorder failing to statistically predict outcomes and/or moderate effects of rupture condition on outcomes. Initial considerations for null results of problem-type moderating effect of rupture condition on therapy outcomes include sampling bias in the current study.

Findings from Hypothesis 7 did not confirm predicted hypotheses that aggregate therapist alliance would demonstrate a therapist effect on alliance-outcome associations among clients that experienced rupture-repair. Although results provided further evidence of alliance effects affecting client outcomes (Level 1), aggregate therapist alliance scores 
across caseload (Level 2) was not found to statistically impact this alliance-outcome relationship. The intended investigation of Hypothesis 7 was intended to provide additional information to account for variability between therapists on known effects of alliance on outcome. In addition to rupture-repair literature recommending increased methods of therapists assessing the presence of rupture, and increasing rupture-repair skills, there is continued need for identifying potentially quantifiable therapist effects that differentiate between therapists (Chen et al., 2016; Eubanks et al., 2019; O'Keeffe et al., 2020). In the present study, it was theorized that therapists that maintain strong alliances across all clients would demonstrate superior alliance-outcome associations compared to therapists with weaker aggregate alliances. Previous results of therapist consistency and effectiveness in client outcomes provide evidence of therapists' aggregate effects on their clients (Owen et al., 2019), indicating that some therapists differ in their therapeutic influence across clients consistently. Considerations for null findings may include multiple possibilities. One possible explanation for null results of Level 2 effects includes sampling biases affecting results. For example, therapists working among military populations may demonstrate established practice effects that do not differentiate alliance-based interventions between therapists, such as systemic adherence to recommended therapy modalities based on the site or refined therapeutic interventions working with specified presentation concerns (Waitzkin et al., 2018). As such, these potential limitations of sampling among clients and therapists may have not accounted for more variance than between-therapist effects of alliance on outcome, or another unknown therapist-level variable not explored in the current study. 


\section{Implications}

Due to the lack of alliance rupture research among military adolescents, the most immediate implication of the current study is that these results provide evidence that therapist awareness, assessment, and resolution of alliance ruptures can have important impacts on therapy outcomes. In the current study, it was shown that the most significant improvements in client outcomes occurred among therapy processes in which there was the presence of at least one rupture, and successful resolution. While the authors of the current study do not recommend therapists attempt to intentionally create alliance ruptures during the therapy process, the results help substantiate recommendations that therapists intervene directly with the rupture as it is occurring. Furthermore, this evidence can serve as encouragement that: a) Ruptures may be a natural process in therapy for many clients and therapists; and b) Successful rupture resolution may lead to beneficial therapy outcomes beyond what is expected from the therapy process. Findings from the current study also provide implications for the importance of addressing and resolving ruptures not only to improve therapy outcomes, but to prevent client dropout, as this study provides evidence that unresolved ruptures are more likely to lead to premature termination.

The current study also provides practical implications for detecting ruptures during treatment with military adolescents. The current study is one of few that use session-to-session measures of alliance to detect ruptures throughout each client's entire therapy process. Much of the previous literature on ruptures have cited session selection as a limitation to exploration of ruptures throughout the therapy process. As such, therapist monitoring of the alliance at each session throughout the therapy process may 
help practicing clinicians detect ruptures between sessions, especially if they fail to detect the ruptures(s) during the session. Furthermore, the current study suggests that timing of detecting and intervening with ruptures is important, in that ruptures are more likely to occur in early sessions.

Another practical implication for the findings from the current study is to provide cultural considerations for potential rupture occurrences. Eubanks et al.'s (2018) metaanalysis of alliance rupture repair specified the continued need for examining "the role of diversity in the occurrence of ruptures, repairs, or rupture repair training" (p. 516). Although these authors specifically state the continued need for gender, race, religion, sexual orientation, and socioeconomic status/class as variables to address, the current study provides evidence of the utility of rupture awareness and repair among a unique subset of populations in terms of military culture. Indeed, some alliance rupture researchers posit that cultural microaggressions in therapy are a specific subset of alliance ruptures in which clients attribute perceived offenses to aspects of a client's identity (Davis et al., 2016). As noted previously, military youth and adolescents may experience unique personal and familial stressors not experienced by civilian youth. Some of these stressors may include the impact of deployment (or multiple deployments), adjustment during relocation, separation and reunion from family members, as well as residual mental health effects to parents returning from combat (Drummet et al., 2003; Huebner et al. 2007; Steenkamp \& Litz, 2013; White et al., 2011). Certain military specific risk factors such as multiple school changes and multiple family deployments have been associated with decreased well-being and increased substance use (Gilreath et al., 2013; Richardson et al., 2016). Foreign residence (i.e. living in a country other than one's own 
national residence) is has also been shown to be negatively related to both physical and psychological well-being (Burrell et al., 2006). Consequently, military youth and adolescents may be using substances to mitigate emotional duress as a result of military systemic stressors (Esposito-Smythers et al., 2011). Failure to communicate awareness of these unique hardships could be perceived by client's as a therapist's inability to adequately understand cultural stressors of military youth. Conversely, if an alliance rupture does occur during therapy, a therapist may consider linking ruptures to possible interpersonal patterns outside of therapy (Eubanks et al., 2018). It could be the case that a therapist becomes unwittingly involved in an enactment that is a result of a client's perceived pattern of others not attending to military cultural stressors in their life. As this study has shown, a rupture is more likely to occur early in treatment, and as such, a therapist may benefit from early consideration of how military cultural factors may influence presenting and persisting problems.

\section{Limitations}

Although the finding from this study can prove to be useful in clinical practice, training, and assessment purposes, there are limitations worth acknowledging. Previous research has demonstrated that different therapies can be associated with different rupture frequencies (Muran et al, 2009). There is further evidence that therapy type can impact perceptual differences between the amount of ruptures, types of confrontation markers, and levels of rupture resolution (Gersh et al., 2017). As this study did not differentiate between therapy modalities, effects of therapy type may have influenced outcomes beyond what was observed, particularly in analyses that yielded null results (age and problem type as moderators, and Level 2 therapist effects in the multilevel model). 
Another limitation from the current study is the consideration that definition of premature termination differs from previous studies that operationalized dropout based on either one operationalized, subjective definition (e.g. "based on whether they had agreed to the ending of treatment”; O'Keeffe et al., 2020, p. 5), or a strict numerical definition (e.g. "dropout as defined as withdrawing from treatment prior to the completion of the eighth session of 16"; Gersh et al., 2017, p.88). Continued disagreement about accurate definition limits validation between studies and increases potential for Type I and Type II errors. The current study, with multiple requirements to define premature termination, may have artificially reduced the effect of rupture condition on odds of premature termination.

\section{Future Research Directions}

Future research on the topic of alliance ruptures, including those among specified groups of clients in therapy (e.g. military adolescents) could benefit from the following suggestions. First, between-session alliance ratings may miss within session, moment-tomoment fluctuations, potential ruptures and repairs (Falkenström \& Larsson, 2017). Increased dynamism and further increased monitoring of fluidity within the working alliance could provide even more nuanced understanding of alliance-outcome effects. As such, comparisons between rupture-condition calculations could help to provide for increased accuracy of detection and appropriate intervention for ruptures. For example, the current study utilized Miller et al.'s (2006) recommendation of using single-point decreases between subsequent sessions as indication for the presence of a rupture. However, use of different methodologies for defining ruptures may yield different rupture-outcome results (e.g. Miller et al., 2006; Stiles et al., 2004; Strauss et al., 2006). 
Next, as mentioned above, more accurate diagnosis may provide necessary information and data for client effects that influence alliance-rupture-outcome associations. That is, clients with differing presentation of diagnostic symptoms may present different patterns of alliance ruptures (Colli et al., 2019). While rupture-outcomes studies that use more specific diagnostic considerations demonstrate general findings consistent with generalized rupture-outcome research (e,g., Gersh et al., 2017), observing specific patterns of rupture processes may provide necessary indications for practical interventions unique to symptoms of diagnoses.

It could also prove beneficial for future research to include comparisons of session timing between rupture conditions (repaired versus unrepaired). Differences in effects of early repaired versus unrepaired ruptures likely affect treatment process and outcome. Previous literature has shown that there are difference between early repaired and unrepaired ruptures, in that repaired rupture patterns early in treatment predicted alliance strengthening later in treatment, whereas early unrepaired ruptures showed more stability in alliance throughout the treatment process (Zilcha-Mano \& Errázuriz, 2017).

Alternative therapist effects should be investigated. For example, Saxon et al. (2017) found that more therapists were found to have fewer therapy dropouts and show increased therapy effectiveness with clients that completed therapy versus less effective therapists. Differentiating therapist effectiveness based on different criteria and effects on alliance other than aggregate alliance may yield more variance explained than current MLM. As there remained variance left unexplained in the Level 2 between-therapist condition, hypothesized therapist effects should be considered for an increased explanatory model. 


\section{Conclusion}

The present study sought to examine the impact of alliance ruptures on outcomes of therapy among youth and adolescents, with a specific focus on military youth and adolescents. Specifically, the current study sought to address comparisons between therapy non-ruptures, repaired ruptures, and unrepaired ruptures among therapy processes among military youth. Results of the current study indicate that the presence, detection, and resolution of ruptures in the therapeutic alliance have important impacts on therapy outcomes. Therapy processes that include repaired ruptures have significantly higher therapy outcomes compared to unrepaired ruptures among military adolescents, and repaired ruptures show greater change in well-being across therapy compared to both unrepaired ruptures and processes without ruptures. Additionally, unresolved ruptures are more likely to lead to premature termination from therapy compared to repaired ruptures. Age, problem-type, and aggregate therapist alliance failed to show significant effects on rupture-outcome effects observed in this study. 


\section{REFERENCES}

Agnew-Davies, R., Stiles, W.B., Hardy, G.E., Barkham, M., \& Shapiro, D.A. (1998). Alliance structure assessed by the Agnew Relationship Measure (ARM). British Journal of Clinical Psychology, 37, 155-172.

Albright, J.J., \& Marinova, D.M. (2010). Estimating multilevel models using SPSS, Stata, SAS, and R.https://scholarworks.iu.edu/dspace/bitstream/handle/2022/197 37/Estimating\%20Multilevel\%20Models\%20using\%20SPSS\%2c\%20Stata\%2c\% 20SAS\%20and\%20R.pdf? sequence=1\&isAllowed=y

Andrusyna, T. P., Tang, T. Z., DeRubeis, R. J., \& Luborsky, L. (2001). The factor structure of the Working Alliance Inventory in cognitive-behavioral therapy. Journal of Psychotherapy Practice \& Research, 10, 173-178.

Aspland, H., Llewelyn, S., Hardy, M.B., \& Stiles, W. (2008). Alliance ruptures and rupture resolution in cognitive-behavior therapy: A preliminary task analysis. Psychotherapy Research, 18, 699-710.

Bachelor, A. (2013). Clients' and therapists' views of the therapeutic alliance: Similarities, differences and relationship to therapy outcome. Clinical Psychology and Psychotherapy, 20, 118-135.

Baer, J.S., Barr, H.M., Bookstein, F.L., Sampson, P.D, \& Streissguth, A.P. (1998). Prenatal alcohol exposure and family history of alcoholism in teh etiology of adolescent alcohol problems. Journal of Studies on Alcohol, 59, 533-543.

Baer, J.S., Sampson, P.D., Barr, H.M., Connor, P.D., \& Streissguth, A.P. (2003). A 21- 
ear longitudinal analysis of the effects of prenatal alcohol exposure on young adult drinking. Archives of General Psychiatry, 60, 377-385.

Bailey, J.A., \& McCloskey, L.A. (2005). Pathways to adolescent substance abuse among sexaually abused girls. Journal of Abnormal Child Psychology, 33, 39-53.

Baldwin, M. (1992). Relational schemas and the processing of social information. Psychological Bulletin, 112, 461-484.

Baldwin, S.A., Wampold, B.E., \& Imel, Z.E. (2007). Untangling the alliance-outcome correlation: Exploring the relative importance of therapist and patient variability in the alliance. Journal of Consulting and Clinical Psychology, 75, 842-852.

Barkham, M., Connell, J., Stiles, W.B., Miles. J.N., Margison, F., Evans, C., \& MellorClark, J. (2006). Dose-effect relations and responsive regulation of treatment duration: The good enough level. Journal of Consulting and Clinical Psychology, $74,160-167$.

Beck, A.T. (1976). Cognitive Therapy and the Emotional Disorders. New York: International Universities Press.

Beck, J.S. (2011). Cognitive Behavior Therapy: Basics and Beyond (2 ${ }^{\text {nd }}$ ed). New York, NY: The Guilford Press.

Bennett, D., Parry, G., \& Ryle, A. (2006). Resolving threats to the therapeutic alliance in cognitive analytic therapy of borderline personality disorder: A task analysis. Psychology and Psychotherapy: Theory, Research, and Practice, 79, 395-418.

Bertolino, B., \& Miller, S.D. (2012). ICCE manuals on feedback informed treatment (Vol. 1-6). Chicago, IL: ICCE Press.

Binder, J.L. (2004). Key competencies in Brief Dynamic Psychotherapy. New York: 


\section{Guilford Press.}

Binder, P., Holgersen, H., \& Nielsen, G. (2008). Re-establishing contact: A qualitative exploration of how therapists work with ruptures in adolescent psychotherapy. Counselling and Psychotherapy Research, 8, 239-245.

Blakemore, S.J., \& Mills, K.L. (2014). Is adolescence a sensitive period for sociocultural processing? Annual Review of Psychology, 65, 187-207.

Bordin, E.S. (1979). The generalizability of the psychoanalytic concept of the working alliance. Psychotherapy: Theory, Research, and Practice, 16, 252-260.

Boys, A., Marsden, J., \& Strang, J. (2001). Understanding reasons for drug use amongst young people: A functional perspective. Heath Education Research, 16, 457-469.

Bradshaw, C.P., Sudhinaraset, M., Mmari, K., Blum, R. (2010). School transitions among military adolescents: A qualitative study of stress and coping. School Psychology Review, 39, 84-105.

Bringhurst, D., Watson, C., Miller, S., \& Duncan, B. (2006). The reliability and validity of the ORS: A replication study of a brief clinical measure. Journal of Brief Therapy, 5, 23-29.

Bronfenbrenner, U. (1979). The ecology of human development: Experiments by nature and design. Harvard University Press

Brook, J.S., Balka, E.B., Crossman, A.M., Dermatis, H., Galanter, M., \& Brook, D.W. (2010). The relationship between parental alcohol use, early and late adolescent alcohol use, and young adult psychological symptoms: A longitudinal study. The American Journal on Addictions, 19, 534-542.

Burrell, L.M., Adams, G.A., Durand, D.B., \& Castro, C.A. (2006). The impact of military 
lifestyle demands on well-being, army, and family outcomes. Armed Forces and Society, 33, 43-58.

Cairns, A.J., Kavanagh, D.J., Dark, F., \& McPhail, S.M. (2019). Goal setting improves retention in youth mental health: A cross-sectional analysis. Child and Adolescent Psychiatry and Mental Health, 13, 31.

Castillo, H. (2003). Personality disorder: Temperament or Trauma? London: Jessica Kingsley.

Castonguay, L.G., Constantino, M.J., \& Grosse Holtforth, M.G. (2006). The working alliance: Where are we and where should we go? Psychotherapy, Theory, Research, Practice, Training, 43, 271-279.

Castonguay, L.G., Eubanks, C.F., Goldfried, M.R., Muran, J.C., \& Lutz, W. (2015). Research on psychotherapy integration: Building on the past, looking to the future. Psychotherapy Research, 25, 365-382.

Campbell, A., \& Hemsley, S. (2009). Outcome Rating Scale and Session Rating Scale in psychological practice: Clinical utility of ultra-brief measures. Clinical Psychologist, 13, 1-9.

Chilenski, S.M., \& Greenberg, M.T. (2009). The importance of the community context in the epidemiology of early adolescent substance use and delinquency in a rural sample. American Journal of Community Psychology, 44, 287-301.

Chu, B.C., Suveg, C., Creed, T.A., \& Kendall, P.C. (2010). Involvement shifts, alliance ruptures, and managing engagement over therapy. In: Castro-Blanc, D., Karver, M.S. (Eds.), Elusive alliance: Treatment engagement strategies with high-risk 
adolescents (95-122). Washington, D.C.: American Psychological Association Press.

Colder, C.R., Read, J.P., Wieczorek, W.F., Eiden, R.D., Lengua, L.J., Hawk, L.W., Trucco, E.M., \& Lopez-Vergara, H.I. (2017). Cognitive appraisals of alcohol use in early adolescence: Psychosocial Predictors and reciprocal associations with alcohol use. Journal of Early Adolescence, 37, 525-558.

Colli, A., Gentile, D., Condino, V., \& Lingiardi, V. (2019). Assessing alliance ruptures and resolutions: Reliability and validity of the Collaborative Interactions Scalerevised version. Psychotherapy Research, 29, 279-292.

Connell, C.M., Gilreath, T.D., Aklin, W.M., \& Brex, R.A. (2010). Social-ecological influences on patterns of substance use among non-metropolitan high school students. American Journal of Community Psychology, 45, 36-48.

Cook, T.D., Herman, M.R., Phillips, M., \& Settersten, R.A. (2002). Some ways in which neighborhoods, nuclear families, friendship groups, and school jointly affect changes in early adolescent development. Child Development, 73, 1283-1309.

Cooper, M.L. (1994). Motivations for alcohol use among adolescents: Developments and validation of a four-factor model. Psychological Assessment, 6, 117-128.

Constantino, M.J., Castonguay, L.G., \& Schut, A.J. (2002). The working alliance: A flagship for the "scientist-practitioner" model in psychotherapy. In G.S. Tyron (Ed.), Counseling based on process research: Applying what we know (pp. 81131). Boston: Allyn \& Bacon.

Corrigan, J.D., Schmidt, L.D. (1983). Development and validation of the Counselor Rating Form. Journal of Counseling Psychology, 30, 64-75. 
Corrigan, P.W., Druss, B.G., \& Perlick, D.A. (2014). The impact of mental illness stigma on seeking and participating in mental health care. Psychological Science in the Public Interest, 15, 37-70.

Coutinho, J., Ribeiro, E., Hill, C., \& Safran, J., (2011). Therapists' and clients' experiences of alliance ruptures: A qualitative study. Psychotherapy Research, 21, 525-540.

Crits-Christoph, P., \& Crits-Christoph, K. (1998). Alliance-fostering therapy for major depressive disorder. Unpublished manuscript, University of Pennsylvania.

Crits-Christoph, P., Connolly Gibbon, M.B., \& Hearon, B. (2006). Does the alliance cause good outcome? Recommendations for future research on the alliance. Psychotherapy: Theory, Research, Practice, and Training, 43, 280-285.

Crits-Christoph, P., Gibbons, M. B. C., Hamilton, J., Ring-Kurtz, S., \& Gallop, R. (2011). The dependability of alliance assessments: The alliance- outcome correlation is larger than you might think. Journal of Consulting and Clinical Psychology, 79, 267-278.

Crone, E.A., \& Dahl, R.E. (2012). Understanding adolescence as a period of socialaffective engagement and goal flexibility. Nature Reviews Neuroscience, 13, 636650.

Cservenka, A. (2016). Neurobiological phenotypes associated with a family history of alcoholism. Drug and Alcohol Dependence, 158, 8-21.

D’Amico, E.J., \& McCarthy, D.M. (2006). Escalation and initiation of younger adolescents' substance use: The impact of perceived peer use. Journal of Adolescent Health, 39, 481-487. 
Daly, A., Llewelyn, S., McDougall, E., \& Chanen, A.M. (2010). Rupture resolution in cognitive analytic therapy for adolescents with borderline personality disorder. Psychology and Psychotherapy: Theory, Research, and Practice, 83, 273-288.

Das, J.K., Salam, R.A., Arshad, A., Finkelstein, Y., \& Bhutta, Z.A. (2016). Interventions for adolescent substance abuse: An overview of systematic reviews. Journal of Adolescent Health, 59, S61-S75.

Davidow, J.Y., Insel, C., \& Sommerville, L.H. (2018). Adolescent development of valueguided goal pursuit. Trends in Cognitive Sciences, 22, 725-736.

Davis, D.E., Deblaere, C., Brubaker, K., Owen, J., Jordan II, T.A., Hook, J.N., \& Van Tongeren, D.R. (2016). Microaggressions and perceptions of cultural humility in counseling. Journal of Counseling and Development, 94, 483-493.

Day, N., Goldschmidt, L., \& Thomas, C.A. (2006). Prenatal marijuana exposure contributes to the prediction of marijuana use at age 14. Addiction, 101, 13131322.

De Bolle, M., Johnson, J. G., \& De Fruyt, F. (2010). Patient and clinician perceptions of therapeutic alliance as predictors of improvement in depression. Psychotherapy and Psychosomatics, 79, $378-385$.

Del Re, A.C., Flückiger, C., Horvath, A.O., Symonds, D., \& Wampold, B.E. (2012). Therapist effects in the therapeutic alliance-outcome relationship: A restrictedmaximum likelihood meta-analysis. Clinical Psychology Review, 32, 642-649.

Doremus-Fitzwater, T.L., Varlinskaya, E.I, \& Spear, L.P. (2010). Motivational systems in adolescence: Possible implications for age differences in substance abuse and other risk-taking behaviors. Brain and Cognition, 72, 114-123. 
Drummet, A.R., Coleman, M., \& Cable, S. (2003). Military families under stress: Implications for family life education. Family Relations, 52, 279-287.

Duncan, B.L., Miller, S.D., Sparks, J.A., Claud, D.A., Reynolds, L.R., Brown, J., \& Johnson, L.D. (2003). The Session Rating Scale: Preliminary psychometric properties of a "working alliance measure." Journal of Brief Therapy, 3, 3-12.

Duncan, B. L., Sparks, J. A., Miller, S. D., Bohanske, R. T., \& Claud, D. A. (2006). Giving youth a voice: A preliminary study of the reliability and validity of a brief outcome measure for children, adolescents, and caretakers. Journal of Brief Therapy, 5, 71-88.

Eames, V., \& Roth, A. (2000). Patient attachment orientation and the early working alliance: A study of patient and therapist reports of alliance quality and ruptures. Psychotherapy Research, 10, 421-434.

Eisenberg, M.E., Toumbourou, J.W., Catalano, R.F., \& Hemphill, S.A. (2014). Social norms in the development of adolescent substance use: A longitudinal analysis of the International Youth Development Study. Journal of Youth and Adolescence, $43,1486-1497$.

Esposito-Smythers, C., Wolff, J., Lemmon, K.M., Bodzy, M., Swenson, R.R., \& Spirito, A. (2011). Military youth and the deployment cycle: Emotional health consequences and recommendations for intervention. Journal of Family Psychology, 25, 497-507.

Eubanks, C.F., Muran, J.C., \& Safran, J.D. (2018). Alliance rupture repair: A metaanalysis. Psychotherapy, 55, 508-519.

Eubanks, C.F., Lubitz, J., Murank, J.C., \& Safran, J.D. (2019). Rupture Resolution 
Rating System (3RS): Development and validation. Psychotherapy Research, 29, 306-319.

Eubanks-Carter, C., Muran, J.C., \& Safran, J.D. (2010). Alliance ruptures and resolution. In J.C. Muran \& J.P. Barber (Eds.), The therapeutic alliance: An evidence-based guide to practice (pp. 74-94). New York, NY, US: Guilford Press.

Fagan, A.A., Wright, E.M., \& Pinchevsky, G.M. (2014). The protective effects of neighborhood collective efficacy on adolescent substance use and violence following exposure to violence. Journal of Youth and Adolescence, 43, 14981512.

Fagan, R. (2006). Counseling and treating adolescents with alcohol and other substance use problems and their families. The Family Journal, 14, 326-333.

Falkenstöm F., Granström, F., \& Homqvist, R. (2013). Therapeutic alliance predicts symptomatic improvement session by session. Journal of Counseling Psychology, 60, 317-328.

Falkenstöm F., \& Larrson, M.H. (2017). The working alliance: From global outcome prediction to micro-analyses of within-session fluctuations. Psychoanalytic Inquiry, 37, 167-178.

Ferenczi, S. (1988). The clinical diary of Sandor Ferenczi (M.B.N.Z. Jackson, Trans.). Cambridge, MA: Harvard University Press. (Original work published 1932).

Freud, S. (1912/1958). The dynamics of transference [Zur Dynamik der Übertragung]. (J. Starchey, Trans.). In J. Starchey (Ed.), The standard edition of the complete psychological works of Sigmund Freud (vol. 12, p. 99-108). London: Hogarth Press. 
Friedman, A.S., Buckell, J., \& Sindelar, J.L. (2019). Tobacco-21 laws and young adult smoking: Quasi-experimental evidence. Addiction, 114, 1816-1823.

Garcia, J. A., \& Weisz, J. R. (2002). When youth mental health care stops: Therapeutic relationship problems and other reasons for ending youth outpatient treatment. Journal of Consulting and Clinical Psychology, 70, 439-443.

Garson, G.D. (Ed.). (2013). Hierarchical Linear Modeling: Guide and applications. SAGE Publications, Inc.

Gelso, C.J. (2009). The real relationship in a postmodern world: Theoretical and empirical explorations. Psychotherapy Research, 19, 253-264.

Gelso, C.J., \& Carter, J.A. (1994). Components of the psychotherapy relationship: Their interaction and unfolding during treatment. Journal of Counseling Psychology, 41, 296-306.

Gersh, E., Hulbert, C.A., McKechnie, B., Ramadan, R., Worotniuk, T., \& Chanen, A.M. (2017). Alliance rupture and repair processes and therapeutic change in youth with borderline personality disorder. Psychology and Psychotherapy: Theory, Research, and Practice, 90, 84-104.

Giedd, J.N., \& Rapoport, J.L. (2010). Structural MRI of pediatric brain development: What have we learned and where are we going? Neuron, 67, 728-734.

Gilreath, T.D., Cederbaum, J.A., Avi Astor, R., Benbenishty, R., Pineda, D., \& Atuel, H. (2013). Substance use among military connected youth: The California Healthy Kids Survey. American Journal of Preventative Medicine, 44, 150-153.

Gottfredson, D.C., \& Wilson, D.B. (2003). Characteristics of effective school-based substance abuse prevention. Prevention Science, 4, 27-38. 
Gray, K.M., \& Squeglia, L.M. (2018). Research Review: What have we learned about adolescent substance use? Journal of Child Psychology and Psychiatry, 59, 618627.

Green-Shortridge, T.M., Britt, T.W., Castro, C.A. (2007). The stigma of mental health problems in the military. Military Medicine, 172, 157-161.

Greenson, R.R. (1965). The working alliance and the transference of neuroses. Psychoanalysis Quarterly, 34, 155-181.

Greenson, R.R. (1967). The technique and practice of psychoanalysis: Volume 1. New York: International Universities Press.

Greger, H.K., Myhre, A.K., Klöckner, C.A., \& Jozefiak, T. (2017). Childhood maltreatment, psychopathology and well-being: The mediator role of global selfesteem, attachment difficulties and substance use. Child Abuse and Neglect, 70, 122-133.

Griffin, K.W., \& Botvin, G.J. (2010). Evidence-based interventions for preventing substance use disorders in adolescents. Child and Adolescent Psychiatry Clinics of North America, 19, 505-526.

Guerri, C., \& Pascual, M. (2019). Impact of neuroimmune activation induced by alcohol or drug abuse on adolescent brain development. International Journal of Developmental Neuroscience, 77, 89-98.

Gülüm, I.V., Soygüt, G., \& Safran, J.D. (2018). A comparison of pre-dropout and temporary rupture sessions in psychotherapy. Psychotherapy Research, 28, 685707.

Hall, L.K. (2011). The military culture, language, and lifestyle. In Everson, R.B., \& 
Figley, C.R. (Eds.), Families under fire: Systemic Therapy with military families. New York, NY: Routledge.

Harpaz-Rotem, Il, Leslie, D., \& Rosenheck, R.A. (2004). Treatment retention among children entering a new episode of mental health care. Psychiatric Services, 55, 1022-1028.

Harper, H. (1989a). Coding Guide I: Identification of confrontation challenges in exploratory therapy. University of Sheffield, Sheffield, England.

Harper, H. (1989b). Coding Guide II: Identification of withdrawal challenges in exploratory therapy. University of Sheffield, Sheffield, England.

Harrison, P.A., Fulkerson, J.A., \& Park, E. (2000). The relative importance of social versus commercial sources in youth access to tobacco, alcohol, and other drugs. Preventative Medicine, 31, 39-48.

Hatcher, R. L., \& Barends, A. W. (2006). How a return to theory could help alliance research. Psychotherapy: Theory, Research, Practice, Training, 43, 292-299.

Hatchett, G.T., \& Park, H.L. (2003). Comparison of four operational definitions of premature termination. Psychotherapy, 40, 226-231.

Hayre, R.S., Goulter, N., \& Moretti, M.M. (2019). Maltreatment, attachment, and substance use in adolescence: Direct and indirect pathways. Addictive Behaviors, 90, 196-203.

Hemovich, V., Lac, A., \& Crano, W.D. (2011). Understanding early-onset drug and alcohol outcomes among youth: The role of family structure, social factors, and interpersonal perceptions of use. Psychology, Health, \& Medicine, 16, 249-267.

Hendricks, G., Savahl, S., \& Florence, M. (2015). Adolescent peer pressure, leisure 
boredom, and substance use in low-income Cape Town communities. Social Behavior and Personality, 43, 99-110.

Hill, C.E., Nutt-Williams, E., Heaton, K.J., Thompson, B.J., \& Rhodes, R.H. (1996). Therapist retrospective recall of impasses in long term psychotherapy: A qualitative analysis. Journal of Counseling Psychology, 43, 207-217.

Hill, S.Y. (2004). Trajectories of alcohol use and electrophysiological and morphological indices of brain development: Distinguishing causes from consequences. Annals of the New York Academy of Sciences, 1021, 245-259.

Hodge, C.W., Castro, C.A., Messer, S.C., McGurk, D., Cotting, D.I., \& Koffman, R.L. (2004). Combat duty in Iraq and Afghanistan, mental health problems, and barriers to care. The New England Journal of Medicine, 351, 13-22.

Hogue, A., Henderson, C.E., Ozechowski, T.J., \& Robbins, M.S. (2014). Evidence base on outpatient behavioral treatments for adolescent substance use: Updates and recommendations 2007-2013. Journal of Clinical Child and Adolescent Psychology, 43, 695-720.

Horigian, V.E., Feaster, D.J., Brincks, A., Robbins, M.S., Alejandra Perez, M., \& Szapocsnik, J. (2015). The effects of Brief Strategic Family Therapy (BSFT) on parent substance use and the association between parent and adolescent substance use. Addictive Behaviors, 42, 44-50.

Horvath, A. O., \& Greenberg, L. S. (1989). Development and validation of the Working Alliance Inventory. Journal of Counseling Psychology, 36, 223-233.

Horvath, A.O., Del Re, A.C., Flückiger, C., \& Symonds, D. (2011). Alliance in individual therapy. Psychotherapy, 48, 9-16. 
Huebner, A.J., \& Mancini, J.A. (2005). Adjustment among adolescents in military families when a parent is deployed: A final report submitted to the Military Family Research Institute and the Department of Defense Quality of Life Office. Falls Church, VA: Virginia Tech, Department of Human Development.

Huebner, A.J., Mancini, J.A., Willcox, R.M., Grass, S.R., Grass, G.A. (2007). Parental deployment and youth in military families: Exploring uncertainty and ambiguous loss. Family Relations, 56, 112-122.

Hukkelberg, S.S., \& Ogden, T. (2013). Working alliance and the treatment fidelity as predictors of externalizing problem behaviors in parent management training. Journal of Consulting and Clinical Psychology, 81, 1010-1020.

Humphrey, G., \& Dumontheil, I. (2016). Development of risk-taking, perspective-taking, and inhibitory control during adolescence. Developmental Neuropsychology, 41, $59-76$.

Huppert, J.D., Kivity, Y., Barlow, D.H., Gorman, J.M., Shear, M.K., \& Woods, S.W. (2014). Therapist effects and the outcome-alliance correlation in cognitive behavioral therapy for panic disorder with agoraphobia. Behavior Research and Therapy, 52, 26-34.

Hurley, K.D., Van Ryzin, M.J, Lambert, M., \& Stevens, A.L. (2015). Examining change in therapeutic alliance to predict youth mental health outcomes. Journal of Emotional and Behavioral Disorders, 23, 90-100.

Imel, Z., \& Wampold, B. (2008). The importance of treatment and the science of common factors in psychotherapy. Handbook of counseling psychology, 249-262.

Jacobs, T. (1986). On countertransference enactments. Journal of the American 
Psychoanalytic Association, 34, 289-307.

Jacobson, N.S., \& Truax, P. (1991). Clinical significance: A statistical approach to defining meaningful change in psychotherapy research. Journal of Consulting and Clinical Psychology, 59, 12-19.

Johnston, L.D., O’Malley, P.M., Miech, R.A., Bachman, J.G., \& Schlenberg, J.E. (2016). Monitoring the Future: National survey results on drug use, 1975-2015: Overview, key findings on adolescent drug use. Ann Arbor: Institute for Social Research, University of Michigan.

Jordan, C.J., \& Andersen, S.L. (2017). Sensitive periods of substance abuse: Early risk for the transition to dependence. Developmental Cognitive Neuroscience, 25, 2944.

Kazdin, A.E., Whitley, M., \& Marciano, P.L. (2006). Child-therapist and parent-therapist alliance and the therapeutic change in the treatment of children referred for oppositional, aggressive, and antisocial behavior. Journal of Child Psychology and Psychiatry, 47, 436-445.

Kellett, S., Bennett, D., Ryle, T., \& Thake, A. (2013). Cognitive Analytic Therapy for Borderline Personality Disorder: Therapist competence and therapeutic effectiveness in routine practice. Clinical Psychology and Psychotherapy, 20, 216-225.

Kerr, D.C.R., Tiberio, S.S., \& Capaldi, D.M. (2015). Contextual risks linking parents’ adolescent marijuana use to offspring onset. Drug and Alcohol Dependence, 154, $222-228$.

Kilford, E.J., Garrett, E., \& Blakemore, S.J. (2016). The development of social cognition 
in adolescence: An integrated perspective. Neuroscience and Biobehavioral Reviews, 70, 106-120.

Kivlighan, D.M., \& Shaughnessy, P. (2000). Patterns of working alliance development: A typology of client's working alliance ratings. Journal of Counseling Psychology, $47,362-371$.

Klein, D. N., Schwartz, J. E., Santiago, N. J., Vivian, D., Vocisano, C., Castonguay, L. G., Arnow, B., Blalock, J.A., Manber, R., Markowitz, J.C., Riso, L.P., Rothbaum, B., McCullough, J.P., Thase, M.E., Borian, F.E., Miller, I.W., \& Keller, M.B. (2003). Therapeutic alliance in depression treatment: Controlling for prior change and patient characteristics. Journal of Consulting and Clinical Psychology, 71, 997-1006.

Krause, M., Altimir, C., \& Horvath, A. (2011). Deconstructing the therapeutic alliance: Reflections on the underlying dimensions of the concept. Una Deconstrucción de la Alianza Terapéutica: Reflexiones sobre las Dimensiones Subyacentes del Concepto. Clínica y Salud., 22, 267-283

Luborsky, L. (1984). Principles of Psychoanalytic Psychotherapy: A manual for Supportive Expressive Treatment. New York, NY: Basic Books.

Luborsky, L., Barber, J., Siqueland, L., Johnson, S., Najavits, L., Frank, A. et al. (1996). The Revised Helping Alliance questionnaire (HAQ-II): Psychometric properties. The Journal of Psychotherapy Practice and Research, 5, 260-271.

Malmberg, M., Klenjan, M., Vermulst, A.A., Overbeek, G., Monshouwer, K., Lammers, 
J., \& Engels, R.C.M.E. (2012). Do substance use risk personality dimensions predict the onset of substance use in early adolescence? A variable- and personcentered approach. Journal of Youth and Adolescence, 41, 1512-1525.

Marcus, D.K., Kashy, D.A. \& Baldwin, S.A. (2009). Studying psychotherapy using the one-with-many design: The therapeutic alliance as an exemplar. Journal of Counseling Psychology, 56, 537-548.

Margret, C.P., \& Ries, R.K. (2016). Assessment and treatment of adolescent substance use disorders: Alcohol use disorders. Child \& Adolescent Psychiatry Clinics of North America, 25, 411-430.

Marker, C.D., Comer, J.S., Abramova, V., \& Kendall, P.C. (2013). The reciprocal relationship between alliance and symptom improvement across treatment of childhood anxiety. Journal of Clinical Child and Adolescent Psychology, 42, 2233.

Martin, D., Garkse, J. P., \& Davis, M. K. (2000). Relation of the therapeutic alliance with outcome and other variables: A meta-analytic review. Journal of Consulting and Clinical Psychology,68, 438-450.

Mayberry, M.L., Espelage, D.L., \& Koenig, B. (2009). Multilevel modeling of direct effects and interactions of peers, parents, school, and community influences on adolescent substance use. Journal of Youth and Adolescence, 38, 1038-1049.

McCutcheon, J.E., Conrad, K.L., Carr, S.B., Ford, K.A., McGehee, D.S., \& Marinelli, M. (2012). Dopamine neurons in the ventral tegmental area fire faster in adolescent rats than in adults. Journal of Neurophysiology, 108, 1620-1630.

McDonough, M.H., Jose, P.E., \& Stuart, J. (2016). Bi-directional effects of peer 
relationships and adolescent substance use: A longitudinal study. Journal of Youth and Adolescence, 45, 1652-1663.

McLeod, B.D. (2011). Relation of the alliance with outcomes in youth psychotherapy; A meta-analysis. Clinical Psychology Review, 31, 603-616.

Meeus, W. (2016). Adolescent psychosocial development: A review of longitudinal models and research. Developmental Psychology, 52, 1969-1993.

Miech, R., Johnston, L., O’Malley, P.M., Bachman, J.G., \& Patrick, M.E. (2019). Trends in adolescent vaping, 2017-2019. New England Journal of Medicine, 381, 14901491.

Mensinger, J.L., Diamond, G.S., Kaminer, Y., \& Wintersteen, M.B. (2006). Adolescent and therapist perception of barriers to outpatient substance abuse treatment. The American Journal on Addictions, 15, 16-25.

Milburn, N.G., \& Lightfoot, M. (2013). Adolescents in wartime U.S. military families: A developmental perspective on challenges and resources. Clinical Child and Family Psychology Review, 16, 266-277.

Miller, S.D., \& Duncan, B.L. (2000b). Outcome Rating Scale. Chicago, IL: Authors. Retrieved from https://heartandsoulofchange.com/content/measures/docs/english. doc

Miller, S.D., \& Duncan, B.L. (2004). The Outcome and Session Rating Scales: Administration and score manual. Chicago, IL: Institute for the Study of Therapeutic Change.

Miller, S.D., Duncan, B.L., \& Johnson, L.D. (2002). The session rating scale 3.0. 
Chicago, IL: Authors. Retrieved from https://heartandsoulofchange.com/content /measures/docs/eng- lish.doc

Miller, S.D., Duncan, B.L., Brown, J. Sparks, J., \& Claud, D. (2003). The outcome rating scale: A preliminary study of the reliability, validity, and feasibility of a brief visual analog measure. Journal of Brief Therapy, 2, 91-100.

Miller, S.D., Duncan, B.L., Sorrell, R., Brown, G.S., \& Chalk, M.B. (2006). Using outcome to inform therapy practice. Journal of Brief Therapy, 5, 5-22.

Miller, S.M., Siegel, J.T., Hohman, Z., \& Crano, W.D. (2013). Factors mediating the association of the recency of parent's marijuana uses and their adolescent children's subsequent initiation. Psychology of Addictive Behaviors, 27, 848-853.

Mundt, M.P. (2011). The impact of peer social networks on adolescent alcohol use initiation. Academic Pediatrics, 11, 414-421.

Muran, J.C., Safran, J.D., Gorman, B.S., Wallner Samstag, L., Eubanks-Carter, C, \& Winston, A. (2009). The relationship of early alliance ruptures and their resolution to process and outcome in three time-limited psychotherapies for personality disorders. Psychotherapy,46, 233-248.

Muran, J. C., Safran, J. D., \& Eubanks-Carter, C. (2010). Developing therapist abilities to negotiate alliance ruptures. The therapeutic alliance: An evidence-based guide to practice, $320-340$.

Muran, J.C., Safran, J.D., Samstag, L., \& Winston, A. (2005). Evaluating and alliancefocused treatment for personality disorders. Psychotherapy, 42, 512-531.

National Institute on Drug Abuse (2019, December). Vaping of marijuana on the rise 
among teens. https://d14rmgtrwzf5a.cloudfront.net/sites/default/files/mtf-2019-p

r_final-cleared-12-16-19.pdf.

Norberg, K.E., Bierut, L.J., \& Grucza, R.A. (2009). Long-term effects of minimum drinking age laws on past-year alcohol and drug use disorders. Alcoholism: Clinical and Experimental Research, 33, 2180-2190.

O’Keeffe, S.O., Martin, P., \& Midgley, N. (2020). When adolescents stop psychological therapy: Rupture-repair in the therapeutic alliance and association with therapy ending. Psychotherapy. Advance online publication. https://doi.org/10.1037/pst0000279

Owen, J., Miller, S.D., Seidel, J., \& Chow, D. (2016). The working alliance in treatment of military adolescents. Journal of Consulting and Clinical Psychology, 84, 2002010.

Owen, J., Drinane, J.M., Kivlighan III, M., Miller, S., Kopta, M., \& Imel, Z. (2019). Are high-performing therapists both effective and consistent? A test of therapist expertise. Journal of Consulting and Clinical Psychology, 87, 1149-1156.

Park, E., Livingston, J.A., Wang, W., Kwon, M., Eiden, R.D., \& Chang, Y. (2020). Adolescent E-cigarette use trajectories and subsequent alcohol and marijuana use. Addictive Behaviors, 103, 1-10.

Pickett, T., Rothman, D., Crawford, E.F., Brancu, M., Fairbank, J.A., Kudler, H.S. (2015). Mental health among military personnel and veterans. North Carolina Medical Journal, 76, 299-306.

Piko, B.F., \& Kovács, E. (2010). Do parents and school matter? Protective factors for adolescent substance use. Addictive Behaviors, 35, 53-56. 
Raudenbush, S.W., \& Bryk, A.S. (2002). Hierarchical linear models: Applications and data analysis methods. Thousand Oaks, CA: Sage Publications.

Rhodes, R.H., Hill, C.E., Thompson, B.J., Elliot, R. (1994). Client retrospective recall of resolved and unresolved misunderstanding events. Journal of Counseling Psychology, 41, 473-483.

Richardson, E.W., Mallette, J.K., O’Neal, C.W., \& Mancini, J.A. (2016). Do youth development programs matter? An examination of transitions and well-being among military youth. Journal of Child and Family Studies, 25, 1765-1776.

Richardson, G.A., Larkby, C., Goldschmidt; L., \& Day, N.L. (2013). Adolescent initiation of drug use: Effects of prenatal cocaine exposure. Journal of the American Academy of Child and Adolescent Psychiatry, 52, 37-46.

Robbins, M.S., Liddle, H.A., Turner, C.W., Dakof, G.A., Alexander, J.F., \& Kogan, S.M. (2006). Adolescent and parent therapeutic alliances as predictors of dropout in multidimensional family therapy. Journal of Family Psychology, 20, 108-116.

Rusby, J.C., Light, J.M., Crowley, R., \& Westling, E. (2018). Influence of parent-youth relationship, parental monitoring, and parent substance use on adolescent substance use onset. Journal of Family Psychology, 32, 310-320.

Safran, J., Crocker, P., McMain, S., \& Murray, P. (1990). The therapeutic alliance rupture as a therapy event for empirical investigation. Psychotherapy, 27, 154165.

Safran, J.D., \& Kraus, J. (2014). Alliance ruptures, impasses, and enactments: A relational perspective. Psychotherapy, 51, 381-387.

Safran, J.D., \& Muran, J.C. (1996). The resolution of ruptures in the therapeutic alliance. 
Journal of Consulting and Clinical Psychology, 64, 447-458.

Safran, J. D., \& Muran, J. C. (2000). Negotiating the therapeutic alliance: A relational treatment guide. New York: Guilford Press.

Safran, J. D., \& Muran, J. C. (2006). Has the concept of the therapeutic alliance outlived its usefulness? Psychotherapy: Theory, Research, Practice, Training,43(3), 286291.

Safran, J.D., Muran, J.C., \& Eubanks-Carter, C. (2010). Developing therapist abilities to negotiate alliance ruptures. The therapeutic alliance: An evidence-based guide to practice, 320-340.

Safran, J.D., Muran, J.C., \& Eubanks-Carter, C. (2011). Repairing alliance ruptures. Psychotherapy, 48, 80-87.

Safran, J.D., Muran, J.C., Samstag, L.W., \& Stevens, C. (2002). Repairing Alliance Ruptures. In J.C. Norcross (Ed.), Psychotherapy Relationships That Work. 235254. New York: Oxford University Press.

Saxon, D., Firth, N., \& Barkham, M. (2017). The relationship between therapist effects and therapy delivery factors: Therapy modality, dosage, and non-completion. Administration and Policy in Mental Health, 44, 705-715.

Schell, T.L., \& Marshall, G.N. (2008). Survey of individuals previously deployed for OEF/OIF. In Tanielian, T. \& Jaycox, L.H. (Eds.) Invisible wounds of war: Psychological and cognitive injuries, their consequences, and services to assist recovery (pp. 87-115). Santa Monica, CA,: RAND Corporation.

Schindler, A., \& Bröning, S. (2015). A review on attachment and adolescent substance 
abuse: Empirical evidence and implications for prevention and treatment. Substance Abuse, 36, 304-313.

Sharma, A. \& Morrow, J.D. (2016). Neurobiology of adolescent substance use disorders. Child and Adolescent Psychiatric Clinics, 25, 367-375.

Sharp, M.L., Fear, N.T., Rona, R.J., Wessely, S., Greenberg, N., Jones, N., Goodwin, L. (2015). Stigma as a barrier to seeking health care among military personnel with mental health problems. Epidemiologic Reviews, 37, 144-162.

Shekhtmeyster, Z., Sharkey, J., \& You, S. (2011). The influence of multiple ecological assets on substance use patterns of diverse adolescents. School Psychology Review, 40, 386-404.

Shih, R.A., Parast, L., Pedersen, E.R., Troxel, W.M., Tucker, J.S., Miles, J.N.V., Kraus, L., \& D'Amico, E.J. (2017). Individual, peer, and family factor modification of neighborhood-level effects on adolescent alcohol, cigarette, e-cigarette, and marijuana use. Drug and Alcohol Dependence, 180, 76-85.

Shirk, S., \& Karver, M. (2003). Prediction of treatment outcome from relationship variables in child and adolescent therapy: A meta-analytic review. Journal of Consulting and Clinical Psychology, 71, 462-471.

Shirk, S.R, Karver, M.S. \& Brown, R. (2011). The alliance in child and adolescent psychotherapy. Psychotherapy, 48, 17-24.

Siennick, S.E., Widdowson, A.W., Woessner, M., \& Feinberg, M.E. (2015). Internalizing symptoms, peer substance use, and substance use initiation. Journal of Research on Adolescence, 26, 645-657.

Somerville, L.H., Jones, R.M., \& Casey, B.J. (2010). A time of change: Behavioral and 
neural correlates of adolescent sensitivity to appetitive and aversive emotional cues. Brain and Cognition, 72, 124-133.

Steenkamp, M.M., \& Litz, B.T. (2013). Psychotherapy for military-related posttraumatic stress disorder: Review of the evidence. Clinical Psychology Review, 33, 45-53.

Steinberg, L., \& Sheffield Morris, A. (2001). Adolescent development. Annual Review of Psychology, 52, 83-110.

Stiles, W.B., Glick, M.J., Osatuke, K., Hardy, G.E., Shapiro, D.A., Agnew-Davies, R., Rees, A. \& Barkham, M. (2004). Patterns of alliance development and the rupture-repair hypothesis: Are productive relationships U-shaped or V-shaped? Journal of Counseling Psychology 51: 81-92.

Strauss, J.L., Hayes, A.M., Johnson, S.L., Newman, C.F., Brown, G.K., Barber, J.P., Laurenceau, J., \& Beck, A.T. (2006). Early alliance, alliance ruptures, and symptoms change in a nonrandomized trial of cognitive therapy for avoidant and obsessive-compulsive personality disorders. Journal of Consulting and Clinical Psychology, 74, 337-345.

Strupp, H.H., \& Binder, J.L. (1984). Psychotherapy in a new key: A guide to Time Limited Dynamic Psychotherapy. New York: Basic Books.

Su, J., \& Supple, A.J. (2016). School substance use norms and racial composition moderate parental and peer influences on adolescent substance use. American Journal of Community Psychology, 57, 280-290.

Substance Abuse and Mental Health Services Administration (2018). Key Substance Use and Mental Health Indicators in the United States: Results from the 2018 National Survey on Drug Use and Health. https://www.samhsa.gov/ 
data/sites/default/files/cbhsq-repo rts/ N

SDUHNationalFindingsReport2018/NSDUHNationalFindingsReport2018.pdf

Suldo, S.M., Mihalas, S., Powell, H., \& French, R. (2008). Ecological predictors of substance use in middle school students. School Psychology Quarterly, 23, 373388.

Suleiman, A.B., \& Harden, K.P. (2016). The importance of sexual and romantic development in understanding the developmental neuroscience of adolescence. Developmental Cognitive Neuroscience, 17, 145-147.

Sullivan, K.S., Capp, G., \& Gilreath, T.D. (2018). The association of parentification indicators with substance use patterns among military-connected adolescents. American Journal of Orthopsychiatry.

Tait, R.J., Hulse, G.K., \& Robertson, S.I. (2004). Effectiveness of a brief-intervention and continuity of care in enhancing attendance for treatment by adolescent substance users. Drug and Alcohol Dependence, 74, 289-296.

Tracey, T. J., \& Kokotovic, A. M. (1989). Factor structure of the Working Alliance Inventory. Psychological Assessment, 1, 207-210.

Ulvenes, P.G., Berggraf, L., Hoffart, A., Stiles, T.C., Svartberg, M., \& McCullough, L. (2012). Different processes for different therapies: therapist actions, therapeutic bond, and outcome. Psychotherapy, 49, 291-302.

U.S. Department of Defense (2018). Profile of the military community: Demographics 2018. Retrieved from http://download.militaryonesource.mil/12038/MOS/Report s/2018-demographics-report.pdf

Veed, G.J., McGinley, M., \& Crockett, L.J. (2019). Friendship network influence on the 
development of internalizing symptoms during adolescence. Journal of Applied Developmental Psychology, 60, 157-165.

Wachtel, P.L. (2008). Relational theory and the practice of psychotherapy. London: Guilford Press.

Wachtel, P.L. (2014). Cyclical psychodynamics and the contextual self: The inner world, the intimate world, and the world of culture and society. Chicago: Routledge.

Wadsworth, S.M. (2013). Understanding and supporting the resilience of a new generation of combat-exposed military families and their children. Clinical Child and Family Psychology Review, 16, 415-420.

Waitzkin, H., Cruz, M., Shuey, B., Smithers, D., Muncy, L., \& Noble, M. (2018). Military personnel who seek health and mental health services outside the military. Military Medicine, 183, e232-e240.

Waldron, H.B., \& Turner, C.W. (2008). Evidence-based psychosocial treatments for adolescent substance abuse. Journal of Clinical and Adolescent Psychology, 37, $238-261$.

Wampold, B. E., \& Budge, S. L. (2012). The Relationship - and its relationship to the common and specific factors of psychotherapy. The Counseling Psychologist, 40, $601-623$.

Watson, J.C., \& Greenberg, L.S. (2000). Alliance ruptures and repairs in experiential therapy. Journal of Clinical Psychology, 56, 175-186.

Webb, C. A., DeRubeis, R. J., Amsterdam, J. D., Shelton, R. C., Hollon, S. D., \& 
Dimidjian, S. (2011). Two aspects of the therapeutic alliance: Differential relations with depressive symptom change. Journal of Consulting and Clinical Psychology, 79, 279-283.

Weiss, E.L., Coll, J.E., Gerbauer, J., Smiley, K., \& Carillo, E. (2010). The military genogram: A solution-focused approach for resiliency building in service members and their families. The Family Journal, 18, 395-406.

Wen, M. (2017). Social capital and adolescent substance use: The role of family, school, and neighborhood contexts. Journal of Research on Adolescence, 27, 362-378.

Wesche, R., Kreager, D.A., \& Lefkowitz, E.S. (2018). Sources of social influence on adolescents' alcohol use. Journal of Research on Adolescence, 29, 984-1000.

Westwood, M.J., Keats, P.A., \& Wilensky, P. (2003). Therapeutic enactment: Integrating individual and group counseling models for change. The Journal for Specialists in Group Work, 28, 122-138.

White, C.J., de Burgh, H.T., Fear, N.T., \& Iversen, A.C. (2011). The impact of deployment to Iraq or Afghanistan on military children: A review of the literature. International Review of Psychiatry, 23, 210-217.

Whitesell, N.R., Asdigian, N.L., Kaufman, C.E., Big Crow, C., Shangreau, C., Keane, E.M., \& Mitchell, C.M. (2014). Trajectories of substance use among young American Indian adolescents: Patterns and predictors. Journal of Youth and Adolescence, 43, 437-453.

Young. J.E., Klosko, H.S., \& Weishaar, M.E. (2003). Schema therapy: A practitioner's guide. New York: Guilford.

Zetzel, E.R. (1956). Current concepts of transference. International Journal of 
Psychoanalysis, 37, 369-376.

Zilcha-Mano, S., \& Errázuriz, P. (2017). Early development of mechanisms of change as a predictor of subsequent change and treatment outcome: The case of working alliance. Journal of Consulting and Clinical Psychology, 85, 508-520 
APPENDICES

Appendix A: Measures 


\section{Outcome Rating Scale (ORS)}

\begin{tabular}{|l} 
Name__Age (Yrs):___ Sex: M / F \\
Session \#__ Date: \\
Who is filling out this form? Please check one: Self___ Other___ \\
If other, what is your relationship to this person?
\end{tabular}

Looking back over the last week, including today, help us understand how you have been feeling by rating how well you have been doing in the following areas of your life, where marks to the left represent low levels and marks to the right indicate high levels. If you are filling out this form for another person, please fill out according to how you think he or she is doing.

\section{Individually}

(Personal well-being)

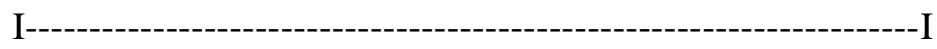

\section{Interpersonally}

(Family, close relationships)

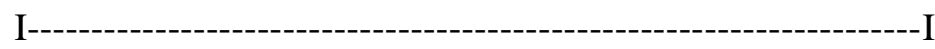

\section{Socially}

(Work, school, friendships)

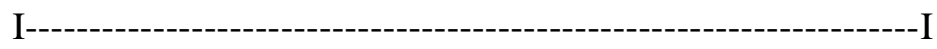

\section{Overall}

(General sense of well-being)

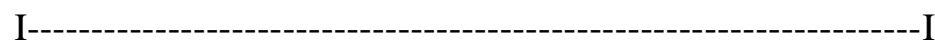

C 2000, Scott D. Miller and Barry 


\section{Session Rating Scale (SRS V.3.0)}

\begin{tabular}{|ll}
\hline \hline Name & Age (Yrs): \\
ID\# & Sex: M / F \\
Session \# __ Date: $\_$ & \\
\end{tabular}

Please rate today's session by placing a mark on the line nearest to the description that best fits your experience.

\section{Relationship}

I did not feel heard, understood, and respected.

We did not work on or talk about what I wanted to work on and talk about.

The therapist's approach is not a good fit for me.

There was something missing in the session today.
I felt heard, understood, and respected.

\section{Goals and Topics}

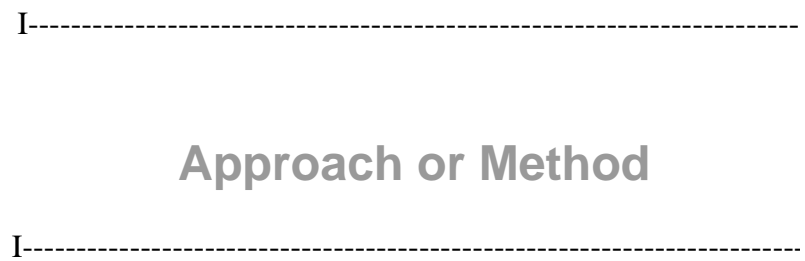

We worked on and talked about what I wanted to work on and talk about.

The therapist's approach is a good fit for me.

\section{Overall}

\section{I--}

Overall, today's session was right for me.

The Heart and Soul of Change Project

www.heartandsoulofchange.com 


\section{U N I V E R S I T Y O F Human Subjects Protection Program Office LOUISVILLE MedCenter One - Suite 200 501 E. Broadway Louisville, KY 40202-1798}

DATE:

TO:

FROM:

IRB NUMBER:

STUDY TITLE:

REFERENCE \#:

IRB STAFF CONTACT: Jackie Powell, CIP 852-4101 jspowe01@louisville.edu
November 09, 2019

Mark M Leach, PhD

The University of Louisville Institutional Review Board 19.0567

Therapeutic Rupture Repair in Treatment of Military Adolescents 692507

This study was reviewed on 11/08/2019 by the Chair of the Institutional Review Board and approved through Expedited Review Procedure, according to 45 CFR 46.110(b), since this study falls under Category 5: Research involving materials (data, documents, records, or specimens) that have been collected, or will be collected solely for nonresearch purposes (such as medical treatment or diagnosis)

This study now has final IRB approval from 11/08/2019 through 11/07/2022.

This study was also approved through 45 CFR 46.116 (D), which means that it has been granted a waiver of informed consent.

The following items have been approved:

\section{Submission Components}

\begin{tabular}{|l|l|l|}
\hline Form Name & Version & Outcome \\
\hline Submit for Initial Review & Version 1.1 & Approved as Submitted \\
\hline Review Response Submission Form & Version 2.0 & Approved as Submitted \\
\hline Review Response Submission Form & Version 1.0 & Approved as Submitted \\
\hline IRB Study Application & Version 1.1 & Approved as Submitted \\
\hline & & \\
\hline
\end{tabular}




\begin{tabular}{|c|c|c|c|}
\hline \multicolumn{4}{|l|}{ Study Document } \\
\hline Title & Version \# & Version Date & Outcome \\
\hline Protocol & Version 1.0 & $10 / 31 / 2019$ & Approved \\
\hline Data Collection Form & Version 1.0 & $10 / 14 / 2019$ & Approved \\
\hline
\end{tabular}

Your study does not require annual continuing review. Your study has been set with a three year expiration date. If your study is still ongoing you will receive iRIS automated reminders to submit a request to continue your study prior to the expiration date above.

All other IRB requirements are still applicable. You are still required to submit amendments, personnel changes, deviations, etc... to the IRB for review. Please submit a closure amendment to close out your study with the IRB if it ends prior to the three year expiration date.

Human Subjects \& HIPAA Research training are required for all study personnel. It is the responsibility of the investigator to ensure that all study personnel maintain current Human Subjects \& HIPAA Research training while the study is ongoing.

For guidance on using iRIS, including finding your approved stamped documents, please follow the instructions at https://louisville.edu/research/humansubjects/iRISSubmissionManual.pdf

Please note: Consent and assent forms no longer have an expiration date stamped on them. The consent/assents expire if the study lapses in IRB approval. Enrollment cannot take place if a study lapses in approval. For additional information view Guide 038.

\section{Site Approval}

If this study will take place at an affiliated research institution, such as UofL Hospital/UofL Health and/or Norton Healthcare, permission to use the site of the affiliated institution is necessary before the research may begin. If this study will take place outside of the University of Louisville Campuses, permission from the organization must be obtained before the research may begin (e.g. Jefferson County Public Schools). Failure to obtain this permission may result in a delay in the start of your research.

\section{Privacy \& Encryption Statement}

The University of Louisville's Privacy and Encryption Policy requires such information as identifiable medical and health records: credit card, bank account and other personal financial information; social security numbers; proprietary research data; dates of birth (when combined with name, address and/or phone numbers) to be encrypted. For additional information: http://security.louisville.edu/PolStds/ISO/PSO18.htm. 


\section{Implementation of Changes to Previously Approved Research}

Prior to the implementation of any changes in the approved research, the investigator will submit any modifications to the IRB and await approval before implementing the changes, unless the change is being made to ensure the safety and welfare of the subjects enrolled in the research. If such occurs, a Protocol Deviation/Violation should be submitted within five days of the occurrence indicating what safety measures were taken, along with an amendment to revise the protocol.

\section{Unanticipated Problems Involving Risks to Subjects or Others (UPIRTSOs)}

In general, these may include any incident, experience, or outcome, which has been associated with an unexpected event(s), related or possibly related to participation in the research, and suggests that the research places subjects or others at a greater risk of harm than was previously known or suspected. UPIRTSOs may or may not require suspension of the research. Each incident is evaluated on a case by case basis to make this determination. The IRB may require remedial action or education as deemed necessary for the investigator or any other key personnel. The investigator is responsible for reporting UPIRTSOs to the IRB within 5 working days. Use the UPIRTSO form located within the iRIS system to report any UPIRTSOs.

Full Accreditation since June 2005 by the Association for the Accreditation of Human Research Protection Programs, Inc.

\section{Payments to Subjects}

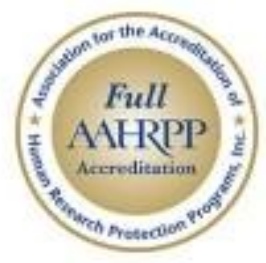

As a reminder, in compliance with University policies and Internal Revenue Service code, all payments

(including checks, pre-paid cards, and gift certificates) to research subjects must be reported to the University Controller's Office. For additional information, please contact the Controller's Office at 8528237 or controll@louisville.edu. For additional information: http://louisville.edu/research/humansubjects/policies/PayingHumanSubjectsPolicy201412.pdf

The committee will be advised of this action at a regularly scheduled meeting.

If you have any questions, please contact: Jackie Powell 852-4101 jspowe01@louisville.edu<smiles>[Mg][Mg][Mg]</smiles>

Peter M. Quesada, Ph.D., Chair

Social/Behavioral/Educational Institutional Review Board $\mathrm{PMQ} / \mathrm{jsp}$ 


\title{
CURRICULUM VITA
}

\section{Brent Anthony Luebcke}

\author{
5849 Julian Ave., Indianapolis, IN
}

(765) 418-0974

brent.a.luebcke@gmail.com

\section{EDUCATION}

Doctor of Philosophy: Counseling Psychology

Expected August 2020

University of Louisville, Louisville, KY

Doctoral Candidate

Graduate Fellow

Graduate Assistant

Dissertation: Therapeutic Rupture Repair in Treatment of Military Adolescents

Master of Science in Education: Mental Health Counseling

May 2012

Indiana University, Bloomington IN

Concentration: Mental Health Counseling

Bachelor of Arts: Psychology

May 2010

Purdue University, West Lafayette, IN

Concentration: Research-Focused Honors

Minor: Child Development and Family Sciences

\section{CLINICAL AND RELEVANT WORK EXPERIENCE}

Psychology Doctoral Intern

July 2019-July 2020

Butler University, Indianapolis, IN

Provides individual and group counseling to university students experiencing depression, anxiety, interpersonal concerns and conflicts, grief, suicidal ideation, multicultural challenges, and learning difficulties. Provides supervision to two master's interns focusing on mental health counseling and sport and exercise psychology. Facilitates an average of one hour per week of outreach to the campus community. Engages in extensive individual and group supervision, as well as didactic seminars. 
Kolbe Center, Inc., Indianapolis, IN

Provided individual, couple, group, and family counseling services to patients in recovery from substance abuse and addiction. Worked in multidisciplinary treatment team combining mental health and behavioral counseling with medication assisted treatment. Devised individualized treatment plans consistent with dual diagnosis presentation.

Mental Health Therapist- Independent Practitioner Associates in Counseling and Psychotherapy, New Albany, IN

July 2015 - July 2017 Provided individual, couple, and family counseling services. Focus in adolescent, young-adult, and adult population.

University Counseling Center Practicum Student Bellarmine University Counseling Center, Louisville, KY

August 2014 - August 2015

Provided individual and group counseling to university students experiencing depression, anxiety, interpersonal concerns and conflicts, grief, suicidal ideation, multicultural challenges, and learning difficulties. Engaged in weekly psychoeducational consultation with residence life coordinators and resident assistants. Engaged in outreach opportunities on campus.

High School Counseling/Therapy Practicum Student October 2014 - August 2015 Academy @ Shawnee, Louisville, KY

Assisted with administrative opening of independent therapy clinic in a high school. Provided individual, group, and family counseling to middle school and high school students experiencing depression, anxiety, interpersonal concerns, grief, suicidal ideation, family conflicts, learning difficulties. Engaged in outreach opportunities to promote clinic to faculty, parents, and members of the community. Administered, interpreted, and produced written integrated reports for cognitive ability, personality, and personal well-being.

Assessment Clinician Practicum Student

Jefferson County Public School Corporation, Louisville, KY

May 2014-August 2014 Administered battery of assessments for cognitive ability and aptitude for adults pursuing General Education Diploma (GED). Battery was consistent with state and local guidelines to meet requirements for testing accommodations. Scored assessments, interpreted results, and provided written integrated reports with recommendations for testing accommodations.

University Counseling Center Practicum Student August 2013 - May 2014 Indiana University Southeast Counseling Center, New Albany, IN 
Provided individual counseling to traditional and non-traditional university students. experiencing depression, anxiety, interpersonal concerns, grief, suicidal ideation, marriage and romantic relationship conflicts, family conflicts, multicultural challenges, and learning difficulties. Engaged in outreach opportunities on campus. Administered, interpreted, and produced written integrated reports for cognitive ability, personality, and personal well-being.

Individual Therapist-Researcher

October 2013 - August 2014

Relationship and Psychotherapy (RAP) Lab, Individual Therapy Outcome Study, University of Louisville

Therapist in individual therapy clinical trial. Provided short-term psychodynamic therapy to individuals experiencing depression, anxiety, and interpersonal conflicts. Administered, interpreted, and wrote integrative reports for cognitive, personality, and individual well-being assessments. Provided and discussed direct feedback measures focusing on individuals' well-being, therapy alliance, and treatment gains during therapeutic process. Attended weekly individual supervision meetings tailored for individual therapy.

Couple Therapist-Researcher

October 2012 - August 2014

Relationship and Psychotherapy (RAP) Lab, Couple Therapy Outcome Study, University of Louisville

Therapist in couple therapy clinical trial. Provided emotion-focused couple counseling for research study examining therapeutic gains from couple therapy. Administered and interpreted assessment data collected from measures of attachment, couple coping, commitment, and therapy alliance. Attended weekly individual and group supervision meetings tailored for couple therapy.

Mental Health Counseling Intern

Larue D. Carter Memorial Hospital, Indianapolis, IN

May 2011 - Spring 2012

Specialized working with clients with dual diagnosis of mental illness and substance abuse. Engaged in individual therapy with clients. Led and coled psychoeducational and personal growth groups. Developed and implemented patient treatment plans. Assisted in hospital-wide outreach programs for substance abuse awareness

Psychiatric Technician

June 2009 - May 2011

River Bend Hospital (formerly Wabash Valley Mental Health Center), Lafayette, IN Engaged in therapeutic patient interaction. Facilitated activities of daily living. Reviewed treatment plans with patients and staff. Recorded daily activities in medical charts. 


\section{RESEARCH AND TEACHING EXPERIENCE}

Adjunct Course Instructor

Fall 2015,Spring 2016, Fall 2016

ECPY 507/607: Learning Theory and Human Growth and Development

Relationship and Psychotherapy (RAP) Lab

August 2012 - August 2014

University of Louisville

Advisor: Dr. Jesse Owen

Reviewed literature on romantic relationships, including initiation, maintenance, dissolution, and relationship commitment. Reviewed literature on psychotherapy process and outcomes. Participated in discussion with lab members regarding discussion of theories, manuscript review, role play exercises, and presentation of current research projects.

Graduate Teaching Assistant May - August 2014 PSYC 301: Quantitative Methods in Psychology, University of Louisville Advisor: Dr. Christian Stilp Assisted professor with instruction of course material.

Graduate Teaching Assistant

August 2013 - May 2014 PSYC 302: Introduction to Research Methodology, University of Louisville Advisors: Dr. Marci DeCaro, Dr. Nicholaus Noles

Assisted professors with instruction of course material. Provided direct teaching instruction to undergraduate students in laboratory sections of course. Organized and facilitated multiple undergraduate research projects in research methodology. Assisted advisors with test construction, administration, and evaluation.

Graduate Research Assistant

Fall 2011 - Spring 2012

Indiana University, Bloomington, IN

Department of Counseling and Educational Psychology

Advisor: Dr. Jesse Steinfeldt

Reviewed literature on stereotyping Native American themed mascots

Coded comments on social media website

Investigated race-based narratives posted in comments on website

Presented findings at regional and national conferences

Research-Focused Honors Program in Psychological Sciences

January 2009 - May 2010

Purdue University, West Lafayette, IN

Honors Thesis: Devaluation of a partner's potential alternatives: A person by situation interaction.

Designed an independent research project investigating the effects of personality traits on devaluation of relationship competitors, supervised directly by William 
G. Graziano, Ph.D. Presented results of study at Purdue University's

Undergraduate Research Conference

Research Assistant

Fall 2008

Purdue University

Department of Psychology

Advisor: Dr. William G. Graziano

Assisted in programming Invisible Support study in MediaLab. Aided implementation of first year graduate project, performing various roles as an experimenter including running and debriefing participants.

Research Assistant

Spring 2008

Purdue University

Department of Psychology

Advisor: Dr. Christopher Eckhardt

Scheduled participants for study investigating intimate partner violence.

Oriented participants through study. Entered participant data in computer system

\section{PUBLICATIONS AND PRESENTATIONS}

Luebcke, B., Owen, J., Keller, B., Shuck, B., Knopp, K., \& Rhoades, G.

(2014). Therapist interventions for couples: A commitment uncertainty

comparison. Couple and Family Psychology, 3, 239-254.

Owen, J., Keller, B., Luebcke, B., Shuck, B., Knopp, K., \& Rhoades, G. K. (2014).

Initial examination of commitment uncertainty in couple therapy. Couple and

Family Psychology, 3, 232-238.

Luebcke, B.A., Keller, B., Owen, J., \& Shuck, B. (2014, March). The effectiveness of therapeutic interventions with couples experiencing commitment uncertainty. Poster presented at 2014 Counseling Psychology Conference, Atlanta, GA.

Steinfeldt, J. A., Good, E., Luebcke, B.A, \& Steinfeldt, M. C. (In progress). Racism on Facebook: Analyzing attitudes about Native-themed mascots, nicknames, and logos. Cultural Diversity and Ethnic Minority Psychology.

Good, E., Luebcke, B.A., \& Steinfeldt, J. A. (2012, August). Racial attitudes about American Indians expressed on Facebook. Poster presented at annual meeting of the American Psychological Association, Orlando, FL.

Steinfeldt, J. A., Good, E., Luebcke, B.A., \& Steinfeldt, M. C. (2012, February). Racism on Facebook: Analyzing attitudes supporting Native-themed nicknames and logos. Poster presented at Big 10 College Counseling Center Conference, Bloomington, IN.

Luebcke, B.A., Good, E., \& Steinfeldt, J. A. (2012, March). Race-based attitudes about American Indians expressed on Facebook. Poster presented at Great Lakes 
Regional Counseling Psychology Conference, West Lafayette, IN.

Luebcke, B.A. (2010, April). Devaluation of a partner's potential alternatives: A person by situation interaction. Presented at Purdue University's Undergraduate Research Conference, West Lafayette, IN.

\section{PROFESSIONAL ACTIVITIES}

\author{
American Psychological Association \\ American Counseling Association \\ Doctoral Student Organization \\ University of Louisville \\ President, 2013-2014 \\ Diversity Club \\ University of Louisville
}

August 2012-Present

August 2010-January 2013

August 2012-Present

August 2012-July 2017

\section{REFERENCES}

Shana Markle, Ph.D., HSPP

Associate Director

Counseling and

Consultation Services

Butler University

Indianapolis, IN 46208

smarkle@butler.edu

(317) 940-9385
Gary Petiprin, Ph.D., HSPP Michael Day, Psy.D., Clinical Director HSPP

University Counseling Clinical Director Center

Bellarmine University Louisville, KY 40205 gpetiprin@bellarmine.edu (502) 272-8480
Personal Counseling

Services

Indiana University, Southeast

New Albany, IN

micaday@ius.edu

(812) 941-2244 